Vinícius Leonardo Biffi

Atributos individuais, formas de manejo e contexto ambiental: quais fatores determinam a chance de cachorros visitarem remanescentes florestais?

Individual traits, management and environmental context: which factors determine the chance of dogs visiting forest remnants?

São Paulo

2017 


$$
\begin{gathered}
\text { Universidade de São Paulo } \\
\text { Instituto de Biociências } \\
\text { Programa de Pós-Graduação em Ecologia }
\end{gathered}
$$

\section{Atributos individuais, formas de manejo e contexto ambiental: quais fatores determinam a chance de cachorros visitarem remanescentes florestais?}

Individual traits, management and environmental context: which factors determine the chance of dogs visiting forest remnants?

Vinícius Leonardo Biffi

Dissertação apresentada ao Instituto de Biociências da Universidade de São Paulo, para a obtenção de Título de Mestre em Ciências, na Área de Ecologia.

Orientadora: Profa. Drª. Renata Pardini

São Paulo

2017 


\section{Ficha catalográfica}

\section{Biffi, Vinícius Leonardo}

Atributos individuais, formas de manejo e contexto ambiental: quais fatores determinam a chance de cachorros visitarem remanescentes florestais?

$62 \mathrm{p.}$

Dissertação (Mestrado) - Instituto de Biociências da Universidade de São Paulo.

1. Invasão biológica 2. Espécie exótica 3. Conservação da biodiversidade 4. Mata Atlântica 5. Canis lupus familiaris 6. Paisagens antropizadas I. Universidade de São Paulo. Instituto de Biociências. Departamento de Ecologia.

Comissão Julgadora: 


\section{AGRADECIMENTOS}

Agradeço a:

FAPESP, pelo financiamento do Projeto Temático Interface (2013/23457-6), ao qual este trabalho é vinculado, e ao CNPq e à CAPES (132467/2015-1), pelas bolsas de estudo concedidas.

Instituto de Biociências, Departamentos de Ecologia e Zoologia, programa de pós-graduação em Ecologia da Universidade de São Paulo e seus professores, pela infraestrutura disponibilizada e pelo aprendizado proporcionado desde a graduação e por todo o mestrado.

Renata Pardini, minha orientadora, por tudo que me ensinou ao longo dos últimos anos. Obrigado pela paciência e por ter me ajudado a me tornar um pesquisador, um profissional e uma pessoa melhor. Te admiro muito.

Jean Paul Metzger, por coordenar o Projeto Temático Interface e possibilitar a realização desse trabalho.

Patrícia Carignano Torres e Camila Righetto Cassano, membros do meu comitê de acompanhamento, pela disponibilidade em ajudar e pelas discussões e conselhos que melhoraram a qualidade deste trabalho.

Colegas do LEPAC, especialmente todos que participaram do mapeamento das paisagens, Larissa Boesing, Elizabeth Nichols e Francisco d'Albertas Gomes de Carvalho, e a Isabella Romitelli pela disponibilidade e paciência para lidar com a prestação de contas.

Todos os colegas de pós, por toda a ajuda e companheirismo, e por terem me ajudado a segurar essa barra que é gostar de ciência.

Colegas do DICOM, pela amizade e pela ajuda em campo, no pós-campo e nas disciplinas, e em especial ao Marcos, pela ajuda em olhar milhares de fotos para identificar os cachorros, à Gabi, por toda a ajuda estatística, e ao Fernando, por toda a ajuda com tudo.

Companheiros de campo, especialmente o pessoal da Casa das Vespas, times Cachorrada (Fer, Lucas e Elvira), Rola-bosta (Vivi, Bruna, Liz e Gabriel) e Passarinhos (Lari, Paulinho, André e Cristian), por toda a ajuda que ofereceram em campo e por toda a diversão que tivemos juntos.

Moradores e proprietários, que permitiram nosso acesso às áreas de estudo e se disponibilizaram a responder as entrevistas. 
Seu Percival, dona Maria, dona Esmeralda, Elmo e seu Brasilino, vizinhos de Joanópolis e Nazaré, pela receptividade, amizade e disponibilidade em ajudar.

Minha família, especialmente meus pais Marcos e Cleuza, pela paciência e por todo o apoio que me deram desde sempre. Sem vocês eu não teria chegado até aqui.

Stephany, minha namorada, pela compreensão, confiança, apoio e companheirismo, e por ter tornado tudo isso mais fácil. 


\section{ÍNDICE}

$\begin{array}{ll}\text { 1. RESUMO } & 1\end{array}$

$\begin{array}{ll}\text { 2. ABSTRACT } & 2\end{array}$

3. INTRODUÇÃO

4. MATERIAL E MÉTODOS

$\begin{array}{ll}\text { 4.1. ÁREA DE ESTUDO } & 7\end{array}$

4.2. DeLINEAMENTO AMOSTRAL $\quad 8$

4.3. ColetA DE DAdOS

4.4. VARIÁVEIS DEPENDENTE E INDEPENDENTES

4.5. ANÁLISE DE DADOS 13

$\begin{array}{ll}\text { 5. RESULTADOS } & 15\end{array}$

5.1. CARACTERÍSTICAS DAS POPULAÇÕES DE CACHORROS

5.2. IMPORTÂNCIA RELATIVA DOS ATRIBUTOS INDIVIDUAIS, FORMAS DE MANEJO E CONTEXTO AMBIENTAL 18

6. DISCUSSÃO 22

$\begin{array}{ll}\text { 7. CONCLUSÃO } & 29\end{array}$

8. REFERÊNCIAS BIBLIOGRÁFICAS

$\begin{array}{ll}\text { 9. ANEXOS } & 37\end{array}$ 


\section{RESUMO}

Invasões biológicas representam hoje a segunda maior ameaça à biodiversidade, e o homem desempenha papel fundamental na introdução de espécies exóticas potencialmente invasoras. 0 cachorro (Canis lupus familiaris) é uma dessas espécies. Presente em todos os continentes, é o carnívoro mais abundante do mundo, e pode causar impactos à fauna nativa através de efeitos letais e não letais da predação, competição, hibridização e transmissão de doenças, além de ser potencialmente importante na epidemiologia de zoonoses. Em áreas rurais, que concentram grande parte dos remanescentes de vegetação nativa no mundo, os cachorros são frequentemente criados soltos e circulam livremente, intensificando a chance de contato com a fauna nativa. Nesse trabalho, avaliamos a importância relativa de fatores associados a atributos individuais (sexo, idade, condição de saúde, comportamento exploratório, tamanho e raça), formas de manejo (incentivo do dono à movimentação, motivo para a criação, confinamento e frequência de alimentação) e contexto ambiental (proximidade à mata nativa) para determinar a chance de cachorros visitarem remanescentes florestais em paisagens fragmentadas de Mata Atlântica. Selecionamos oito paisagens de 2830 ha cada, nas quais visitamos todas as construções em áreas rurais a fim de entrevistar, através da aplicação de questionário, os responsáveis pela criação de cachorros e fotografar os cachorros. Utilizamos a imputação múltipla para estimar os dados faltantes (comuns em dados obtidos via questionários), gerando 10 conjuntos de dados imputados que foram analisados separadamente. Por meio de seleções de modelos através do Critério de Informação de Akaike, comparamos modelos candidatos com até cinco variáveis independentes para determinar a chance de cachorros visitarem remanescentes florestais. Nossos resultados nos permitem afirmar que quatro fatores - dois associados a atributos individuais e dois associados a formas de manejo - atuam em conjunto para determinar a chance de cachorros visitarem remanescentes florestais em paisagens rurais da Mata Atlântica. Cachorros maiores, mais exploradores, que recebem mais incentivo a se movimentar e que passam menos tempo confinados têm maior chance de visitar remanescentes florestais. A maior importância de atributos individuais e da forma de manejo está de acordo com a grande variação fenotípica existente entre cachorros e a variedade de modos como são manejados. Entre os atributos individuais, tanto características físicas como comportamentais são importantes, enquanto os aspectos chave da forma de manejo são aqueles mais diretamente relacionados à movimentação dos cachorros. Independentemente do tempo de confinamento, o incentivo do dono à movimentação do cachorro, em particular o estímulo para que o cachorro o acompanhe em visitas a remanescentes florestais, é fundamental. O contexto ambiental, em especial a proximidade do domicílio a áreas de mata nativa, por sua vez, é irrelevante dada a alta mobilidade dos cachorros. Nossos dados sugerem que a densidade de cachorros em paisagens rurais de Mata Atlântica é uma ordem de magnitude mais alta do que a de carnívoros de médio porte silvestres relativamente comuns, que muitos cachorros já tiveram contato direto com espécies silvestres, e que a vacinação e outras medidas profiláticas são relativamente incomuns. Todos esses dados indicam o potencial de efeitos negativos, tanto para a fauna silvestre como para o homem. Programas de redução destes impactos devem incluir tanto aspectos veterinários, como a expansão de campanhas públicas de profilaxia para além da vacinação antirrábica, quanto aspectos sociais, como a divulgação e conscientização dos potenciais problemas ocasionados pela entrada de cachorros em áreas de vegetação nativa, visando mudanças nas crenças, atitudes e comportamento da população humana. 


\section{ABSTRACT}

Biological invasions are today the second greatest threat to biodiversity, and humans play a significant role in the introduction of potentially invasive exotic species. The dog (Canis lupus familiaris) is one of such species. Distributed across all continents, the dog is the most abundant carnivore in the planet, and can impact wildlife through lethal and non-lethal effects of predation, competition, hybridization and disease transmission, besides being potentially important in the epidemiology of zoonoses. In rural areas where most remnants of native vegetation around the world are concentrated, most dogs are free-ranging, enhancing the chance of interactions with wildlife. Here, we evaluated the relative importance of factors associated with individual traits (sex, age, health condition, exploratory behaviour, size and breed), management (owner's incentive to movement, motive for raising, confinement and feeding frequency), and environmental context (proximity to native forest) to determine the chance of dogs visiting forest remnants in Atlantic Forest fragmented landscapes. We selected eight landscapes of 2830 ha each, where we visited all constructions in rural areas in order to interview dog owners by applying a questionnaire and to photograph dogs. We used multiple imputation to estimate missing data (common in data obtained through questionnaires), obtaining 10 imputed datasets that were analyzed separately. We compared candidate models with up to five independent variables to determine the chance of dogs visiting forest remnants through the Akaike Information Criterion. Our results indicate that four factors - two associated with individual traits and two associated with management - work together to determine the chance of dogs visiting forest remnants in Atlantic Forest rural landscapes. Larger dogs, and those that exhibit exploratory behaviour, are more stimulated to move or confined for shorter periods have greater chance of visiting forest remnants. The greater importance of factors associated with individual traits and management is in accordance with the ample phenotypic variation among dogs and the variety of ways they can be managed. Among individual traits, both morphological and behaviour characteristics are important, whereas the key aspects of management are those directly related to dog movement. Irrespective of the time confined, the owner's incentive to movement, in particular taking the dog to the forest, is a crucial aspect. In contrast, the environmental context, especially the proximity of the household to native forest, is irrelevant given the vagility of dogs. Our results suggest that the density of dogs across rural landscapes in the Atlantic forest is at least one order of magnitude higher than the density of relatively common medium-sized native carnivores, that several dogs have already had direct contact with wild species, and that vaccination and other prophylactic measures are relatively uncommon. All of these highlight the potential for negative effects on both wildlife and human population. Plans to reduce these effects should include not only veterinarian aspects, such as the expansion of public prophylactic campaigns beyond rabies vaccination, but also social aspects, such as the dissemination of information on the problems caused by dogs visiting native vegetation, aiming at changing people's beliefs, attitudes and behaviour. 


\section{INTRODUÇÃO}

Invasões biológicas representam hoje a segunda maior ameaça à biodiversidade (Bellard et al., 2016), afetando diferentes níveis de organização dos sistemas ecológicos, desde o comportamento dos indivíduos (Both \& Grant, 2012) até o funcionamento dos ecossistemas (Raizada et al., 2008). O homem desempenha papel fundamental na introdução de espécies invasoras, seja direta ou indiretamente, agindo sobre a movimentação de espécies proposital e acidentalmente e alterando o ambiente (Heger et al., 2013).

O cachorro (Canis lupus familiaris) pode ser considerado uma espécie invasora sob todas as três perspectivas de invasão biológica disponíveis na literatura: a biogeográfica, a ecológica e evolutiva e a da conservação (Heger et al., 2013). A perspectiva biogeográfica leva em conta a superação de barreiras geográficas que impedem a espécie de se dispersar para outros ambientes, enquanto o foco da perspectiva ecológica e evolutiva está na dispersão da espécie invasora para ambientes distintos daqueles em que evoluiu, levando a novas interações ecológicas. Os cachorros tiveram origem provavelmente há cerca de 15.000 anos no leste asiático ou entre a Ásia e a Europa, de onde, associados ao ser humano, se expandiram para todos os continentes, com exceção da Antártida (Gompper, 2014). Essa expansão levou populações de cachorros a ocuparem áreas com diferentes características geográficas, contextos ecológicos e eventos históricos, os quais levaram a regimes de seleção e histórias demográficas distintos (Boyko \& Boyko, 2014). Já segundo a perspectiva da conservação, uma espécie é considerada invasora quando, além de ser introduzida por ação humana, também representa uma ameaça às espécies nativas. Há evidências de impactos de cachorros à fauna nativa por predação, competição, hibridização e transmissão de doenças (revisão em Hughes \& Macdonald, 2013). Por serem predadores abundantes e altamente vocais, os cachorros também provocam impactos importantes por meio de efeitos não letais da predação (Preisser et al., 2005), que vão desde a interrupção momentânea da atividade a mudanças em padrões de atividade e de uso do habitat (Silva-Rodríguez \& Sieving, 2012; Weston \& Stankowich, 2014; Zapata-Ríos \& Branch, 2016).

O cachorro é hoje o carnívoro mais abundante do mundo, com população estimada em mais de 700 milhões de indivíduos, e sua distribuição está diretamente relacionada à presença humana (Hughes \& Macdonald, 2013). Só nas áreas rurais, que concentram grande parte dos remanescentes de vegetação nativa no mundo, estima-se que existam mais de 500 milhões de indivíduos (Gompper, 2014). Nessas áreas, os cachorros são frequentemente criados soltos e 
circulam livremente (Vanak \& Gompper, 2009; Vanak et al., 2009), interagindo com a comunidade ecológica local. De fato, estudos indicam que cachorros são os carnívoros mais abundantes em algumas áreas de vegetação nativa (Butler et al., 2004; Silva-Rodríguez \& Sieving, 2012), inclusive em regiões tropicais como no Brasil (Srbek-Araujo \& Chiarello, 2008; Lacerda et al., 2009; Paschoal et al., 2012; Frigeri et al., 2014; Lessa et al., 2016; Paschoal et al., 2016, Ribeiro, 2016). A população de cachorros nessas áreas se mantém acima da capacidade de suporte do ambiente devido à provisão de alimentos e abrigo pelo homem, podendo causar grande impacto sobre populações de outras espécies sem que esses declínios afetem sua persistência (Gompper \& Vanak, 2008; Vanak \& Gompper, 2009). Essa situação é especialmente importante em comunidades depauperadas, em que mamíferos predadores de grande porte são escassos e o cachorro pode assumir essa função (Vanak \& Gompper, 2009; Vanak et al., 2009).

O cachorro também é potencialmente importante na epidemiologia de zoonoses, dada sua proximidade com o homem (Traub et al., 2003; Deplazes et al., 2011; Fortes et al., 2011; Curi et al., 2014). Parasitoses como a erliquiose e a babesiose, transmitidas por carrapato, e a leishmaniose, transmitida por moscas, atingem não só a fauna nativa e os cachorros, como também podem infectar o homem (Shaw et al., 2001; Beugnet \& Marié, 2009; Curi et al., 2014). Cachorros podem ainda servir como reservatórios da febre maculosa, doença de alto risco para o ser humano (Horta et al., 2004; Sangioni et al., 2005).

Apesar do crescente reconhecimento da importância dos impactos causados pelos cachorros à fauna silvestre (Doherty et al., 2017) e do seu papel na epidemiologia de zoonoses, pouco se sabe sobre os fatores que favorecem a interação de cachorros com espécies nativas. Alguns estudos buscaram investigar os fatores que influenciam a movimentação e a área de vida de cachorros criados soltos (Rubin \& Beck, 1982; Meek, 1999; Claridge et al., 2009; Robley et al., 2010; Vaniscotte et al., 2011; Ruiz-Izaguirre et al., 2015; Sparkes et al., 2014; Van Bommel \& Johnson, 2014; Molloy et al., 2017), o que deve estar relacionado à chance desses cachorros visitarem áreas de vegetação nativa, e assim interagirem com a fauna. Ruiz-Izaguirre et al. (2015), por exemplo, observaram que cachorros que predam ovos de tartaruga são aqueles que mais se distanciam do local onde são criados. Em conjunto, estes estudos sugerem que fatores associados aos atributos individuais (sexo, idade, tamanho, raça, condição física), às formas de manejo (esterilização, confinamento, alimentação) e ao contexto ambiental local (distância entre áreas naturais e o local de criação) podem influenciar a movimentação e a área de vida de cachorros criados soltos. Rubin \& Beck (1982) observaram que cachorros criados sempre soltos percorrem distâncias maiores que 
aqueles que ficam ocasionalmente presos, e cachorros maiores percorrem distâncias maiores que cachorros menores. Sparkes et al. (2014) e Molloy et al. (2017) verificaram que machos têm maior área de atividade e percorrem maior distância que fêmeas, como observado também em cachorros selvagens (Robley et al., 2010). Já Van Bommel \& Johnson (2014) registraram que o nível de atividade e a área de vida decaem com a idade. Também foi observado que a presença e o número de cachorros em áreas naturais estão negativamente correlacionados à distância de habitações humanas (Silva-Rodríguez et al., 2010; Silva-Rodríguez \& Sieving, 2012) e positivamente ao número de cachorros criados nos arredores destas áreas (Ribeiro, 2016). Entretanto, os estudos disponíveis até o momento analisaram um ou poucos fatores isoladamente, restringindo a compreensão da importância relativa de diferentes fatores, e a maioria não investigou diretamente o uso de áreas de vegetação nativa pelos cachorros.

Este estudo pretende identificar os fatores que determinam a chance de cachorros visitarem remanescentes florestais em paisagens fragmentadas de Mata Atlântica, identificando a importância relativa de fatores associados a atributos individuais (sexo, idade, condição de saúde, comportamento exploratório, tamanho e raça), formas de manejo (incentivo do dono à movimentação, motivo para a criação, confinamento e frequência de alimentação) e contexto ambiental nos arredores de onde são criados (proximidade à mata nativa) (Figura 1). Com isso, pretendemos contribuir para o planejamento de ações que visem diminuir o acesso de cachorros aos remanescentes florestais, reduzindo assim seu contato com a fauna nativa e, consequentemente, os problemas decorrentes desse contato. 


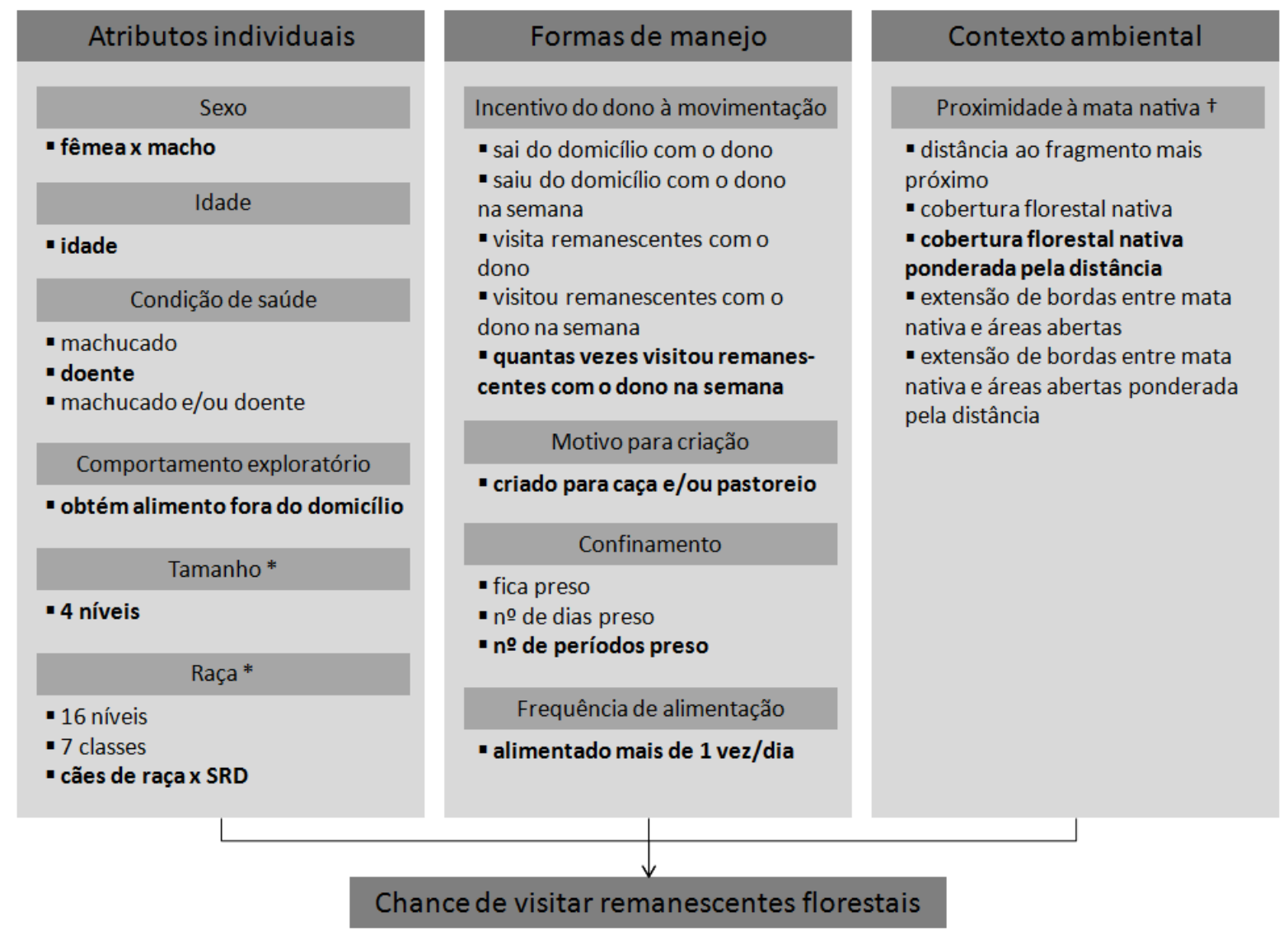

Figura 1. Fatores associados a atributos individuais, formas de manejo e contexto ambiental que podem determinar a chance de cachorros visitarem remanescentes florestais. Para cada um dos três tipos de fatores, são listadas as variáveis teóricas e as variáveis operacionais. Para as variáveis teóricas com mais de uma variável operacional considerada, estão em negrito as variáveis operacionais selecionadas. Ver Material e Métodos para definição de cada variável operacional e forma de seleção. ${ }^{*}=$ dados obtidos através de fotografias dos indivíduos, $\dagger=$ dados obtidos através de mapa de uso do solo. Para as demais varáveis operacionais, os dados formam obtidos através de questionários aplicados por entrevistas aos responsáveis pela criação dos cachorros. 


\section{MATERIAL E MÉTODOS}

\section{1. Área de estudo}

O estudo foi realizado em uma área de cerca de 300 mil hectares na região Cantareira-Mantiqueira do Planalto Atlântico de São Paulo, Brasil (Figura 2), que abrange áreas rurais e urbanas de seis municípios: Bragança Paulista, Igaratá, Joanópolis, Piracaia, São José dos Campos e Vargem. A vegetação nativa é classificada como floresta ombrófila densa montana, parte do domínio fitogeográfico da Mata Atlântica, e o relevo é caracterizado por ondulações e conjuntos de colinas íngremes, com elevação entre 700 e $1700 \mathrm{~m}$. A precipitação média anual é de $1513 \mathrm{~mm}$ e a média das temperaturas mínimas e máximas é, respectivamente, de $14,8^{\circ} \mathrm{C}$ e $27,7^{\circ} \mathrm{C}$ na época mais quente (outubro a março) e de $11,3^{\circ} \mathrm{C}$ e $24,6^{\circ} \mathrm{C}$ na época mais fria (abril a setembro) (www.cpa.unicamp.br).

A população humana dos seis municípios em 2016 foi estimada em pouco mais de 900 mil habitantes, concentrados principalmente em Bragança Paulista e São José dos Campos (94\%). A densidade populacional varia de $32,1 \mathrm{hab} / \mathrm{km}^{2}$ em Igaratá a $633,1 \mathrm{hab} / \mathrm{km}^{2}$ em São José dos Campos. Em 2010, havia pelo menos 7 mil domicílios rurais (não há informações disponíveis para os municípios de Joanópolis e Piracaia), e a população rural era de pelo menos 23 mil habitantes, variando de 2,0\% da população total em São José dos Campos a 49,8\% em Vargem (www.ibge.com.br). Dos 129 mil hectares de propriedades rurais com produção agropecuária nos seis municípios no ano de 2006, 76 mil ha são ocupados por pastagens, 27 mil ha por matas naturais ou plantadas e 19 mil ha por lavouras. A silvicultura e a criação de gado leiteiro são as principais atividades agrossilvipastoris na região, embora a produção de milho também seja expressiva em Bragança Paulista (www.ibge.com.br).

Assim, a maior parte dos remanescentes florestais da região está reduzido a fragmentos de diferentes tamanhos e estágios de regeneração. Esse processo de perda e fragmentação das matas nativas resultou em uma comunidade de mamíferos silvestres relativamente simplificada. Como em outras áreas fragmentadas e sujeitas à caça na Mata Atlântica (Chiarello, 1999; Cullen et al., 2000), não são encontradas na região de estudo algumas espécies de maior porte, como a onça-pintada (Panthera onca), a anta (Tapirus terrestris) e o queixada (Tayassu pecari), enquanto outras, como a onça-parda (Puma concolor) e o cateto (Pecari tajacu), são raras (Ribeiro, dados não publicados). O gambá (Didelphis aurita) é a espécie mais comum e carnívoros de médio porte são relativamente abundantes (Eira barbara, Cerdocyon thous, Nasua nasua e Leopardus spp.) 
(Ribeiro, dados não publicados). A presença de mamíferos invasores nos remanescentes da região é comum, sendo o cachorro a segunda espécie (entre nativas e exóticas) mais frequentemente registrada, com registros da presença também do javali (Sus scrofa), lebre (Lepus europaeus), gado (Bos taurus) e cavalo (Equus caballus) (Ribeiro, dados não publicados).
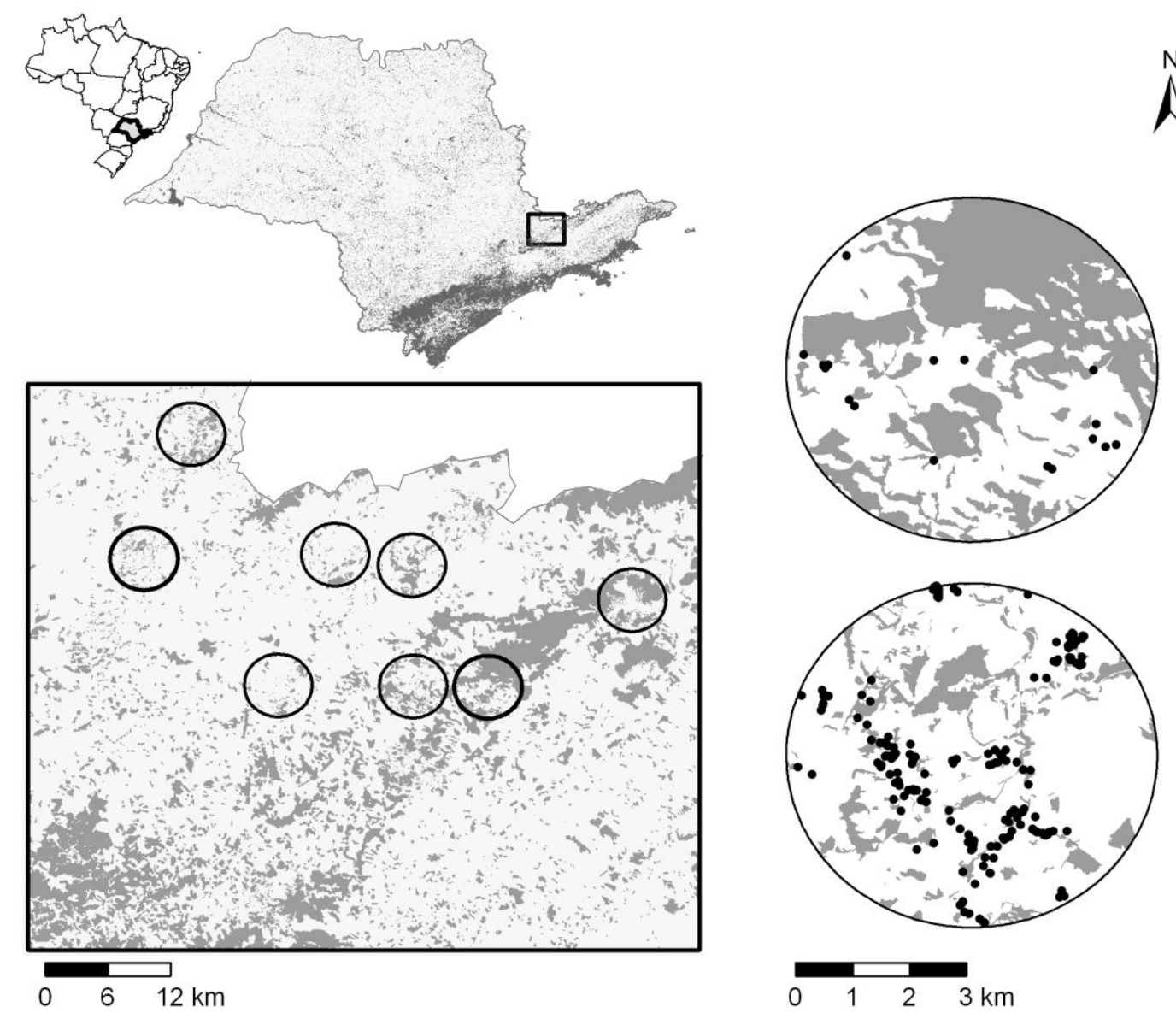

Figura 2. Mapa do Brasil e do estado de São Paulo, com destaque para a área de estudo onde estão representadas as oito paisagens estudadas. Duas delas, uma com baixa e outra com alta proporção de florestas nativas remanescentes e densidade de domicílios, são mostradas em maior detalhe à direita. Áreas em cinza representam os remanescentes florestais, e os pontos pretos a localização dos domicílios em que são criados cachorros.

\subsection{Delineamento amostral}

Utilizamos um delineamento amostral hierárquico, selecionando oito paisagens circulares com 3 km de raio (2830 ha) e, dentro delas, os domicílios onde cachorros são criados. Com o intuito de selecionar paisagens que variassem amplamente quanto à cobertura florestal e, simultaneamente, que controlassem quatro potenciais fatores de confusão, utilizamos o método descrito por Pasher 
et al. (2013). A variação da cobertura florestal entre as paisagens visou assegurar ampla variação no contexto ambiental, isto é, na quantidade e proximidade de matas nativas nos arredores onde são criados cachorros (Figura 2). As oito paisagens foram restritas a altitudes entre 800 e 1200 m, com latossolos férricos vermelhos ou argissolos, onde as áreas desmatadas são ocupadas majoritariamente por áreas de pastagem. Na medida do possível, evitou-se incluir nas paisagens de estudo grandes rodovias e reservatórios de água, assim como grandes núcleos urbanos. 0 processo resultou na escolha de 8 paisagens, com variação de 10 a 49\% na proporção de cobertura florestal nativa (Figura 2; Anexo 1).

\subsection{Coleta de dados}

Dentro de cada paisagem, mapeamos todas as construções em áreas rurais através de imagens do Google Earth e de checagens de campo e visitamos as construções a fim de verificar se representavam domicílios com moradores e/ou cachorros. Das 1223 construções mapeadas, 906 potencialmente atendiam essas condições. Foram feitas até duas visitas a cada um destes domicílios, sendo preferencialmente uma durante a semana e outra no fim de semana, na tentativa de entrevistar os responsáveis pela criação dos cachorros. Em 191 dos 906 domicílios (21,1\%), o responsável não foi encontrado ou se recusou a participar do estudo, enquanto os responsáveis por outros 161 domicílios (17,8\%) afirmaram não ter cachorros.

Nos 554 domicílios em que o responsável pela criação dos cachorros foi encontrado e concordou em participar do estudo, realizamos uma entrevista (Figura 3) através da aplicação de um questionário estruturado fechado (Anexo 2), com a intenção de obter informações detalhadas sobre características, comportamento, saúde e manejo de cada um dos cachorros criados (autorização do Comitê de Ética em Pesquisa - Seres Humanos do Instituto de Biociências da USP parecer 981.535). Se permitido pelo entrevistado, os cachorros foram também fotografados. No total, foram obtidas informações sobre 1625 cachorros, dos quais 1310 foram fotografados.

O questionário foi previamente testado em um estudo piloto e adaptado conforme a necessidade (linguagem, maior clareza e novas perguntas de interesse). Após a coleta de dados, as fotografias foram organizadas e todos os questionários foram revisados a fim de corrigir possíveis erros de preenchimento. As entrevistas foram realizadas por Vinícius Leonardo Biffi com a ajuda de outras três pessoas treinadas, divididos em duplas, entre março e agosto de 2015. 


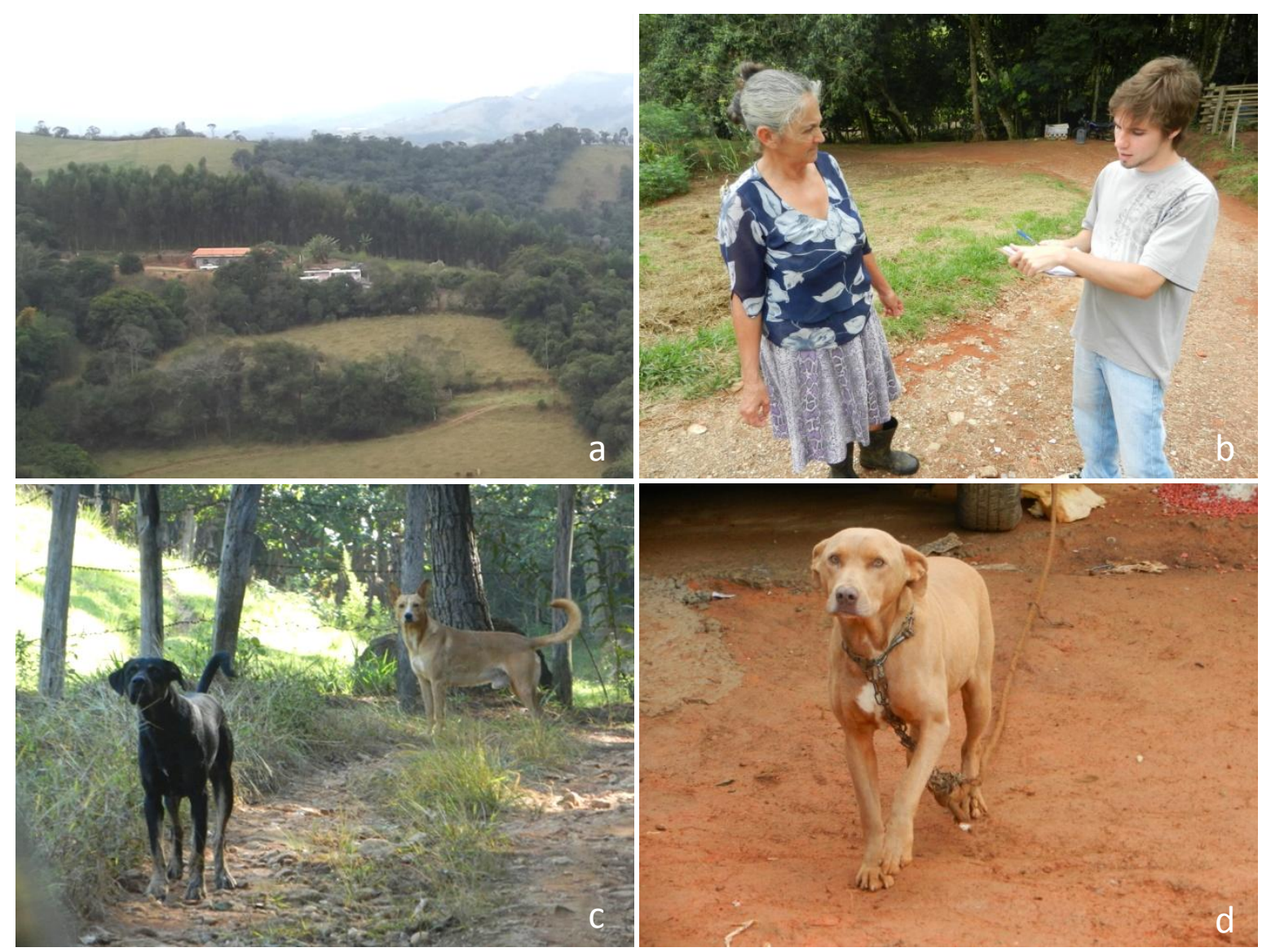

Figura 3. (a) Domicílio localizado na área de estudo, (b) entrevista com moradora, (c) cachorros circulando livremente, (d) cachorro mantido preso.

\subsection{Variáveis dependente e independentes}

A partir do questionário ou das fotografias, foram quantificadas para cada cachorro a chance de visitarem remanescentes florestais, assim como variáveis relacionadas a atributos individuais (seis variáveis) e formas de manejo (quatro variáveis) (Figura 1). O contexto ambiental nos arredores de onde os cachorros são criados foi quantificado a partir de mapas de uso do solo de $5 \mathrm{~km}$ de raio a partir do centro de cada uma das oito paisagens de estudo.

\section{Chance do cachorro visitar remanescentes florestais}

Quantificamos para cada um dos cachorros uma variável binária relacionada ao cachorro ter ou não visitado remanescentes florestais por conta própria (i.e. sem estar acompanhando o responsável) pelo menos uma vez nos 7 dias anteriores à entrevista.

\section{Atributos individuais}


As variáveis independentes associadas aos atributos individuais utilizadas foram sexo, idade, condição de saúde, comportamento exploratório, tamanho e raça (Figura 1). Os dados sobre sexo, idade, condição de saúde e comportamento exploratório foram obtidos através das entrevistas, enquanto os dados sobre tamanho e raça o foram através das fotografias.

Como variáveis operacionais da condição de saúde, quantificamos variáveis binárias relacionadas ao cachorro ter sido consultado por veterinário (1) devido a doença, (2) devido a ferimento e (3) devido a doença e/ou ferimento no período de 1 ano anterior à entrevista. Para medir o comportamento exploratório, quantificamos uma variável binária relacionada ao cachorro obter alimento em outros locais que não o domicílio onde era criado.

A partir das fotografias, os cachorros foram classificados em quatro categorias de tamanho. Também através das fotografias, classificamos os cachorros utilizando três variáveis categóricas associadas a características morfológicas que indicam raças diferentes: (1) variável categórica com 16 níveis, chamados de morfotipos, definidos de acordo com semelhanças físicas com raças estabelecidas, (2) variável categórica com 7 níveis, chamados de classes, nas quais os 16

morfotipos foram agrupados com base na classificação de grupos de raças da Federação Cinológica Internacional (www.fci.be), (3) variável binária, dividindo os cachorros entre cães de raça e cães sem raça definida (SRD).

\section{Formas de manejo}

As variáveis independentes associadas à forma de manejo foram o incentivo do dono à movimentação, o motivo para criação do cachorro, o confinamento e a frequência de alimentação, todas obtidas a partir das entrevistas (Figura 1).

Como variáveis operacionais do incentivo do dono à movimentação, quantificamos variáveis binárias ou contínuas relacionadas (1) ao cachorro acompanhar o dono quando este sai de perto do domicílio, (2) a isso ter acontecido ao menos uma vez nos 7 dias anteriores à entrevista, (3) ao cachorro acompanhar o dono quando este visita remanescentes florestais, (4) a isso ter acontecido ao menos um vez nos 7 dias anteriores à entrevista e (5) a quantas vezes isso se repetiu nos 7 dias anteriores à entrevista.

Como variável operacional do motivo para a criação, quantificamos uma variável binária relacionada ao motivo pelo qual o cachorro é criado, tendo dividido os cachorros entre os que são criados para caça e/ou pastoreio e os que não. Essa divisão foi feita pois cachorros criados para 
caça e/ou pastoreio poderiam ter maior facilidade e/ou maior incentivo para se movimentar e/ou entrar em áreas de mata (Van Bommel \& Johnson, 2014).

Já como variáveis operacionais do confinamento do cachorro, quantificamos uma variável binária relacionada (1) ao cachorro ficar preso em algum momento do dia, e duas variáveis contínuas, relacionadas a (2) quantos dias na semana e (3) quantos períodos na semana o cachorro fica preso. Caso observássemos que o cachorro tinha condições de escapar facilmente do local ao qual deveria estar restrito (i.e., espaços na cerca ou muro baixo), consideramos que ele não ficava preso.

Para medir a frequência de alimentação, quantificamos uma variável binária relacionada à frequência com que cada cachorro era alimentado, separando os que eram alimentados mais de uma vez por dia dos que eram alimentados apenas uma vez por dia ou menos.

\section{Contexto ambiental}

Para avaliar o contexto ambiental nos arredores de onde os cachorros são criados, a proximidade à mata nativa foi quantificada através de cinco métricas diferentes: (1) distância do domicílio onde o cachorro é criado ao fragmento de mata nativa mais próximo, (2) cobertura florestal nativa ao redor do domicílio onde o cachorro é criado, (3) cobertura florestal nativa ao redor do domicílio onde o cachorro é criado ponderada pela distância ao domicílio, (4) extensão de bordas entre mata nativa e áreas abertas ao redor do domicílio onde o cachorro é criado e (5) extensão de bordas entre mata nativa e áreas abertas ao redor do domicílio onde o cachorro é criado ponderada pela distância ao domicílio.

Com exceção da distância do domicílio onde o cachorro é criado ao fragmento de mata nativa mais próximo, as demais quatro métricas foram quantificadas em oito diferentes raios $(100,200$, $300,400,500,1000,1500$ e 2000 metros) a partir de cada domicílio. Utilizando o programa ArcGIS e o ambiente $R$, foram calculadas a cobertura florestal nativa $\left(\mathrm{em}^{2}\right.$ ) e a extensão de bordas entre mata nativa e área aberta (em metros) dentro de cada raio. A partir desses valores foram calculadas também as quantidades de mata nativa e de borda ponderadas pela distância ao domicílio (QMPD e QBPD, respectivamente) para cada raio, da seguinte forma:

$$
\mathrm{QMPD}_{\mathrm{r}} \text { ou } \mathrm{QBPD}_{\mathrm{r}}=\sum 1-\left(\frac{1}{r} d_{i}\right)
$$

onde $r$ é a medida do raio definido ao redor do domicílio e $d_{i}$ é a distância entre cada ponto inserido dentro desse raio e o domicílio. A cada ponto é atribuído um valor de 0 a 1 , sendo esse 
valor menor quanto mais próximo ao limite do raio e maior quanto mais próximo ao domicílio, e, ao fim, soma-se os valores de todos os pontos inseridos dentro do raio.

\subsection{Análise de dados}

Foram excluídos das análises 197 cachorros com menos de 4 meses de idade, criados presos em canis ou cujo dono não soube responder se haviam visitado remanescentes florestais nos 7 dias anteriores à entrevista, restando 1428 indivíduos.

Para cerca de um terço (461 indivíduos) de todos os 1428 indivíduos analisados, havia dados faltantes para uma ou mais variáveis independentes, devido, em sua maior parte, a respostas do tipo "não sei" a questões do questionário ou à impossibilidade de fotografar o indivíduo. A exclusão dos indivíduos com dados incompletos antes da análise dos dados é prática comum, mas desaconselhada, por ter menor poder preditivo e maior probabilidade de viés nos resultados (Rubin, 1987). Para solucionar o problema, utilizamos o método de imputação múltipla, que preenche os dados faltantes múltiplas vezes com valores preditos a partir da distribuição dos valores observados (Rubin, 1987; Van Buuren \& Groothuis-Oudshoorn, 2011). Utilizando esse método, geramos 10 conjuntos de dados imputados que foram analisados separadamente, como descrito a seguir.

Utilizamos a abordagem de seleção de modelos candidatos através do Critério de Informação de Akaike para investigar, em cada um dos conjuntos de dados imputados, a importância relativa dos atributos individuais, formas de manejo e contexto ambiental na determinação da chance de um indivíduo visitar remanescentes florestais. Como o desenho amostral foi hierárquico (indivíduos em domicílios dentro de paisagens), utilizamos modelos lineares generalizados mistos (GLMM), utilizando as paisagens e os domićlios como fatores aleatórios aninhados em todos os modelos candidatos. Todos os modelos foram ajustados a uma distribuição binomial, usando o logito como função de ligação. Todas as variáveis contínuas foram padronizadas, com média 0 e desvio-padrão 1, a fim de melhorar a convergência dos modelos.

Em uma primeira etapa, para as cinco variáveis independentes com mais de uma forma de quantificação - condição de saúde (três variáveis operacionais), raça (três variáveis operacionais), incentivo do dono à movimentação (cinco variáveis operacionais), confinamento (três variáveis operacionais) e proximidade à mata nativa (33 variáveis operacionais) - realizamos uma seleção de modelos com o objetivo de selecionar a variável operacional que melhor explica a chance do cachorro visitar remanescentes florestais. Para cada uma destas cinco variáveis independentes, o 
conjunto de modelos candidatos incluiu: (1) um modelo de referência (contendo apenas o intercepto, sem nenhum fator fixo) e (2) modelos simples contendo cada uma das variáveis operacionais como fator fixo. Comparamos os modelos candidatos com base no Critério de Informação de Akaike (AIC) (Burnham \& Anderson, 2002) e consideramos como a melhor forma de quantificar cada variável independente aquela presente no modelo melhor ranqueado (menor AIC), excluindo o modelo de referência. Para todas as cinco variáveis independentes, com exceção da raça, o modelo melhor ranqueado não variou entre os 10 conjuntos de dados imputados; para a variável raça, consideramos o modelo (e a variável operacional) melhor ranqueado no maior número de conjuntos de dados (cinco dos 10 conjuntos de dados) (Figura 1; Anexo 3).

Em uma segunda etapa, realizamos uma seleção de modelos com o objetivo de investigar a importância relativa de variáveis independentes relacionadas aos atributos individuais (seis variáveis), formas de manejo (quatro variáveis) e contexto ambiental nos arredores do domicílio (uma variável) para a determinação da chance de cachorros visitarem remanescentes florestais. 0 conjunto de modelos candidatos incluiu: (1) um modelo de referência (contendo apenas o intercepto, sem nenhum fator fixo), (2) modelos simples contendo cada uma das variáveis independentes como fator fixo e (3) modelos aditivos contendo todas as possíveis combinações entre variáveis independentes, até o máximo de 5 variáveis por modelo. Os modelos foram selecionados com base no Critério de Informação de Akaike (AIC) e considerados igualmente plausíveis sempre que $\Delta \mathrm{AIC} \leq 2$ (Burnham \& Anderson, 2002). A importância de cada variável foi avaliada considerando (1) o número e a proporção de modelos selecionados em que cada variável estava presente em cada conjunto de dados imputado e no total; (2) o número de conjuntos de dados imputados nos quais cada modelo candidato foi selecionado; e (3) a soma dos pesos de evidência dos modelos contendo cada variável (Burnham \& Anderson, 2002) em cada conjunto de dados imputado.

Não houve colinearidade entre as 11 variáveis independentes (Variance Inflation Factor < 2) (Anexo 4). As análises foram realizadas em ambiente $\mathrm{R}$ com os pacotes Imer4, mice, MuMin e usdm. 


\section{RESULTADOS}

\subsection{Características das populações de cachorros}

As oito paisagens estudadas apresentam em média 4,01 domicílios $/ \mathrm{km}^{2}( \pm 3,81)$, e densidade populacional humana de 10,58 habitantes $/ \mathrm{km}^{2}( \pm 11,26)$. A densidade de cachorros se aproxima da densidade populacional humana, com em média 7,25 indivíduos $/ \mathrm{km}^{2}( \pm 5,36)$ e uma razão de $1,26( \pm 0,37)$ pessoas por cachorro. Cachorros são criados em ao menos $77,5 \%$ dos domicílios amostrados $(83,7 \pm 10,2 \%$ por paisagem), onde o número de indivíduos varia de 1 a 83 (média 2,29 $\pm 3,70)$.

Foram analisados 1428 cachorros, de 540 domicílios, distantes em média 131 metros ( $\pm 122,2 \mathrm{~m}$ ) do remanescente florestal mais próximo, sendo que $89 \%$ eram criados a menos de 300 metros de um remanescente (Figura S4). Cerca de metade dos cachorros (51\%) tem até 5 anos (média 5,0 \pm 4,0, Figura 4) e a mesma proporção é criada pelo mesmo dono há no máximo 3 anos (média 4,2 \pm 3,7 , Figura S3). A proporção de machos é um pouco maior que a de fêmeas (1,34:1, Figura 4) e um quarto dos cachorros é castrado ( $41 \%$ das fêmeas e $13 \%$ dos machos, Figura S3). Aproximadamente metade (53\%) é de médio porte (Figura 4) e a maior parte (63\%) não tem raça definida (Figura 4; Figura S2).

Apenas cerca de um terço (31\%) dos cachorros foi consultado por um veterinário no ano anterior à entrevista (Figura S7). A maior parte deles (80\%) foi vacinada contra raiva até um ano antes da entrevista (Figura S7), geralmente através das campanhas de vacinação realizadas gratuitamente pelas prefeituras, mas uma proporção bem menor (31\%) recebeu a vacina polivalente (Figura S7), que protege contra cinomose, parvovirose, hepatite canina e outras doenças, no mesmo período. Pouco mais da metade dos cachorros (58\%) tomou algum tipo de vermífugo nos 6 meses anteriores à entrevista (Figura S8), enquanto quase dois terços (65\%) tomavam banho com alguma frequência (Figura S8) e um terço (32\%) recebeu algum tipo de tratamento contra carrapatos no mês anterior (Figura S8). Ainda assim, foram observados carrapatos em quase um quarto dos cachorros (23\%) no mês anterior à entrevista (Figura S8), isso porque geralmente o tratamento era posterior à infestação (obs. pessoal).

Os cachorros são criados principalmente para companhia (83\%) e segurança do domicílio (44\%) (Figura S2). A grande maioria é alimentada mais de uma vez por dia (88\%, Figura 4), a maior parte (56\%) tanto com ração quanto com restos de comida (Figura S3), enquanto $15 \%$ consegue alimento também em outros locais que não o domicílio onde é criado (Figura 4; Figura S3). 
Pouco mais da metade dos cachorros (53\%) não é totalmente confinada em nenhum momento (Figura 4; Figura S5). A maior parte dos que sofrem alguma restrição de movimentos fica confinada em algum momento todos os dias (42\%, Figura S5), e tanto no período diurno quanto no noturno (31\%, Figura S5). Muitos cachorros (41\%) saem sozinhos dos arredores do domicílio (Figura S5), e $12 \%$ havia visitado remanescentes florestais por conta própria nos 7 dias anteriores à entrevista (Figura 4; Figura S5). Pouco mais da metade dos cachorros (59\%) acompanham os donos quanto estes saem dos arredores do domicílio (Figura S6), sendo que 10\% visitaram remanescentes com os donos nos 7 dias anteriores à entrevista (Figura 4). Quase um terço dos cachorros (30\%) já teve alguma interação com a fauna silvestre, tendo perseguido e/ou matado algum animal ou sendo ferido por eles (Figura S4). 


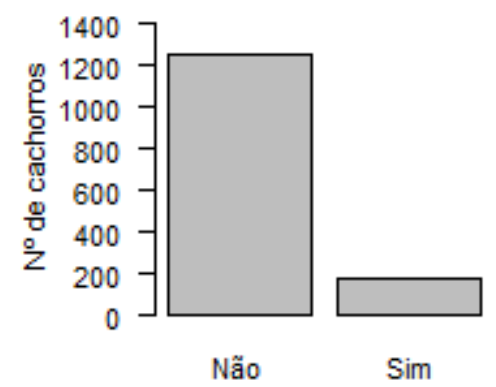

Visitou remanescentes (semana)
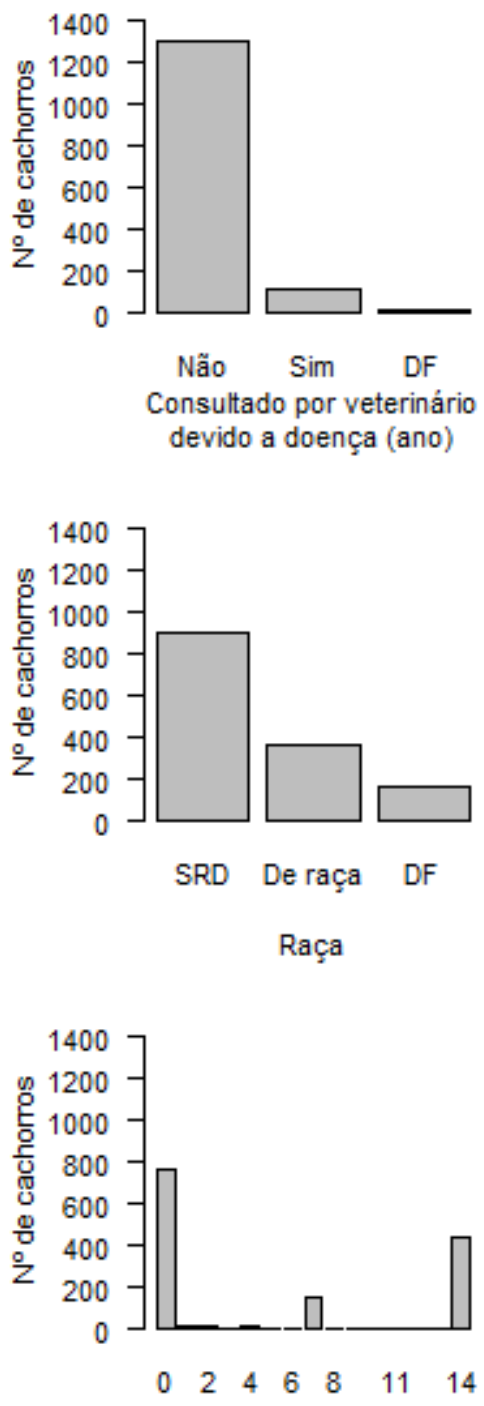

$N^{\circ}$ de periodos preso (semana)
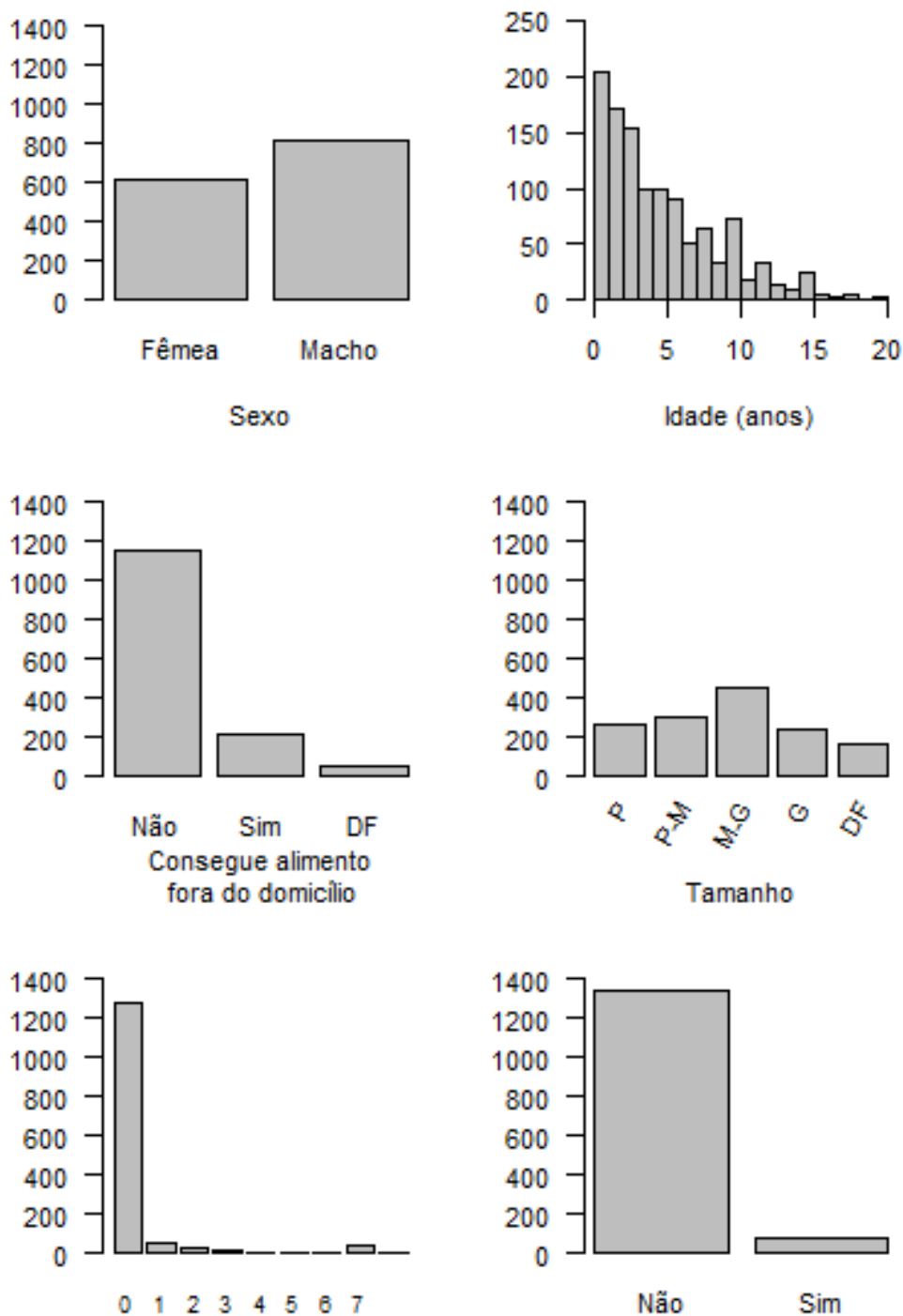

$N^{\circ}$ de vezes que acompanhou 0 dono a remanescentes (semana)

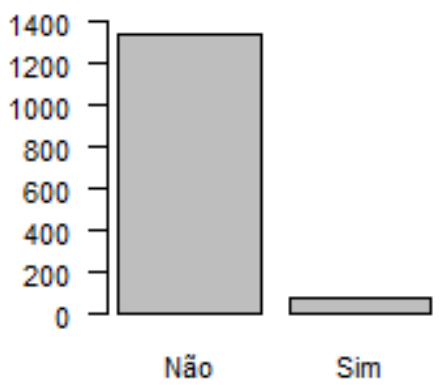

Criado para caça ou pastoreio

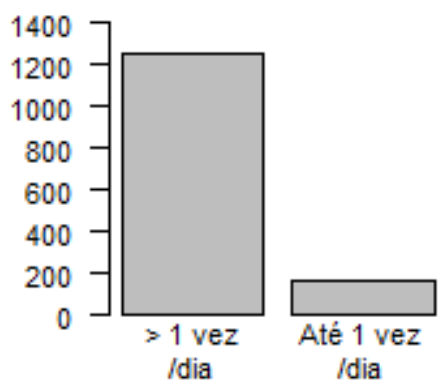

Frequência de alimentação

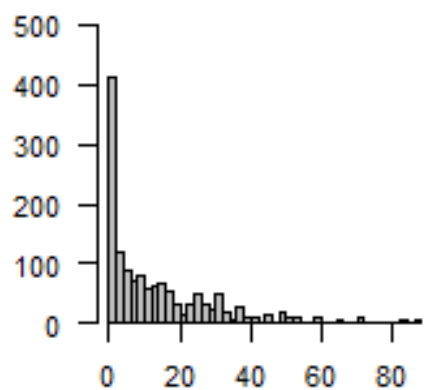

$\mathrm{QMPD}_{\mathbf{F}} / 1000(200 \mathrm{~m})$

Figura 4. Histogramas das variáveis dependente e independentes associadas à chance de cachorros visitarem remanescentes florestais, a atributos individuais, formas de manejo e contexto ambiental nos arredores de onde são criados. DF: dados faltantes; $\operatorname{QPMP}_{R}(200 \mathrm{~m})$ : quantidade de mata nativa ponderada pela distância ao domicílio no raio de $200 \mathrm{~m}$. 


\subsection{Importância relativa dos atributos individuais, formas de manejo e contexto ambiental}

Na primeira etapa da seleção de modelos, foram selecionadas as seguintes variáveis operacionais para as cinco variáveis independentes com mais de uma variável operacional (Figura 1; Anexo 3): cachorro ter sido consultado por veterinário devido a doença no período de 1 ano anterior à entrevista (condição de saúde), divisão entre cães de raça e cães sem raça definida (raça), quantas vezes o cachorro acompanhou o dono quando este visitou remanescentes florestais nos 7 dias anteriores à entrevista (incentivo do dono à movimentação), número de períodos na semana em que o cachorro fica preso (confinamento) e cobertura florestal nativa no raio de 200 metros ponderada pela distância do domicílio (proximidade à mata nativa). Essas medidas foram então incorporadas à segunda etapa do processo de seleção de modelos.

Na segunda etapa da seleção de modelos (Anexo 6), o número de modelos selecionados para cada um dos 10 conjuntos de dados imputados variou de 2 a 17 (Tabela 1), apenas um modelo foi selecionado para todos os conjuntos de dados (Tabela 2) e 18 dos 1024 modelos candidatos foram selecionados pelo menos em um dos 10 conjuntos de dados (Tabela 2).

No entanto, todos os modelos selecionados em todos os 10 conjuntos de dados imputados são modelos aditivos que incluem pelo menos as mesmas três variáveis: uma associada a um atributo individual - 'comportamento exploratório', e duas associadas à forma de manejo - 'incentivo à movimentação' e 'confinamento' (Tabela 1). A importância dessas variáveis é ressaltada pelo alto valor da soma dos pesos de evidência dos modelos que as incluem - próximo a 1 em todos os 10 conjuntos de dados para 'comportamento exploratório' e 'incentivo à movimentação', e variando de 0,71 a 0,81 entre os 10 conjuntos para 'confinamento' (Tabela 3). Estes altos valores de peso de evidência indicam que essas variáveis estão presentes em praticamente todos os modelos mais bem ranqueados, mesmo entre os modelos não selecionados. Todos os modelos selecionados indicam que cachorros mais exploradores, que recebem mais incentivo a se movimentar e que passam menos tempo confinados têm maior chance de visitar remanescentes florestais.

A variável 'tamanho' esteve presente na maior parte dos modelos selecionados em todos os conjuntos de dados (Tabela 1), sempre em modelos que contêm também as variáveis 'comportamento exploratório', 'incentivo à movimentação' e 'confinamento' (Tabela 2). Estes modelos contendo 'tamanho' foram selecionados em um número maior de conjuntos de dados do que os modelos que não incluem essa variável (Tabela 2). Porém, a soma dos pesos de evidência dos modelos que a contêm foi menor e variou mais entre os conjuntos de dados, em comparação 
às três variáveis mencionadas anteriormente (Tabela 3), indicando que 'tamanho' não está presente em todos os modelos mais bem ranqueados em todos os conjuntos de dados. Os modelos selecionados indicam que cachorros de tamanho médio a grande têm maior chance de visitar remanescentes florestais que cachorros de tamanho pequeno.

As variáveis 'idade', 'proximidade à mata nativa', 'frequência de alimentação', 'sexo', 'condição de saúde', 'raça' e 'motivo para criação' estão presentes numa pequena proporção dos modelos selecionados (Tabela 1) e somam baixos pesos de evidência (Tabela 3), com exceção da 'idade' em dois dos conjuntos de dados. Os modelos selecionados que contêm uma dessas variáveis incluem também as variáveis 'comportamento exploratório', 'incentivo à movimentação', 'confinamento' e, muitas vezes, 'tamanho' (Tabela 2). Esses modelos indicam que fêmeas, cachorros mais novos, que são criados onde há mais mata nativa, que são mais bem alimentados e que não tiveram problemas recentes de saúde têm maior chance de visitar remanescentes florestais. Há informações divergentes sobre raça e motivo para criação, mas a maior parte dos modelos selecionados indica que cães de raça e cachorros criados para caça e/ou pastoreio têm maior chance de visitar remanescentes florestais. Não é possível, porém, confirmar a importância de nenhuma dessas variáveis, já que, ao contrário das quatro variáveis anteriores, essas estão ausentes da maioria dos modelos selecionados (Tabelas 1 e 2) e somam baixo peso de evidência (Tabela 3), além de possuírem coeficientes baixos, cujos intervalos de confiança incluem o zero (Anexo 6). 
Tabela 1. Quantidade de modelos selecionados para determinar a chance de cachorros visitarem remanescentes florestais. São mostrados o número de modelos selecionados em cada um dos 10 conjuntos de dados imputados e o número desses modelos em que cada uma das 11 variáveis independentes está presente, por conjunto de dados e no total. SEX: sexo, IDA: idade, SAU: condição de saúde, EXP: comportamento exploratório, TAM: tamanho, RAC: raça, INC: incentivo à movimentação, MOT: motivo para criação, CON: confinamento, ALI: frequência de alimentação, PRO: proximidade à mata nativa. Cinza escuro a branco: variável presente em todos, ao menos metade, ao menos um ou nenhum modelo selecionado.

\begin{tabular}{|c|c|c|c|c|c|c|c|c|c|c|c|c|}
\hline \multirow{2}{*}{$\begin{array}{l}\text { Conjunto de } \\
\text { dados }\end{array}$} & \multicolumn{12}{|c|}{ Número de modelos selecionados } \\
\hline & Total & EXP & INC & CON & TAM & IDA & PRO & ALI & SEX & SAU & RAC & MOT \\
\hline 1 & 2 & 2 & 2 & 2 & 1 & 2 & & & & & & \\
\hline 2 & 14 & 14 & 14 & 14 & 6 & 2 & 2 & 2 & 2 & 2 & 1 & 1 \\
\hline 3 & 8 & 8 & 8 & 8 & 8 & 1 & 1 & 1 & 1 & 1 & 1 & 1 \\
\hline 4 & 14 & 14 & 14 & 14 & 8 & 2 & 2 & 2 & 2 & 2 & 1 & 1 \\
\hline 5 & 14 & 14 & 14 & 14 & 7 & 3 & 3 & 2 & 2 & 2 & 1 & \\
\hline 6 & 2 & 2 & 2 & 2 & 1 & 2 & & & & & & \\
\hline 7 & 8 & 8 & 8 & 8 & 8 & 1 & 1 & 1 & 1 & 1 & 1 & 1 \\
\hline 8 & 17 & 17 & 17 & 17 & 8 & 3 & 4 & 3 & 2 & 2 & 2 & 1 \\
\hline 9 & 8 & 8 & 8 & 8 & 8 & 1 & 1 & 1 & 1 & 1 & 1 & 1 \\
\hline 10 & 9 & 9 & 9 & 9 & 8 & 1 & 1 & 1 & 1 & 1 & 1 & 1 \\
\hline \multirow[t]{2}{*}{ Total } & 96 & 96 & 96 & 96 & 63 & 18 & 15 & 13 & 12 & 12 & 9 & 7 \\
\hline & & $100 \%$ & $100 \%$ & $100 \%$ & $66 \%$ & $19 \%$ & $16 \%$ & $14 \%$ & $13 \%$ & $13 \%$ & $9 \%$ & $7 \%$ \\
\hline
\end{tabular}


Tabela 2. Quantidade de conjuntos de dados imputados para os quais cada modelo candidato para determinar a chance de cachorros visitarem remanescentes florestais foi selecionado. SEX: sexo, IDA: idade, SAU: condição de saúde, EXP: comportamento exploratório, TAM: tamanho, RAC: raça, INC: incentivo à movimentação, MOT: motivo para criação, CON: confinamento, ALI: frequência de alimentação, PRO: proximidade à mata nativa.

\begin{tabular}{lc}
\hline Modelo & № de conjuntos para os quais foi selecionado \\
\hline EXP+TAM+INC+CON+IDA & 10 \\
EXP+TAM+INC+CON & 8 \\
EXP+TAM+INC+CON+SEX & 8 \\
EXP+TAM+INC+CON+SAU & 8 \\
EXP+TAM+INC+CON+ALI & 8 \\
EXP+TAM+INC+CON+PRO & 8 \\
EXP+TAM+INC+CON+RAC & 7 \\
EXP+TAM+INC+CON+MOT & 6 \\
EXP+INC+CON+IDA & 6 \\
EXP+INC+CON & 5 \\
EXP+INC+CON+SEX & 4 \\
EXP+INC+CON+SAU & 4 \\
EXP+INC+CON+ALI & 4 \\
EXP+INC+CON+PRO & 4 \\
EXP+INC+CON+RAC & 2 \\
EXP+INC+CON+IDA+PRO & 2 \\
EXP+INC+CON+ALI+PRO & 1 \\
EXP+INC+CON+MOT & 1 \\
\hline
\end{tabular}

Tabela 3. Soma dos pesos de evidência dos modelos para determinar a chance de cachorros visitarem remanescentes florestais que incluem cada uma das 11 variáveis independentes em cada um dos 10 conjuntos de dados imputados. SEX: sexo, IDA: idade, SAU: condição de saúde, EXP: comportamento exploratório, TAM: tamanho, RAC: raça, INC: incentivo à movimentação, MOT: motivo para criação, CON: confinamento, ALI: frequência de alimentação, PRO: proximidade à mata nativa. Cinza escuro a cinza claro: soma do peso de evidência, do maior valor para o menor.

\begin{tabular}{lccccccccccc}
\hline $\begin{array}{l}\text { Conjunto } \\
\text { de dados }\end{array}$ & EXP & INC & CON & TAM & IDA & PRO & ALI & SEX & SAU & RAC & MOT \\
\hline 1 & 1 & 1 & 0,751 & 0,389 & 0,524 & 0,176 & 0,162 & 0,163 & 0,146 & 0,126 & 0,126 \\
2 & 1 & 1 & 0,762 & 0,321 & 0,164 & 0,232 & 0,199 & 0,21 & 0,187 & 0,162 & 0,162 \\
3 & 1 & 1 & 0,805 & 0,831 & 0,136 & 0,167 & 0,158 & 0,148 & 0,121 & 0,173 & 0,173 \\
4 & 1 & 1 & 0,785 & 0,336 & 0,217 & 0,22 & 0,184 & 0,199 & 0,181 & 0,154 & 0,154 \\
5 & 1 & 1 & 0,776 & 0,312 & 0,244 & 0,217 & 0,192 & 0,197 & 0,181 & 0,155 & 0,155 \\
6 & 1 & 1 & 0,809 & 0,405 & 0,563 & 0,173 & 0,148 & 0,148 & 0,136 & 0,12 & 0,12 \\
7 & 0,997 & 1 & 0,714 & 0,725 & 0,252 & 0,171 & 0,161 & 0,153 & 0,142 & 0,136 & 0,136 \\
8 & 1 & 1 & 0,777 & 0,327 & 0,236 & 0,25 & 0,2 & 0,181 & 0,176 & 0,165 & 0,165 \\
9 & 1 & 1 & 0,798 & 0,623 & 0,123 & 0,222 & 0,17 & 0,15 & 0,145 & 0,212 & 0,212 \\
10 & 1 & 1 & 0,781 & 0,433 & 0,206 & 0,208 & 0,192 & 0,175 & 0,17 & 0,179 & 0,179 \\
\hline
\end{tabular}




\section{DISCUSSÃO}

Nas paisagens rurais de Mata Atlântica da região de estudo, cachorros são criados na maior parte dos domicílios, e o tamanho da população de cachorros se aproxima da população humana. Grande parte desses cachorros é criada solta, o que permite que muitos saiam sozinhos dos arredores do domicílio, e parte visite remanescentes florestais com frequência e/ou interaja com animais silvestres. Apesar da vacinação contra raiva ser eficiente na região, a população de cachorros carece de outros cuidados veterinários. Todos estes aspectos corroboram a ideia de que cachorros exercem impacto significativo sobre a fauna silvestre e tenham papel importante na epidemiologia de zoonoses em paisagens rurais. Nossos resultados nos permitem afirmar que quatro fatores atuam em conjunto para determinar a chance de cachorros visitarem remanescentes florestais. Cachorros de tamanhos maiores, mais exploradores, que recebem mais incentivo a se movimentar e que passam menos tempo confinados têm maior chance de visitar remanescentes florestais. Dois desses fatores - 'comportamento exploratório' e 'tamanho' - são associados a atributos individuais, enquanto os outros dois - 'incentivo do dono à movimentação' e 'confinamento' - são associados a formas de manejo, sugerindo que características do cachorro e a forma como é manejado influenciam a chance de visitas a remanescentes florestais mais do que o contexto ambiental nos arredores de onde é criado. A evidência sobre a relevância dos demais fatores analisados - 'sexo', 'idade', 'condição de saúde', 'raça', 'motivo para criação', 'frequência de alimentação' e 'proximidade à mata nativa' - é inconclusiva.

Nos próximos parágrafos iremos, inicialmente, contextualizar a maior importância de determinadas variáveis entre aquelas associadas aos atributos individuais e às formas de manejo, e, posteriormente, a menor importância do contexto ambiental, na determinação da chance de cachorros visitarem remanescentes florestais. Em seguida, discutiremos as implicações das características das populações de cachorros para o impacto sobre a fauna silvestre e a transmissão de zoonoses em paisagens rurais de Mata Atlântica. Por fim, apontaremos as implicações dos nossos resultados para o planejamento de programas para reduzir os impactos de cachorros que circulam livremente em paisagens rurais.

A importância de atributos individuais na determinação da chance de cachorros visitarem remanescentes florestais é esperada dada a grande variação fenotípica entre cachorros. Cachorros variam em tamanho, forma e comportamento mais do que qualquer outro mamífero, especialmente devido à seleção de linhagens com fenótipos exagerados para o desenvolvimento 
de novas raças (Boyko \& Boyko, 2014). Nossos resultados sugerem que tanto características físicas (i.e. tamanho) como comportamentais (i.e. comportamento exploratório) são importantes para a chance de cachorros visitarem áreas de florestas nativas.

Embora muito menos exploradas na literatura sobre movimentação de cachorros, características comportamentais são tidas como fundamentais para o sucesso de invasões biológicas (Chapple et al., 2012). O comportamento exploratório está relacionado à maior atividade em ambientes não familiares (Sih et al., 2004) e se correlaciona também a outros comportamentos como agressividade, audácia e formação de rotinas (Verbeek et al., 1994, 1996; Rehage \& Sih, 2004; Cote et al., 2010), fazendo com que indivíduos exploradores tenham mais chance de visitar remanescentes florestais.

Dentre as características físicas, nossos resultados indicam que o tamanho é muito mais importante que outros atributos, como sexo, idade, raça ou condição de saúde, para parte dos quais (e.g., sexo e idade) também há evidências anteriores de efeito sobre a movimentação de cachorros (Robley et al., 2010; Sparkes et al., 2014; Van Bommel \& Johnson, 2014; Molloy et al., 2017). De fato, já havia sido demonstrado que cachorros maiores percorrem maiores distâncias em áreas urbanas (Rubin \& Beck, 1982) e, de maneira geral em mamíferos, espécies maiores apresentam maior área de vida (Sandell, 1989; Gompper \& Gittleman, 1991). É importante ter em mente que o número de cachorros analisados em trabalhos prévios é consideravelmente menor do que o que analisamos neste estudo, e nenhum considerou o tamanho junto às outras características físicas. Como o tamanho dos indivíduos tem relação com sua idade, sexo e raça, esta característica física pode ser mais importante para definir a movimentação de cachorros do que as demais, principalmente se consideradas isoladamente. Já a condição de saúde independe do tamanho do indivíduo, mas foi pouco estudada, e nesse estudo foi analisada através de proxies simples (consulta veterinária devido a ferimento ou doença no período de um ano), indicando a importância de análises mais detalhadas deste aspecto em trabalhos futuros (e.g. com uso de body condition score, German et al., 2006).

De maneira similar às características fenotípicas, há imensa variação nas formas como cachorros são manejados, que podem ir de extremos como cachorros de estimação criados totalmente confinados e completamente dependentes de recursos providos pelo homem até cachorros perifericamente associados a habitações humanas ou mesmo ferais que pouco ou nada dependem de recursos de origem humana (Vanak \& Gompper, 2009). Algumas formas de manejo afetam diretamente a capacidade dos animais se movimentarem livremente e, consequentemente, a 
chance de visitarem áreas de vegetação nativa. De fato, nossos resultados indicam que, dentre os diferentes aspectos da forma de manejo estudados (frequência de alimentação, motivo para criação, confinamento e incentivo à movimentação), os mais importantes para a chance de cachorros visitarem remanescentes florestais são aqueles mais diretamente relacionados à movimentação dos cachorros (confinamento e incentivo à movimentação).

Poucos estudos se dedicaram a investigar o efeito de diferentes formas de manejo sobre a movimentação e os impactos causados por cachorros, a não ser pelo confinamento (Rubin \& Beck, 1982) e alimentação (Silva-Rodríguez \& Sieving, 2011; Ruiz-Izaguirre et al., 2015). De acordo com esses estudos, cachorros criados sempre soltos percorrem distâncias maiores que aqueles que ficam ocasionalmente presos (Rubin \& Beck, 1982), enquanto a má nutrição é determinante para a predação por cachorros (Silva-Rodríguez \& Sieving, 2011; Ruiz-Izaguirre et al., 2015). De fato, verificamos que cachorros que ficam presos por períodos menores têm maior chance de visitar remanescentes florestais. A influência do nível nutricional, por outro lado, não foi corroborada pelos nossos resultados. No entanto, todos os cachorros em nossa área de estudo, exceto por dois, são alimentados ao menos uma vez por dia e $88 \%$ mais de uma vez (Figura 4). Também não avaliamos a qualidade nutricional dos alimentos consumidos, de modo que esse aspecto deveria ser melhor analisado em estudos futuros em que haja maior variação na frequência e qualidade de alimentação.

Apesar de não terem sido estudados anteriormente, é de se esperar que o motivo para criação do cachorro e o incentivo dos responsáveis à sua movimentação - aspectos relacionados entre si influenciem a chance de um cachorro visitar áreas de vegetação nativa. Cachorros podem ser criados para diversos fins, como companhia, caça, pastoreio, guarda, levar cargas, encontrar pessoas, auxiliar deficientes, entre outros (Boyko \& Boyko, 2014), cada um dos quais está associado com determinadas características desejadas e que geralmente dependem de condicionamento dos cachorros por seus responsáveis. Seja através de condicionamento ou treinamento, ou apenas através do convívio, comportamentos e incentivos do dono devem ser muito importantes para a movimentação de cachorros, que desenvolvem laços com seus donos (Wedl et al., 2010), podendo considerá-los membros do grupo (Rubin \& Beck, 1982).

De fato, nossos resultados sugerem existir uma forte associação entre o incentivo do dono à movimentação dos cachorros e sua chance de visitar remanescentes florestais desacompanhado. Especificamente, observamos que a chance do cachorro visitar remanescentes florestais desacompanhado aumenta com a frequência com que acompanha seu responsável em visitas a 
remanescentes, sugerindo papel importante do aprendizado. Por outro lado, os motivos para criação dos cachorros variaram relativamente pouco na região de estudo, com a grande maioria dos cães criados por múltiplos motivos, principalmente para companhia e segurança do domicílio. Assim, esse aspecto pode se mostrar mais importante em outras regiões onde a utilização dos cachorros para atividades como caça, pastoreio e guarda da criação sejam mais comuns.

Por fim, em comparação aos atributos individuais e formas de manejo, que variam amplamente, o contexto ambiental, em especial a proximidade entre o local de criação e áreas de vegetação nativa, deve variar pouco frente a grande capacidade de deslocamento dos cachorros. Em geral, cachorros criados soltos em áreas rurais podem ter áreas de vida grandes (1-2451 ha, Meek, 1999; 45 ha, Vanak \& Gompper, 2010; 0-104 ha, Dürr \& Ward, 2014; 9-134 ha, Sparkes, 2014; 31-1161 ha, Van Bommel \& Johnson, 2014; 1-131 ha, Molloy et al., 2017) e realizar grandes deslocamentos diários (1591-5182 m, Sparkes et al., 2014; 10 km; Molloy et al., 2017), se afastando bastante de seu domicílio (máx. 1519 m, Vaniscotte et al., 2011; 534-1985 m, Sepúlveda et al. 2015). De fato, em nossa região de estudo, a distância linear entre o domicílio de criação e pontos no interior de matas nativas onde cachorros foram registrados em câmeras fotográficas variou de 94 a 3975 m (Ribeiro, 2016). Assim, a grande capacidade de deslocamento de cachorros faz com que, mesmo em paisagens bastante desmatadas ou alteradas, as distâncias dos domicílios às áreas de vegetação nativa não sejam suficientemente grandes para impedir a visitação destas áreas. A distribuição espacial dos domicílios não influencia o número de cachorros registrados em matas nativas da nossa região de estudo (Ribeiro, 2016), e a distância dos domicílios não influencia o número de visitas de cachorros a uma praia onde predam ovos de tartarugas (Ruiz-Izaguirre et al., 2015). Além disso, há evidências vindas de estudo prévio na mesma região de estudo de que o número de cachorros registrados em áreas de vegetação nativa é maior quanto menor a cobertura de vegetação nativa, independentemente do número ou da distribuição de cachorros criados na região (Ribeiro, 2016). Isso sugere que florestas (e potencialmente outros tipos de vegetação nativa) servem de barreira à movimentação de cachorros, que preferem se movimentar por áreas abertas (Sepúlveda et al., 2015). Assim, o desmatamento, embora torne maiores as distâncias até as áreas de vegetação nativa, facilita que cachorros alcancem os fragmentos remanescentes (Ribeiro, 2016).

Além de nos permitir analisar os fatores que determinam a chance de um indivíduo visitar remanescentes florestais, os dados coletados através das entrevistas nos permitem também avaliar o tamanho e as características da população de cachorros, aferindo indiretamente o 
potencial impacto sobre a fauna silvestre. Nossos dados sugerem que as densidades de cachorros em paisagens rurais de Mata Atlântica são muito mais altas do que a de carnívoros silvestres. A densidade média de cachorros na região de estudo $\left(7,25\right.$ indivíduos $\left./ \mathrm{km}^{2}\right)$ é semelhante à reportada em outras comunidades rurais no mundo, como no Chile e em países da África (3-12 indivíduos $/ \mathrm{km}^{2}$, Gompper, 2014) ou mesmo no Brasil (6,3 km², Torres \& Prado, 2010), ainda que não seja tão alta quanto em outros locais (Gompper, 2014). Por outro lado, a razão pessoas:cachorros $(1,26: 1)$ que registramos é uma das menores, inclusive no Brasil $(4,7: 1$, DantasTorres et al., 2010), aproximando-se apenas de comunidades no Chile, Bolívia, Argentina e México (1,1-2,0:1, Gompper, 2014). É importante ressaltar que esses números não englobam os cachorros de rua (não associados a nenhum domicílio), que são relativamente comuns na região, e potencialmente tem maior chance de visitar remanescentes florestais, uma vez que não são manejados e precisam procurar por alimento. Já a densidade de canídeos silvestres em áreas de Mata Atlântica é uma ordem de magnitude mais baixa (Cerdocyon thous, 0,35 indivíduo/km², Beisiegel et al., 2013). Mesmo considerando estimativas populacionais que abrangem apenas os cachorros que entram nas matas da região de estudo a partir de registros em câmeras fotográficas, a densidade de cachorros é alta e maior que a de muitos carnívoros silvestres (12-79 ind./paisagem, ou 6-21\% da população de cachorros criados, Ribeiro, 2016). Estes dados e comparações indicam o grande potencial de impactos à fauna silvestre.

Além do tamanho populacional, uma série de características da população de cachorros na área de estudo reforça os impactos potenciais para a fauna silvestre. Em primeiro lugar, quase um terço (30\%) dos cachorros já teve contato direto relacionado a predação ou competição com espécies silvestres. O impacto, porém, deve ser ainda maior, dado a importância dos efeitos não letais da predação (Preisser et al., 2005). Além disso, a vacinação e outras medidas profiláticas são relativamente incomuns, assim como em outras regiões do mundo, e indicam o potencial de efeitos negativos via transmissão de doenças, tanto para a fauna silvestre como para o homem. A cobertura da vacinação antirrábica (80\%) é maior do que em outras áreas rurais, inclusive no Brasil (4-70\%, Silva-Rodríguez \& Sieving, 2011, 2012; Frigeri, 2013), e supera o mínimo recomendado para prevenir uma epidemia (70\%, Coleman \& Dye, 1996). Entretanto, mais de dois terços (69\%) dos cachorros podem estar vulneráveis a outras doenças, como a cinomose e a parvovirose, devido à falta da vacina polivalente. O alcance dessa vacina é menor que em outra área no Brasil (66\%, Frigeri, 2013), mas maior que em uma comunidade no México (0\%, Silva-Rodríguez \& Sieving, 2011). A cinomose e a parvovirose são recorrentes entre cachorros na região e afetam 
também outros mamíferos, como o cachorro-do-mato Cerdocyon thous (Curi et al., 2010; Hübner et al., 2010), uma das espécies mais comuns na região (Ribeiro, dados não publicados). Os cachorros também estão expostos à infestação por parasitas, como demonstrado pelo número de cachorros observados com carrapatos no mês anterior à entrevista (23\%). Isso se deve à falta de ações profiláticas, como o tratamento com vermífugos e carrapaticidas, aplicados a apenas $58 \%$ e 32\% dos cachorros, respectivamente, proporção bastante variável em áreas rurais no Brasil e no México (8-78\%, Silva-Rodríguez \& Sieving, 2011, 2012; Curi et al., 2014). Através de carrapatos, os cachorros podem contrair parasitoses como a erliquiose e a babesiose (Shaw et al., 2001; Beugnet \& Marié, 2009) ou mesmo servir como reservatórios da febre maculosa (Horta et al., 2004; Sangioni et al., 2005), todas elas transmissíveis para o homem. Esses dados demonstram o potencial de transmissão de doenças não só à fauna silvestre, mas também aos próprios cachorros e ao homem.

\section{Implicações para o manejo de cachorros em paisagens rurais}

Poucos trabalhos atualmente tratam do manejo de cachorros em áreas rurais, onde os cachorros frequentemente circulam livremente e tem fácil acesso a áreas de vegetação nativa. Esses trabalhos geralmente propõem ações de vacinação e esterilização, esta última direcionada especialmente a fêmeas, com o fim de reduzir o potencial de transmissão de doenças e zoonoses e de reduzir a população de cachorros a médio-longo prazo, respectivamente (Vanak \& Gompper, 2010; Silva-Rodríguez \& Sieving, 2012; Hughes \& Macdonald, 2013; Curi et al., 2014). Outra medida comumente proposta para minimizar os impactos de cachorros é mantê-los confinados em períodos específicos (Vanak \& Gompper, 2010; Silva-Rodríguez \& Sieving, 2012; Ruiz-Izaguirre et al., 2015), especialmente quando são mais ativos.

Nosso estudo permite analisar duas dessas estratégias: ações de vacinação e controle de movimentação. No primeiro caso, nossos resultados sugerem que há espaço para a expansão de campanhas públicas de profilaxia para além da vacinação antirrábica. O amplo alcance das campanhas municipais de vacinação antirrábica permite que uma proporção de cachorros acima da cobertura mínima recomendada para a prevenção de epidemias seja atingida (Coleman \& Dye, 1996). Entretanto, a proporção de cachorros que tomam outras vacinas ou que são tratados contra ecto e endoparasitas é baixa, de modo que há risco de transmissão de outras doenças, como a cinomose, a parvovirose e diversas parasitoses, que ameaçam não só a saúde dos cachorros, como também da fauna silvestre e do homem. 
No segundo caso, nossos dados sugerem que, para além da restrição da movimentação dos cachorros através de seu confinamento, o comportamento do responsável é fundamental para limitar a visita de cachorros a remanescentes de vegetação nativa em paisagens rurais. 0 confinamento dos cachorros e o incentivo à sua movimentação dependem de mudanças de comportamento dos responsáveis, e, portanto, de mudanças em seus valores, crenças e atitudes (Miller et al., 2014). É provavelmente comum que os responsáveis tenham atitudes favoráveis em relação a manter seus cachorros soltos e a estimulá-los a os acompanhar em suas atividades, devido a crenças associadas ao bem-estar e à saúde do cachorro. É provável também que muitos responsáveis por cachorros em áreas rurais ignorem os potenciais impactos negativos de cachorros sobre a fauna nativa e os riscos ao próprio cachorro e à saúde humana. De fato, grande parte dos proprietários de cachorros em uma pequena comunidade rural no México consideram aceitável que cachorros circulem livremente e que procurem por alimento (Ruiz-Izaguirre et al., 2015). Também foi verificado que a utilização de coleira está associada à crença de que o cachorro representa uma ameaça à fauna e de que a recreação sem coleira não é importante, assim como à percepção das atitudes de outras pessoas em favor de sua utilização (Williams et al., 2009). Assim, o desconhecimento sobre os riscos impostos pelos cachorros à fauna é um dos fatores que impedem a adesão à utilização de coleiras (Williams et al., 2009). Isso indica a importância que programas de redução dos impactos de cachorros considerem também aspectos sociais, além de aspectos veterinários (Hughes \& Macdonald, 2013; Miller et al., 2014), e incluam a divulgação e conscientização dos potenciais problemas ocasionados pela entrada de cachorros em áreas de vegetação nativa. 


\section{CONCLUSÃO}

Quatro fatores associados aos atributos individuais e às formas de manejo atuam em conjunto para determinar a chance de cachorros visitarem remanescentes florestais em paisagens rurais da Mata Atlântica. Cachorros de tamanhos maiores, mais exploradores, que recebem mais incentivo a se movimentar e que passam menos tempo confinados têm maior chance de visitar esses remanescentes.

A importância de atributos individuais é esperada dada a grande variedade fenotípica existente entre cachorros. Nossos resultados sugerem que tanto características físicas (i.e. tamanho) como comportamentais (i.e. comportamento exploratório) são importantes para a chance de cachorros visitarem áreas de florestas nativas. Do mesmo modo, há uma grande variação nas formas como cachorros são manejados. Nossos resultados indicam que os aspectos do manejo mais importantes para a chance de cachorros visitarem remanescentes florestais são aqueles mais diretamente relacionados à movimentação dos cachorros. Além disso, apontam que, independentemente do tempo de confinamento, o incentivo do dono à movimentação do cachorro, em particular o estímulo para que o cachorro o acompanhe em visitas a remanescentes florestais, é fundamental. O contexto ambiental, por sua vez, é pouco importante dada a alta mobilidade dos cachorros.

Dadas as características da população de cachorros das paisagens estudadas, é grande o potencial de impacto dos cachorros sobre a fauna, assim como o risco de transmissão de doenças. A fim de reduzir tais problemas, seria necessário expandir as ações profiláticas para além da vacinação antirrábica, dando maior atenção à prevenção de doenças como a cinomose, a parvovirose e diversas parasitoses, que podem afetar a saúde de animais silvestres, de cachorros e também do ser humano. Para além do confinamento, é fundamental que os responsáveis não incentivem que seus cachorros os acompanhem, especialmente em visitas a áreas de vegetação nativa. Tais mudanças de comportamento dos responsáveis pelos cachorros, requerem mudanças em valores, crenças e atitudes relacionadas tanto ao bem-estar e à saúde do cachorro quanto aos potenciais efeitos negativos de cachorros sobre a fauna silvestre. Assim, programas de redução dos impactos de cachorros devem incorporar aspectos sociais, incluindo a divulgação e conscientização dos potenciais problemas ocasionados pela entrada de cachorros em áreas de vegetação nativa. 


\section{REFERÊNCIAS BIBLIOGRÁFICAS}

Beisiegel BM, Lemos FG, Azevedo FC, Queirolo D, Jorge RSP. 2013. Avaliação do risco de extinção do Cachorro-do-mato Cerdocyon thous (Linnaeus, 1766) no Brasil. Biodiversidade Brasileira $3: 138-145$.

Bellard C, Cassey P, Blackburn TM. 2016. Alien species as a driver of recent extinctions. Biology Letters 12:20150623.

Beugnet F, Marié J-L. 2009. Emerging arthropod-borne diseases of companion animals in Europe. Veterinary Parasitology 163:298-305.

Both C, Grant T. 2012. Biological invasions and the acoustic niche: the effect of bullfrog calls on the acoustic signals of white-banded tree frogs. Biology Letters 8:714-716.

Boyko RH, Boyko AR. 2014. Dog conservation and the population genetic structure of dogs. Pages 185-210. Free-Ranging Dogs and Wildlife Conservation.

Burnham KP, Anderson DR. 2002. Model Selection and Multimodel Inference: A Practical Information-Theoretic Approach (2nd ed). Ecological Modelling 172:488.

Butler JR., du Toit J., Bingham J. 2004. Free-ranging domestic dogs (Canis familiaris) as predators and prey in rural Zimbabwe: threats of competition and disease to large wild carnivores. Biological Conservation 115:369-378.

Chapple DG, Simmonds SM, Wong BBM. 2012. Can behavioral and personality traits influence the success of unintentional species introductions? Trends in Ecology \& Evolution 27:57-64.

Chiarello AG. 1999. Effects of fragmentation of the Atlantic forest on mammal communities in south-eastern Brazil. Biological Conservation 89:71-82.

Claridge AW, Mills DJ, Hunt R, Jenkins DJ, Bean J. 2009. Satellite tracking of wild dogs in southeastern mainland Australian forests: Implications for management of a problematic toporder carnivore. Forest Ecology and Management 258:814-822.

Coleman PG, Dye C. 1996. Immunization coverage required to prevent outbreaks of dog rabies. Vaccine 14:185-186.

Cote J, Fogarty S, Weinersmith K, Brodin T, Sih A. 2010. Personality traits and dispersal tendency in the invasive mosquitofish (Gambusia affinis). Proceedings of the Royal Society B: Biological Sciences 277:1571-1579. 
Cullen L, Bodmer RE, Valladares Pádua C. 2000. Effects of hunting in habitat fragments of the Atlantic forests, Brazil. Biological Conservation 95:49-56.

Curi NHDA, Araújo AS, Campos FS, Lobato ZIP, Gennari SM, Marvulo MFV, Silva JCR, Talamoni SA. 2010. Wild canids, domestic dogs and their pathogens in Southeast Brazil: disease threats for canid conservation. Biodiversity and Conservation 19:3513-3524.

Curi NHDA, Paschoal AMDO, Massara RL, Marcelino AP, Ribeiro AA, Passamani M, Demétrio GR, Chiarello AG. 2014. Factors Associated with the Seroprevalence of Leishmaniasis in Dogs Living around Atlantic Forest Fragments. PLoS ONE 9:e104003.

Dantas-Torres F, de Paiva-Cavalcanti M, Figueredo LA, Melo MF, da Silva FJ, da Silva AL, Almeida EL, Brandão-Filho SP. 2010. Cutaneous and visceral leishmaniosis in dogs from a rural community in northeastern Brazil. Veterinary Parasitology 170:313-317.

Deplazes P, van Knapen F, Schweiger A, Overgaauw PAM. 2011. Role of pet dogs and cats in the transmission of helminthic zoonoses in Europe, with a focus on echinococcosis and toxocarosis. Veterinary Parasitology 182:41-53.

Doherty TS, Dickman CR, Glen AS, Newsome TM, Nimmo DG, Ritchie EG, Vanak AT, Wirsing AJ. 2017. The global impacts of domestic dogs on threatened vertebrates. Biological Conservation 210:56-59.

Dürr S, Ward MP. 2014. Roaming behaviour and home range estimation of domestic dogs in Aboriginal and Torres Strait Islander communities in northern Australia using four different methods. Preventive Veterinary Medicine 117:340-357.

Fortes FS, Dutra LH, Biondo AW, Molento MB. 2011. Febre maculosa brasileira em cães. Semina: Ciências Agrárias 32:339.

Frigeri E. 2013. Invasão por cães domésticos (Canis lupus familiaris) na Mata Atlântica: efeitos da perda de habitat e da intensificação agrícola. USP.

Frigeri E, Cassano CR, Pardini R. 2014. Domestic dog invasion in an agroforestry mosaic in southern Bahia, Brazil. Tropical Conservation Science 7:508-528.

German AJ, Holden SL, Moxham GL, Holmes KL, Hackett RM, Rawlings JM. 2006. A simple, reliable tool for owners to assess the body condition of their dog or cat. The Journal of nutrition 136:2031S-2033S. 
Gompper ME, Vanak AT. 2008. Subsidized predators, landscapes of fear and disarticulated carnivore communities. Animal Conservation 11:13-14.

Gompper ME. 2014. The dog-human-wildlife interface: assessing the scope of the problem. Pages 9-54. Free-Ranging Dogs and Wildlife Conservation.

Gompper ME, Gittleman JL. 1991. Home range scaling: intraspecific and comparative trends. Oecologia 87:343-348.

Heger T, Saul W-C, Trepl L. 2013. What biological invasions "are" is a matter of perspective. Journal for Nature Conservation 21:93-96.

Horta MC, Labruna MB, Sangioni LA, Vianna MCB, Gennari SM, Galvão MAM, Mafra CL, Vidotto O, Schumaker TTS, Walker DH. 2004. Prevalence of antibodies to spotted fever group rickettsiae in humans and domestic animals in a Brazilian spotted fever-endemic area in the state of São Paulo, Brazil: Serologic evidence for infection by Rickettsia rickettsii and another spotted fever gr. American Journal of Tropical Medicine and Hygiene 71:93-97.

Hübner S de O, Pappen FG, Ruas JL, Vargas GD, Fischer G, Vidor T. 2010. Exposure of pampas fox (Pseudalopex gymnocercus) and crab-eating fox (Cerdocyon thous) from the Southern region of Brazil to Canine distemper virus (CDV), Canine parvovirus (CPV) and Canine coronavirus (CCoV). Brazilian Archives of Biology and Technology 53:593-597.

Hughes J, Macdonald DW. 2013. A review of the interactions between free-roaming domestic dogs and wildlife. Biological Conservation 157:341-351.

Lacerda ACR, Tomas WM, Marinho-Filho J. 2009. Domestic dogs as an edge effect in the Brasília National Park, Brazil: interactions with native mammals. Animal Conservation 12:477-487.

Lessa I, Corrêa Seabra Guimarães T, de Godoy Bergallo H, Cunha A, M. Vieira E. 2016. Domestic dogs in protected areas: a threat to Brazilian mammals? Natureza \& Conservação 14:46-56. Associação Brasileira de Ciência Ecológica e Conservação.

Meek PD. 1999. The movement, roaming behaviour and home range of free-roaming domestic dogs, Canis lupus familiaris, in coastal New South Wales. Wildlife Research 26:847.

Miller KK, Ritchie EG, Weston MA. 2014. The human dimensions of dog-wildlife interactions. Pages 286-304. Free-Ranging Dogs and Wildlife Conservation. 
Molloy S, Burleigh A, Dürr S, Ward M. 2017. Roaming behaviour of dogs in four remote Aboriginal communities in the Northern Territory, Australia: preliminary investigations. Australian Veterinary Journal 95:55-63.

Paschoal AMO, Massara RL, Santos JL, Chiarello AG. 2012. Is the domestic dog becoming an abundant species in the Atlantic forest? A study case in southeastern Brazil. Mammalia 76:67-76.

Paschoal AMO, Massara RL, Bailey LL, Kendall WL, Doherty PF, Hirsch A, Chiarello AG, Paglia AP. 2016. Use of Atlantic Forest protected areas by free-ranging dogs: estimating abundance and persistence of use. Ecosphere 7:e01480.

Pasher J, Mitchell SW, King DJ, Fahrig L, Smith AC, Lindsay KE. 2013. Optimizing landscape selection for estimating relative effects of landscape variables on ecological responses. Landscape Ecology 28:371-383.

Preisser EL, Bolnick DI, Benard MF. 2005. Scared to death? The effects of intimidation and consumption in predator-prey interactions. Ecology 86:501-509.

Raizada P, Raghubanshi AS, Singh JS. 2008. Impact of invasive alien plant species on soil processes: a review. Proceedings of the National Academy of Sciences India Section B - Biological Sciences 78.

Rehage JS, Sih A. 2004. Dispersal behavior, boldness, and the link to invasiveness: A comparison of four gambusia species. Biological Invasions 6:379-391.

Ribeiro FS. 2016. Pressão de propágulos ou distúrbios? Decifrando os determinantes da invasão por cachorros na Mata Atlântica. USP.

Robley A, Gormley A, Forsyth DM, Wilton AN, Stephens D. 2010. Movements and habitat selection by wild dogs in eastern Victoria. Australian Mammalogy 32:23.

Rubin DB. 1987. Multiple Imputation for Nonresponse in Surveys. Page (Rubin DB, editor). John Wiley \& Sons, Inc., Hoboken, NJ, USA.

Rubin HD, Beck AM. 1982. Ecological behavior of free-ranging urban pet dogs. Applied Animal Ethology 8:161-168. 
Ruiz-Izaguirre E, van Woersem A, Eilers K, van Wieren SE, Bosch G, van der Zijpp a. J, de Boer IJM. 2015. Roaming characteristics and feeding practices of village dogs scavenging sea-turtle nests. Animal Conservation 18:146-156.

Sandell M. 1989. The Mating Tactics and Spacing Patterns of Solitary Carnivores. Pages 164182Carnivore Behavior, Ecology, and Evolution. Springer US, Boston, MA.

Sangioni LA, Horta MC, Vianna MCB, Gennari SM, Soares RM, Galvão MAM, Schumaker TTS, Ferreira F, Vidotto O, Labruna MB. 2005. Rickettsial Infection in Animals and Brazilian Spotted Fever Endemicity. Emerging Infectious Diseases 11:265-270.

Sepúlveda M, Pelican K, Cross P, Eguren A, Singer R. 2015. Fine-scale movements of rural freeranging dogs in conservation areas in the temperate rainforest of the coastal range of southern Chile. Mammalian Biology 80:290-297.

Shaw SE, Day MJ, Birtles RJ, Breitschwerdt EB. 2001. Tick-borne infectious diseases of dogs. Trends in Parasitology 17:74-80.

Sih A, Bell A, Johnson JC. 2004. Behavioral syndromes: an ecological and evolutionary overview. Trends in Ecology \& Evolution 19:372-378.

Silva-Rodríguez EA, Ortega-Solís GR, Jiménez JE. 2010. Conservation and ecological implications of the use of space by chilla foxes and free-ranging dogs in a human-dominated landscape in southern Chile. Austral Ecology 35:765-777.

Silva-Rodríguez EA, Sieving KE. 2012. Domestic dogs shape the landscape-scale distribution of a threatened forest ungulate. Biological Conservation 150:103-110.

Silva-Rodríguez EA, Sieving KE. 2011. Influence of care of domestic carnivores on their predation on vertebrates. Conservation biology : the journal of the Society for Conservation Biology 25:808-15.

Sparkes J, Körtner G, Ballard G, Fleming PJS, Brown WY. 2014. Effects of Sex and Reproductive State on Interactions between Free-Roaming Domestic Dogs. PLoS ONE 9:e116053.

Srbek-Araujo A, Chiarello A. 2008. Domestic dogs in Atlantic forest preserves of south-eastern Brazil: a camera-trapping study on patterns of entrance and site occupancy rates. Brazilian Journal of Biology 68:771-779. 
Torres P, Prado P. 2010. Domestic dogs in a fragmented landscape in the Brazilian Atlantic Forest: abundance, habitat use and caring by owners. Brazilian Journal of Biology 70:987-994.

Traub RJ, Robertson ID, Irwin P, Mencke N, Monis P, Thompson RCA. 2003. Humans, dogs and parasitic zoonoses - unravelling the relationships in a remote endemic community in northeast India using molecular tools. Parasitology Research 90:S156-S157.

Van Bommel L, Johnson CN. 2014. Where Do Livestock Guardian Dogs Go? Movement Patterns of Free-Ranging Maremma Sheepdogs. PLoS ONE 9:e111444.

Van Buuren S, Groothuis-Oudshoorn K. 2011. Multivariate Imputation by Chained Equations. Journal Of Statistical Software 45:1-67.

Vanak AT, Gompper ME. 2009. Dogs canis familiaris as carnivores: Their role and function in intraguild competition. Mammal Review 39:265-283.

Vanak AT, Gompper ME. 2010. Interference competition at the landscape level: the effect of freeranging dogs on a native mesocarnivore. Journal of Applied Ecology 47:1225-1232.

Vanak AT, Thaker M, Gompper ME. 2009. Experimental examination of behavioural interactions between free-ranging wild and domestic canids. Behavioral Ecology and Sociobiology 64:279-287.

Vaniscotte $A$ et al. 2011. Role of dog behaviour and environmental fecal contamination in transmission of Echinococcus multilocularis in Tibetan communities. Parasitology 138:131629.

Verbeek MEM, Drent PJ, Wiepkema PR. 1994. Consistent individual differences in early exploratory behaviour of male great tits. Animal Behaviour 48:1113-1121.

Verbeek MEM, Boon A, Drent PJ. 1996. Exploration, aggressive behaviour and dominance in pairwise confrontations of juvenile male great tits. Behaviour 133:945-963.

Wedl M, Schöberl I, Bauer B, Day J, Kotrschal K. 2010. Relational factors affecting dog social attraction to human partners. Interaction Studies 11:482-503.

Weston MA, Stankowich T. 2014. Dogs as agents of disturbance. Pages 94-116. Free-Ranging Dogs and Wildlife Conservation. Oxford University Press. 
Williams KJH, Weston MA, Henry S, Maguire GS. 2009. Birds and Beaches, Dogs and Leashes: Dog Owners' Sense of Obligation to Leash Dogs on Beaches in Victoria, Australia. Human Dimensions of Wildlife 14:89-101.

Zapata-Ríos G, Branch LC. 2016. Altered activity patterns and reduced abundance of native mammals in sites with feral dogs in the high Andes. Biological Conservation 193:9-16. 


\section{ANEXOS}

Anexo 1. Uso do solo e distribuição dos domicílios com cachorros nas oito paisagens de estudo.

Anexo 2. Questionário aplicado através de entrevistas aos responsáveis pela criação de cachorros.

Anexo 3. Resultados da primeira etapa da seleção de modelos para determinar a chance de cachorros visitarem remanescentes florestais.

Anexo 4. Multicolineariedade (Variance Inflation Factor - VIF) entre variáveis independentes utilizadas para explicar a chance de cachorros visitarem remanescentes florestais.

Anexo 5. Histograma dos atributos individuais, formas de manejo, contexto ambiental, entre outras informações, na população de cachorros das paisagens de estudo.

Anexo 6. Resultados da segunda etapa da seleção de modelos para determinar a chance de cachorros visitarem remanescentes florestais, individualizados por conjunto de dados imputado. 
Anexo 1. Uso do solo e distribuição dos domicílios com cachorros nas oito paisagens de estudo.
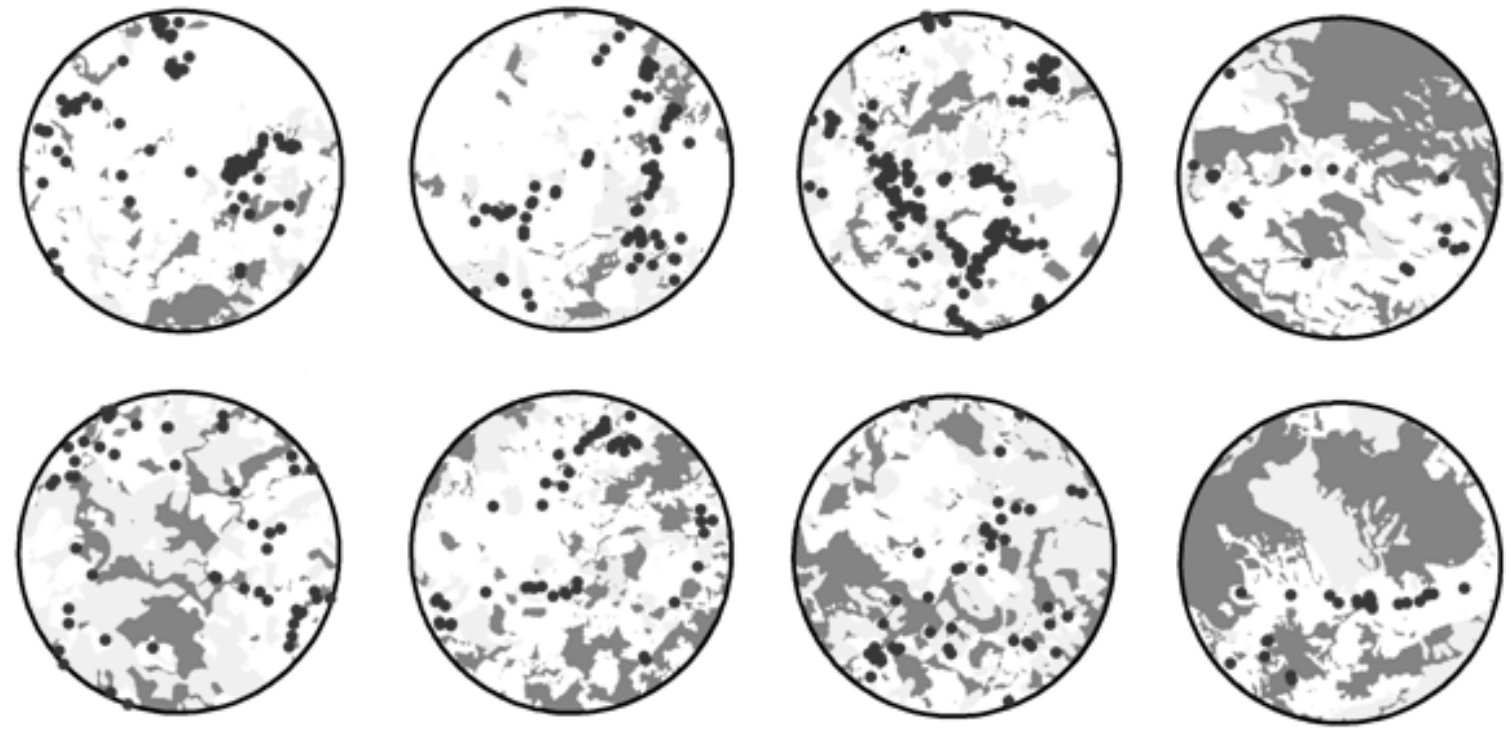

Figura S1. Uso do solo e distribuição dos domicílios onde são criados cachorros em cada uma das oito paisagens de estudo. Cinza escuro: remanescentes de florestas nativas; cinza claro: plantações de eucalipto; branco: áreas alteradas abertas; pontos pretos: domicílios. 


\section{Anexo 2. Questionário aplicado através de entrevistas aos responsáveis pela criação de cachorros.}

MÓDULO 1 - TIPO DE CASA, E NÚMERO E IDADE DOS MORADORES SE HOUVER

Nota: Deverão ser registradas todas as casas (construções da região que sirvam para habitação humana), mesmo que não haja moradores permanentes ali - por exemplo, casa de veraneio - e/ou não sejam criados cachorros.

Nota: O entrevistado deve ser um dos moradores ou funcionário responsável por cada casa, que cuide diretamente dos cães ou saiba informar sobre eles.

\subsection{Nome do entrevistado (nome completo):}

Nota: Ler ao entrevistado antes de começar as perguntas:

Vou começar a entrevista perguntando informações sobre as pessoas que moram nesta casa.

1.2. O(a) senhor(a) mora nesta casa? [ ] SIM [ ] NÃO

Se sim:

Nota: Anotar as respostas à pergunta 1.3. na tabela abaixo da pergunta 1.3.

1.3. Por favor, o(a) senhor(a) pode identificar todas as pessoas que moram há pelo menos um mês nesta casa, me dizendo o sexo e a idade de cada uma delas? (incluir o entrevistado na lista, $0=$ mulher, 1=homem, idade em anos)

Se não:
1.4. O senhor mora em outra casa, mas cuida desta?
[ ] SIM
[ ] NÃO

\section{MÓDULO 2 - NÚMERO, IDADE, SEXO e MOTIVOS DE CRIAÇÃO DOS CÃES}

Nota: Ler ao entrevistado antes de começar as perguntas:

Agora vou fazer algumas perguntas gerais sobre os cachorros que vocês criam aqui.

Nota: Anotar as respostas às próximas 6 perguntas na tabela abaixo da pergunta 2.6.

2.1. Por favor, o(a) senhor(a) pode identificar todos os cães que vocês criam ou cuidam nesta casa, me dizendo o nome de cada um deles?

2.2. Por favor, o(a) senhor(a) pode me dizer qual é a idade de cada um dos cães? (em meses, se menor que 1 ano, ou em anos, se maior que 1 ano)

2.3. Por favor, o(a) senhor(a) pode me dizer há quanto tempo vocês criam ou cuidam de cada um dos cães? (em meses, se menos que 1 ano, ou em anos, se mais que 1 ano)

2.4. Por favor, o(a) senhor(a) pode me dizer qual é o sexo de cada um dos cães? (0=fêmea, $1=m a c h o)$

2.5. Por favor, o(a) senhor(a) pode me dizer se cada um dos cães é castrado? ( $0=n \tilde{o} o, 1=\operatorname{sim}$, 9=não sei)

Se houver cão fêmea: 
2.6. Por favor, o(a) senhor pode me dizer se cada um dos cães fêmeas tomou injeção para não pegar cria? (0=não, 1=sim, 9=não sei)

Nota: Anotar a respostas à próxima pergunta na tabela abaixo da pergunta.

2.7. Por favor, o(a) senhor(a) pode me dizer quais são os motivos para vocês criarem cada um dos cães? (segurança da casa e dos moradores, companhia, caçar, proteger a criação, cuidar do gado, outro, não sei)

\section{MÓDULO 3 - CUIDADOS VETERINÁRIOS COM OS CÃES}

Nota: Ler ao entrevistado antes de começar as perguntas:

Agora vou perguntar informações sobre vacinação e outros cuidados com os cachorros.

Nota: Anotar as respostas às próximas 12 perguntas na tabela abaixo da pergunta 3.12 .

3.1. Por favor, o(a) senhor(a) pode me dizer se cada um dos cães foi vacinado contra raiva no último ano, entre hoje e um ano atrás? ( $0=n a \tilde{o}, 1=\operatorname{sim}, 9=n \tilde{a} o$ sei)

Se sim:

3.2. $O$ cão foi vacinado na campanha da prefeitura ou em um veterinário particular? (1=campanha da prefeitura, 2=veterinário particular, 3=outro, 9=não sei)

3.3. Por favor, o(a) senhor(a) pode me dizer se cada um dos cães tomou a vacina polivalente, aquela contra cinomose, parvovirose e outras doenças, no último ano, entre hoje e um ano atrás? ( $0=n a \tilde{o}, 1=\operatorname{sim}, 9=n \tilde{o} o$ sei)

Se sim:

3.4. $O$ cão foi vacinado em um veterinário particular ou por vocês mesmos com a vacina comprada na agropecuária? (1=veterinário particular, 2=agropecuária, 3=outro, 9=não sei)

3.5. Por favor, o(a) senhor(a) pode me dizer se cada um dos cães foi levado ou recebeu a visita de um veterinário no último ano, entre hoje e um ano atrás? ( $0=n a ̃ o, ~ 1=\operatorname{sim,~9=não~sei)~}$

Se sim:

3.6. Por qual motivo? (1=doença, $2=$ =vacina, $3=$ rotina, 4=banho, 5=machucado, $6=$ outro, 9=não sei)

3.7. Por favor, o(a) senhor(a) pode me dizer se cada um dos cães tomou algum comprimido contra vermes nos últimos 6 meses, ou seja, entre e hoje? ( $0=$ não, $1=\operatorname{sim}, 9=$ não sei)

3.8. Por favor, o(a) senhor(a) pode me dizer se cada um dos cães recebeu remédio contra carrapatos nos

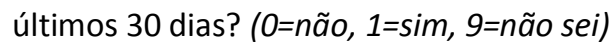

Se sim:

3.9. Qual remédio contra carrapatos cada um dos cães recebeu? (1=comprimido, $2=$ de passar no pelo, $3=$ coleira, $4=$ outro, 9=não sei)

3.10. Por favor, o(a) senhor(a) pode me dizer se cada um dos cães pegou carrapato nos últimos 30 dias? (0=não, 1=sim, 9=não sei)

3.11. Por favor, o(a) senhor(a) pode me dizer se vocês dão banho em cada um dos cães? ( $0=n a ̃ o, ~ 1=s i m$, 9=não sei) 
Se sim:

3.12. Quantas vezes por mês cada um dos cães toma banho?

\section{MÓDULO 4 - ALIMENTAÇÃO DOS CÃES}

Nota: Ler ao entrevistado antes de começar as perguntas:

Agora vou fazer algumas perguntas sobre a alimentação dos cachorros.

Nota: Anotar as respostas às próximas 4 perguntas na tabela abaixo da pergunta 4.4 .

4.1. Por favor, o(a) senhor(a) pode me dizer quantas vezes cada um dos cães é alimentado? (1=mais que uma vez por dia, 2=uma vez por dia, 3=entre 4 e 6 vezes por semana, 4=entre 1 e 3 vezes por semana, $5=$ nunca)

Se o cão é alimentado:

4.2. Que tipo de alimento vocês dão a cada um dos cães? (1=apenas ração, 2=apenas comida, 3=ração e comida)

4.3. Por favor, o(a) senhor(a) pode me dizer se o cão consegue alimento em outros lugares? $(0=n a ̃ o, 1=\operatorname{sim}$, $9=n \tilde{a} o$ sei)

Se sim:

4.4. Onde? (na mata, na lixeira, em outras casas, não sei)

\section{MÓDULO 5 - RESTRIÇÃO DE MOVIMENTO DOS CÃES}

Nota: Ler ao entrevistado antes de começar as perguntas:

Agora vou perguntar sobre a movimentação dos cachorros.

Nota: Anotar as respostas às próximas 5 perguntas na tabela abaixo da pergunta $\mathbf{5 . 5}$.

5.1. Por favor, o(a) senhor(a) pode me dizer se em algum momento cada um dos cães fica fechado dentro da casa, não consegue sair de perto da casa por causa de muros ou cercas, ou porque fica acorrentado? $(0=n a \tilde{o}$, 1=sim, 9=não sei)

Se sim:

5.2. Quantos dias nos últimos 7 dias cada um dos cães ficou preso em algum momento?

5.3. Em qual período do dia cada um dos cães costuma ficar preso? (1=só de dia, 2=só de noite, 3=durante o dia e a noite)

5.4. Quando cada um dos cães fica solto, ele sai sozinho de perto dos arredores da casa? $(0=n a ̃ o, 1=\operatorname{sim}$, $9=n \tilde{a} o$ sei)

Se sim:

5.5. Quantos dias nos últimos 7 dias cada um dos cães saiu sozinho? 


\section{MÓDULO 6 - VISITAS A MATA E FORMAÇÃO DE GRUPOS DE CÃES}

Nota: Anotar as respostas às próximas 7 perguntas na tabela abaixo da pergunta 6.7.

6.1. Por favor, o(a) senhor(a) pode me dizer se cada um dos cães vai por conta dele no mato, isto é, se quando está solto sai de perto da casa e entra no mato (na floresta nativa, sem ser pasto, plantação ou eucalipto)? (0=não, $1=\operatorname{sim}, 9=n \tilde{a} o$ sei)

Se sim:

6.2. Quantos dias nos últimos 7 dias cada um dos cães foi no mato por conta dele?

6.3. Alguma vez nos últimos 7 dias cada um dos cães foi para o mato com outros cães? $(0=n a ̃ o, 1=\operatorname{sim}, 9=n a ̃ o$ sei)

6.4. Por favor, o(a) senhor(a) pode me dizer se cada um dos cães acompanha vocês quando vocês saem dos arredores da casa? ( $0=n \tilde{a} o, 1=\operatorname{sim}, 9=n \tilde{o} o$ sei)

Se sim:

6.5. Quantos dias nos últimos 7 dias cada um dos cães acompanhou vocês?

6.6. Por favor, o(a) senhor(a) pode me dizer se quando vocês vão no mato (floresta nativa, sem ser pasto,

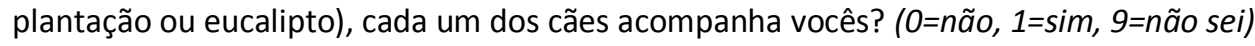

Se sim:

6.7. Quantos dias nos últimos 7 dias cada um dos cães foi no mato acompanhando vocês?

\section{MÓDULO 7 - INTERAÇÕES COM A FAUNA SILVESTRE}

Nota: Ler ao entrevistado antes de começar as perguntas:

Vou terminar com algumas perguntas sobre encontro dos cachorros com animais do mato.

7.1. Por favor, o(a) senhor(a) pode me dizer se cada um dos cães alguma vez foi machucado por algum bicho do mato? (0=não, $1=\operatorname{sim}, 9=n \tilde{o} o$ sei)

Se sim:

7.2. Quais bichos do mato machucaram cada um dos cães?

7.3. Quantas vezes cada um dos cães foi machucado por algum bicho do mato nos últimos 3 meses, ou seja, desde até hoje?

7.4. Por favor, o(a) senhor(a) sabe dizer se algum cão desta casa alguma vez correu algum bicho do mato?
[ ] SIM (ir para 7.5)
[ ] NÃO (ir para 7.13)
[ ] NÃO SEI (ir para 7.13)

7.5. O senhor sabe identificar exatamente quais cães desta casa correram bichos do mato?
[ ] SIM (ir para 7.6)
[ ] NÃO (ir para 7.9)
[ ] EM ALGUNS CASOS (ir para 7.6 e 7.9)

Nota: Anotar as respostas às 3 perguntas seguintes na tabela abaixo da pergunta 7.8 .

7.6. Por favor, o(a) senhor(a) pode me dizer se cada um dos cães alguma vez correu algum bicho do mato? (0=não, 1=sim, 9=não sei) 
7.7. Quais bichos do mato cada um dos cães já correu?

7.8. Quantas vezes cada um dos cães correu algum bicho do mato nos últimos 30 dias?

Se não:

Nota: Ler ao entrevistado antes de começar as perguntas, no caso da opção EM ALGUNS CASOS da pergunta 7.5:

Agora vou pedir informações sobre os casos em que o senhor não sabe qual cachorro foi que correu os bichos do mato.

Nota: Anotar as respostas às próximas 3 perguntas na tabela abaixo da pergunta 7.11.

7.9. Por favor, o(a) senhor(a) sabe dizer quais bichos do mato os cães desta casa já correram?

7.10. O senhor sabe identificar quais cães podem ter corrido esses bichos?

7.11. O(a) senhor(a) não sabe exatamente qual cão correu esses bichos pois foram todos eles juntos ou porque o(a) senhor(a) não viu? (0=não viu, 1=todos juntos)

7.12. Quantas vezes algum cão desta casa correu algum bicho do mato nos últimos 30 dias? Número de vezes

7.13. Por favor, o(a) senhor(a) sabe dizer se algum cão desta casa alguma vez matou algum bicho do mato? [ ] SIM (ir para 7.14) [ ] NÃO (finalizar) [ ] NÃO SEI (finalizar)

7.14. O senhor sabe identificar exatamente quais cães desta casa mataram bichos do mato?

[ ] SIM (ir para 7.15) [ ] NÃO (ir para 7.18) [ ] EM ALGUNS CASOS (ir para 7.15 e 7.18 )

Nota: Anotar as respostas às 3 perguntas seguintes na tabela abaixo da pergunta 7.17.

7.15. Por favor, o(a) senhor(a) pode me dizer se cada um dos cães alguma vez matou algum bicho do mato? (0=não, 1=sim, 9=não sei)

7.16. Quais bichos do mato cada um dos cães já matou?

7.17. Quantas vezes cada um dos cães matou algum bicho do mato nos últimos 3 meses, ou seja, desde até hoje?

Se não:

Nota: Ler ao entrevistado antes de começar as perguntas, no caso da opção EM ALGUNS CASOS da pergunta 7.14:

Agora vou pedir informações sobre os casos em que o senhor não sabe qual cachorro foi que matou os bichos do mato.

Nota: Anotar as respostas às próximas 3 perguntas na tabela abaixo da pergunta 7.20.

7.18. Por favor, o(a) senhor(a) sabe dizer quais bichos do mato os cães desta casa já mataram?

7.19. $O$ senhor sabe identificar quais cães podem ter matado esses bichos? 
7.20. $O(a)$ senhor (a) não sabe exatamente qual cão matou esses bichos pois foram todos eles juntos ou porque o(a) senhor(a) não viu? ( $0=$ não viu, 1=todos juntos)

7.21. Quantas vezes algum cão desta casa matou um bicho do mato nos últimos 3 meses, ou seja, desde até hoje?

Número de vezes [

]


Anexo 3. Resultados da primeira etapa da seleção de modelos para determinar a chance de cachorros visitarem remanescentes florestais.

Tabela S1. Resultados da seleção de modelos para determinar a chance de cachorros visitarem remanescentes florestais em função de variáveis operacionais utilizadas para quantificar a variável independente 'confinamento'. Como não houve dados faltantes nessas variáveis, há nesse caso apenas um conjunto de dados e uma seleção de modelos. Modelo melhor ranqueado, excluindo o modelo de referência, destacado em negrito. K: número de parâmetros. AIC: valor do AIC. $\triangle$ AIC: diferença no valor do AIC em relação ao modelo melhor ranqueado. wi: peso de evidência do modelo.

\begin{tabular}{lccccc}
\hline Modelo & K & AIC & $\Delta$ AIC & $\mathbf{\Omega i}$ & Coeficiente \\
\hline períodos preso & $\mathbf{4}$ & $\mathbf{5 7 6 , 8}$ & $\mathbf{0}$ & $\mathbf{0 , 6 7 9}$ & $\mathbf{- 1 . 3 6 7 ( 0 . 4 )}$ \\
dias preso & 4 & 578,4 & 1,5 & 0,315 & $-1.081(0.313)$ \\
preso & 4 & 586,4 & 9,6 & 0,006 & $-1.298(0.508)$ \\
referência & 3 & 591,5 & 14,6 & 0,000 & \\
\hline
\end{tabular}

Tabela S2. Resultados da seleção de modelos para determinar a chance de cachorros visitarem remanescentes florestais em função de variáveis operacionais utilizadas para quantificar a variável independente 'proximidade à mata nativa'. Como não houve dados faltantes nessas variáveis, há nesse caso apenas um conjunto de dados e uma seleção de modelos. Modelo melhor ranqueado, excluindo o modelo de referência, destacado em negrito. K: número de parâmetros. AIC: valor do AIC. $\triangle \mathrm{AIC}$ : diferença no valor do AIC em relação ao modelo melhor ranqueado. wi: peso de evidência do modelo.

\begin{tabular}{lccccc}
\hline Modelo & K & AIC & DAIC & wi & Coeficiente \\
\hline referência & 3 & 591,5 & 0 & 0,064 & \\
QMPD.200 & $\mathbf{4}$ & $\mathbf{5 9 2 , 4}$ & $\mathbf{0 , 9}$ & $\mathbf{0 , 0 4 0}$ & $\mathbf{0 . 3 9 8}(\mathbf{0 . 3 6 3 )}$ \\
cob.florestal.100 & 4 & 592,5 & 1,0 & 0,039 & $0.371(0.344)$ \\
QMPD.300 & 4 & 592,5 & 1,0 & 0,039 & $0.406(0.384)$ \\
cob.florestal.200 & 4 & 592,5 & 1,0 & 0,038 & $0.394(0.382)$ \\
cob.florestal.300 & 4 & 592,7 & 1,2 & 0,036 & $0.374(0.392)$ \\
QMPD.100 & 4 & 592,7 & 1,2 & 0,035 & $0.322(0.33)$ \\
QMPD.400 & 4 & 592,7 & 1,2 & 0,034 & $0.358(0.392)$ \\
dist.min & 4 & 592,7 & 1,3 & 0,034 & $-0.432(0.543)$ \\
ext.borda.2000 & 4 & 592,9 & 1,5 & 0,031 & $-0.331(0.457)$ \\
ext.borda.1500 & 4 & 593,0 & 1,5 & 0,030 & $-0.314(0.454)$ \\
QMPD.500 & 4 & 593,0 & 1,5 & 0,030 & $0.281(0.397)$ \\
QBPD.2000 & 4 & 593,1 & 1,6 & 0,028 & $-0.275(0.452)$ \\
cob.florestal.400 & 4 & 593,2 & 1,7 & 0,028 & $0.239(0.398)$ \\
QBPD.100 & 4 & 593,2 & 1,7 & 0,027 & $0.214(0.38)$ \\
QBPD.1500 & 4 & 593,3 & 1,8 & 0,026 & $-0.215(0.448)$ \\
QBPD.200 & 4 & 593,3 & 1,8 & 0,026 & $0.189(0.4)$ \\
\hline
\end{tabular}




\begin{tabular}{llllll}
\hline ext.borda.1000 & 4 & 593,3 & 1,8 & 0,026 & $-0.191(0.445)$ \\
ext.borda.100 & 4 & 593,3 & 1,8 & 0,026 & $0.179(0.406)$ \\
QBPD.300 & 4 & 593,3 & 1,8 & 0,026 & $0.171(0.402)$ \\
QBPD.400 & 4 & 593,3 & 1,8 & 0,025 & $0.169(0.405)$ \\
ext.borda.300 & 4 & 593,3 & 1,8 & 0,025 & $0.162(0.405)$ \\
ext.borda.200 & 4 & 593,4 & 1,9 & 0,025 & $0.145(0.404)$ \\
cob.florestal.500 & 4 & 593,4 & 1,9 & 0,025 & $0.138(0.414)$ \\
QBPD.500 & 4 & 593,4 & 1,9 & 0,024 & $0.122(0.412)$ \\
cob.florestal.2000 & 4 & 593,4 & 1,9 & 0,024 & $-0.113(0.454)$ \\
cob.florestal.1500 & 4 & 593,4 & 1,9 & 0,024 & $-0.112(0.458)$ \\
ext.borda.400 & 4 & 593,4 & 1,9 & 0,024 & $0.098(0.416)$ \\
QBPD.1000 & 4 & 593,4 & 2,0 & 0,024 & $-0.09(0.443)$ \\
QMPD.2000 & 4 & 593,5 & 2,0 & 0,024 & $-0.084(0.452)$ \\
cob.florestal.1000 & 4 & 593,5 & 2,0 & 0,024 & $-0.064(0.453)$ \\
QMPD.1500 & 4 & 593,5 & 2,0 & 0,024 & $-0.054(0.45)$ \\
QMPD.1000 & 4 & 593,5 & 2,0 & 0,024 & $0.044(0.431)$ \\
ext.borda.500 & 4 & 593,5 & 2,0 & 0,023 & $0.01(0.432)$ \\
\hline
\end{tabular}

Tabela S3. Resultados da seleção de modelos para determinar a chance de cachorros visitarem remanescentes florestais em função de variáveis operacionais utilizadas para quantificar a variável independente 'condição de saúde', para cada um dos 10 conjuntos de dados imputados. Modelo melhor ranqueado, excluindo o modelo de referência, destacado em negrito. K: número de parâmetros. AIC: valor do AIC. $\triangle \mathrm{AIC}$ : diferença no valor do AIC em relação ao modelo melhor ranqueado. wi: peso de evidência do modelo.

\begin{tabular}{|c|c|c|c|c|c|c|}
\hline & Modelo & $\mathbf{K}$ & AIC & $\Delta \mathrm{AIC}$ & $\omega i$ & Coeficiente \\
\hline \multirow{4}{*}{1} & referência & 3 & 591,5 & 0 & 0,391 & \\
\hline & doença & 4 & 592,2 & 0,7 & 0,276 & $-1.172(1.083)$ \\
\hline & ferimento & 4 & 593,2 & 1,7 & 0,167 & $0.586(1.054)$ \\
\hline & vet & 4 & 593,2 & 1,7 & 0,167 & $-0.453(0.85)$ \\
\hline & Modelo & K & AIC & $\Delta \mathrm{AIC}$ & $\omega \mathbf{i}$ & Coeficiente \\
\hline \multirow{5}{*}{2} & referência & 3 & 591,5 & 0 & 0,391 & \\
\hline & doença & 4 & 592,2 & 0,7 & 0,275 & $-1.168(1.085)$ \\
\hline & ferimento & 4 & 593,2 & 1,7 & 0,170 & $0.619(1.045)$ \\
\hline & vet & 4 & 593,2 & 1,7 & 0,164 & $-0.417(0.843)$ \\
\hline & Modelo & K & AIC & $\Delta \mathrm{AIC}$ & $\omega i$ & Coeficiente \\
\hline \multirow{4}{*}{3} & referência & 3 & 591,5 & 0 & 0,396 & \\
\hline & doença & 4 & 592,3 & 0,8 & 0,265 & $-1.109(1.066)$ \\
\hline & ferimento & 4 & 593,1 & 1,7 & 0,173 & $0.627(1.047)$ \\
\hline & vet & 4 & 593,2 & 1,7 & 0,165 & $-0.415(0.844)$ \\
\hline
\end{tabular}




\begin{tabular}{|c|c|c|c|c|c|c|}
\hline & Modelo & $K$ & AIC & $\Delta \mathrm{AIC}$ & $\omega i$ & Coeficiente \\
\hline \multirow{4}{*}{4} & referência & 3 & 591,5 & 0 & 0,391 & \\
\hline & doença & 4 & 592,2 & 0,7 & 0,275 & $-1.17(1.084)$ \\
\hline & ferimento & 4 & 593,1 & 1,6 & 0,172 & $0.634(1.035)$ \\
\hline & vet & 4 & 593,3 & 1,8 & 0,162 & $-0.401(0.84)$ \\
\hline & Modelo & $\mathbf{K}$ & AIC & $\triangle \mathrm{AIC}$ & $\omega \mathbf{i}$ & Coeficiente \\
\hline \multirow{4}{*}{5} & referência & 3 & 591,5 & 0 & 0,391 & \\
\hline & doença & 4 & 592,2 & 0,7 & 0,275 & $-1.17(1.084)$ \\
\hline & ferimento & 4 & 593,2 & 1,7 & 0,170 & $0.611(1.043)$ \\
\hline & vet & 4 & 593,2 & 1,7 & 0,164 & $-0.423(0.842)$ \\
\hline & Modelo & K & AIC & $\triangle \mathrm{AIC}$ & $\omega \mathbf{i}$ & Coeficiente \\
\hline \multirow{4}{*}{6} & referência & 3 & 591,5 & 0 & 0,391 & \\
\hline & doença & 4 & 592,2 & 0,7 & 0,274 & $-1.168(1.085)$ \\
\hline & ferimento & 4 & 593,1 & 1,6 & 0,172 & $0.633(1.034)$ \\
\hline & vet & 4 & 593,3 & 1,8 & 0,162 & $-0.401(0.84)$ \\
\hline & Modelo & K & AIC & $\Delta \mathrm{AIC}$ & $\omega \mathbf{i}$ & Coeficiente \\
\hline \multirow{4}{*}{7} & referência & 3 & 591,5 & 0 & 0,392 & \\
\hline & doença & 4 & 592,2 & 0,7 & 0,275 & $-1.168(1.085)$ \\
\hline & ferimento & 4 & 593,2 & 1,7 & 0,169 & $0.592(1.038)$ \\
\hline & vet & 4 & 593,2 & 1,7 & 0,165 & $-0.425(0.841)$ \\
\hline & Modelo & $\mathbf{K}$ & AIC & $\Delta \mathrm{AIC}$ & $\omega \mathbf{i}$ & Coeficiente \\
\hline \multirow{4}{*}{8} & referência & 3 & 591,5 & 0 & 0,391 & \\
\hline & doença & 4 & 592,2 & 0,7 & 0,274 & $-1.168(1.085)$ \\
\hline & ferimento & 4 & 593,1 & 1,6 & 0,172 & $0.634(1.035)$ \\
\hline & vet & 4 & 593,3 & 1,8 & 0,162 & $-0.401(0.84)$ \\
\hline & Modelo & K & AIC & $\triangle \mathrm{AIC}$ & $\omega \mathbf{i}$ & Coeficiente \\
\hline \multirow{5}{*}{9} & referência & 3 & 591,5 & 0 & 0,396 & \\
\hline & doença & 4 & 592,3 & 0,8 & 0,268 & $-1.115(1.064)$ \\
\hline & ferimento & 4 & 593,2 & 1,7 & 0,171 & $0.6(1.039)$ \\
\hline & vet & 4 & 593,2 & 1,8 & 0,164 & $-0.403(0.839)$ \\
\hline & Modelo & $\mathbf{K}$ & AIC & $\triangle \mathrm{AIC}$ & $\omega \mathbf{i}$ & Coeficiente \\
\hline \multirow{4}{*}{10} & referência & 3 & 591,5 & 0 & 0,396 & \\
\hline & doença & 4 & 592,3 & 0,8 & 0,266 & $-1.111(1.065)$ \\
\hline & ferimento & 4 & 593,1 & 1,6 & 0,174 & $0.634(1.035)$ \\
\hline & vet & 4 & 593,3 & 1,8 & 0,164 & $-0.401(0.84)$ \\
\hline
\end{tabular}


Tabela S4. Resultados da seleção de modelos para determinar a chance de cachorros visitarem remanescentes florestais em função de variáveis operacionais utilizadas para quantificar a variável independente 'raça', para cada um dos 10 conjuntos de dados imputados. Modelo melhor ranqueado, excluindo o modelo de referência, destacado em negrito. K: número de parâmetros. AIC: valor do AIC. $\triangle \mathrm{AIC}$ : diferença no valor do AIC em relação ao modelo melhor ranqueado. wi: peso de evidência do modelo.

\begin{tabular}{|c|c|c|c|c|c|c|}
\hline & Modelo & $\mathbf{K}$ & AIC & $\triangle \mathrm{AIC}$ & $\omega \mathbf{i}$ & Coeficiente \\
\hline \multirow{4}{*}{1} & morfotipo & 18 & 591,0 & 0 & 0,367 & $-21.652(862719.68)$ \\
\hline & referência & 3 & 591,5 & 0,5 & 0,283 & \\
\hline & raça & 4 & 592,3 & 1,3 & 0,187 & $-0.54(0.507)$ \\
\hline & classe & 9 & 592,6 & 1,6 & 0,163 & $3.032(1.386)$ \\
\hline & Modelo & $\mathbf{K}$ & AIC & $\triangle \mathrm{AIC}$ & $\omega \mathbf{i}$ & Coeficiente \\
\hline \multirow{4}{*}{2} & classe & 9 & 587,3 & 0 & 0,702 & $1.969(1.731)$ \\
\hline & raça & 4 & 590,4 & 3,1 & 0,147 & $-0.888(0.525)$ \\
\hline & referência & 3 & 591,5 & 4,2 & 0,087 & \\
\hline & morfotipo & 18 & 592,1 & 4,8 & 0,064 & -17.845 (281219.757) \\
\hline & Modelo & K & AIC & $\triangle \mathrm{AIC}$ & $\omega \mathbf{i}$ & Coeficiente \\
\hline \multirow{4}{*}{3} & referência & 3 & 591,5 & 0 & 0,547 & \\
\hline & raça & 4 & 592,3 & 0,8 & 0,359 & $-0.512(0.482)$ \\
\hline & classe & 9 & 595,2 & 3,7 & 0,087 & $0.747(1.51)$ \\
\hline & morfotipo & 18 & 600,0 & 8,5 & 0,008 & -13.035 (10716.584) \\
\hline & Modelo & $\mathbf{K}$ & AIC & $\triangle \mathrm{AIC}$ & $\omega \mathbf{i}$ & Coeficiente \\
\hline \multirow{4}{*}{4} & classe & 9 & 587,4 & 0 & 0,841 & $2.762(1.436)$ \\
\hline & referência & 3 & 591,5 & 4,1 & 0,108 & \\
\hline & raça & 4 & 593,0 & 5,6 & 0,050 & $-0.324(0.476)$ \\
\hline & morfotipo & 18 & 599,6 & 12,3 & 0,002 & $-21.254(63235.156)$ \\
\hline & Modelo & $\mathbf{K}$ & AIC & $\triangle \mathrm{AIC}$ & $\omega i$ & Coeficiente \\
\hline \multirow{5}{*}{5} & referência & 3 & 591,5 & 0 & 0,580 & \\
\hline & raça & 4 & 592,4 & 0,9 & 0,368 & $-0.504(0.49)$ \\
\hline & classe & 9 & 596,3 & 4,8 & 0,052 & $1.969(1.255)$ \\
\hline & morfotipo & 18 & 610,9 & 19,4 & 0,000 & $-20.724(905010.204)$ \\
\hline & Modelo & $\mathbf{K}$ & AIC & $\triangle \mathrm{AIC}$ & $\omega \mathbf{i}$ & Coeficiente \\
\hline \multirow{4}{*}{6} & raça & 4 & 590,5 & 0 & 0,560 & $-0.804(0.48)$ \\
\hline & referência & 3 & 591,5 & 1,0 & 0,348 & \\
\hline & classe & 9 & 594,1 & 3,6 & 0,092 & $0.46(1.469)$ \\
\hline & morfotipo & 18 & 608,3 & 17,8 & 0,000 & $-22.105(1085933.904)$ \\
\hline
\end{tabular}




\begin{tabular}{|c|c|c|c|c|c|c|}
\hline & Modelo & $\mathbf{K}$ & AIC & $\triangle \mathrm{AIC}$ & $\omega \mathbf{i}$ & Coeficiente \\
\hline \multirow{4}{*}{7} & classe & 9 & 584,7 & 0 & 0,920 & $2.832(1.548)$ \\
\hline & raça & 4 & 590,7 & 5,9 & 0,048 & $-0.808(0.493)$ \\
\hline & referência & 3 & 591,5 & 6,8 & 0,031 & \\
\hline & morfotipo & 18 & 598,8 & 14,1 & 0,001 & $-16.095(2347.116)$ \\
\hline & Modelo & $\mathbf{K}$ & AIC & $\triangle \mathrm{AIC}$ & $\omega \mathbf{i}$ & Coeficiente \\
\hline \multirow{4}{*}{8} & referência & 3 & 591,5 & 0 & 0,419 & \\
\hline & classe & 9 & 591,6 & 0,2 & 0,388 & $2.198(1.426)$ \\
\hline & raça & 4 & 593,0 & 1,6 & 0,193 & $-0.323(0.486)$ \\
\hline & morfotipo & 18 & 604,9 & 13,4 & 0,001 & $-16.404(45003.995)$ \\
\hline & Modelo & $\mathbf{K}$ & AIC & $\Delta \mathrm{AIC}$ & $\omega i$ & Coeficiente \\
\hline \multirow{5}{*}{9} & referência & 3 & 591,5 & 0 & 0,638 & \\
\hline & raça & 4 & 593,4 & 1,9 & 0,251 & $-0.17(0.471)$ \\
\hline & classe & 9 & 595,0 & 3,5 & 0,110 & 1.635 (1.245) \\
\hline & morfotipo & 18 & 604,1 & 12,6 & 0,001 & $-15.916(41588.935)$ \\
\hline & Modelo & $\mathbf{K}$ & AIC & $\Delta \mathrm{AIC}$ & $\omega \mathbf{i}$ & Coeficiente \\
\hline \multirow{4}{*}{10} & raça & 4 & 589,5 & 0 & 0,722 & $-1.037(0.54)$ \\
\hline & referência & 3 & 591,5 & 2,0 & 0,265 & \\
\hline & classe & 9 & 597,5 & 8,0 & 0,013 & $0.714(1.525)$ \\
\hline & morfotipo & 18 & 605,3 & 15,8 & 0,000 & $-17.673(5579.819)$ \\
\hline
\end{tabular}


Tabela S5. Resultados da seleção de modelos para determinar a chance de cachorros visitarem remanescentes florestais em função de variáveis operacionais utilizadas para quantificar a variável independente 'incentivo do dono à movimentação', para cada um dos 10 conjuntos de dados imputados. Modelo melhor ranqueado, excluindo o modelo de referência, destacado em negrito. K: número de parâmetros. AIC: valor do AIC. $\triangle \mathrm{AIC}$ : diferença no valor do AIC em relação ao modelo melhor ranqueado. wi: peso de evidência do modelo.

\begin{tabular}{|c|c|c|c|c|c|c|}
\hline & Modelo & K & AIC & $\triangle \mathrm{AIC}$ & $\omega \mathbf{i}$ & Coeficiente \\
\hline \multirow{6}{*}{1} & mata.dono.freq & 4 & 524,8 & 0 & 0,982 & $3.867(0.695)$ \\
\hline & mata.dono.sem & 4 & 532,8 & 8,0 & 0,018 & $6.236(1.14)$ \\
\hline & mata.dono & 4 & 544,3 & 19,5 & 0,000 & $3.771(0.685)$ \\
\hline & sai.dono.sem & 4 & 550,6 & 25,8 & 0,000 & $3.523(0.68)$ \\
\hline & sai.dono & 4 & 561,5 & 36,8 & 0,000 & $3.13(0.669)$ \\
\hline & referência & 3 & 591,5 & 66,7 & 0,000 & \\
\hline & Modelo & K & AIC & $\triangle \mathrm{AIC}$ & $\omega \mathbf{i}$ & Coeficiente \\
\hline \multirow{7}{*}{2} & mata.dono.freq & 4 & 527,7 & 0 & 0,958 & $3.721(0.566)$ \\
\hline & mata.dono.sem & 4 & 533,9 & 6,3 & 0,042 & 6.107 (1.133) \\
\hline & mata.dono & 4 & 544,3 & 16,6 & 0,000 & $3.771(0.685)$ \\
\hline & sai.dono.sem & 4 & 550,8 & 23,2 & 0,000 & $3.521(0.682)$ \\
\hline & sai.dono & 4 & 561,5 & 33,9 & 0,000 & $3.13(0.669)$ \\
\hline & referência & 3 & 591,5 & 63,8 & 0,000 & \\
\hline & Modelo & K & AIC & $\triangle \mathrm{AIC}$ & $\omega \mathbf{i}$ & Coeficiente \\
\hline \multirow{7}{*}{3} & mata.dono.freq & 4 & 525,0 & 0 & 0,982 & $3.876(0.701)$ \\
\hline & mata.dono.sem & 4 & 533,0 & 8,0 & 0,018 & $6.241(1.142)$ \\
\hline & mata.dono & 4 & 544,3 & 19,3 & 0,000 & 3.771 (0.685) \\
\hline & sai.dono.sem & 4 & 550,8 & 25,8 & 0,000 & $3.521(0.682)$ \\
\hline & sai.dono & 4 & 561,5 & 36,5 & 0,000 & $3.13(0.669)$ \\
\hline & referência & 3 & 591,5 & 66,5 & 0,000 & \\
\hline & Modelo & K & AIC & $\triangle \mathrm{AIC}$ & $\omega \mathbf{i}$ & Coeficiente \\
\hline \multirow{7}{*}{4} & mata.dono.freq & 4 & 533,6 & 0 & 0,570 & $3.593(0.482)$ \\
\hline & mata.dono.sem & 4 & 534,1 & 0,6 & 0,428 & $6.061(1.14)$ \\
\hline & mata.dono & 4 & 544,3 & 10,7 & 0,003 & $3.771(0.685)$ \\
\hline & sai.dono.sem & 4 & 550,7 & 17,1 & 0,000 & $3.522(0.681)$ \\
\hline & sai.dono & 4 & 561,5 & 28,0 & 0,000 & 3.13 (0.669) \\
\hline & referência & 3 & 591,5 & 57,9 & 0,000 & \\
\hline & Modelo & K & AIC & $\triangle \mathrm{AIC}$ & $\omega \mathbf{i}$ & Coeficiente \\
\hline \multirow{3}{*}{5} & mata.dono.freq & 4 & 526,8 & 0 & 0,971 & $3.741(0.575)$ \\
\hline & mata.dono.sem & 4 & 533,9 & 7,1 & 0,029 & 6.117 (1.132) \\
\hline & mata.dono & 4 & 544,3 & 17,5 & 0,000 & $3.771(0.685)$ \\
\hline
\end{tabular}




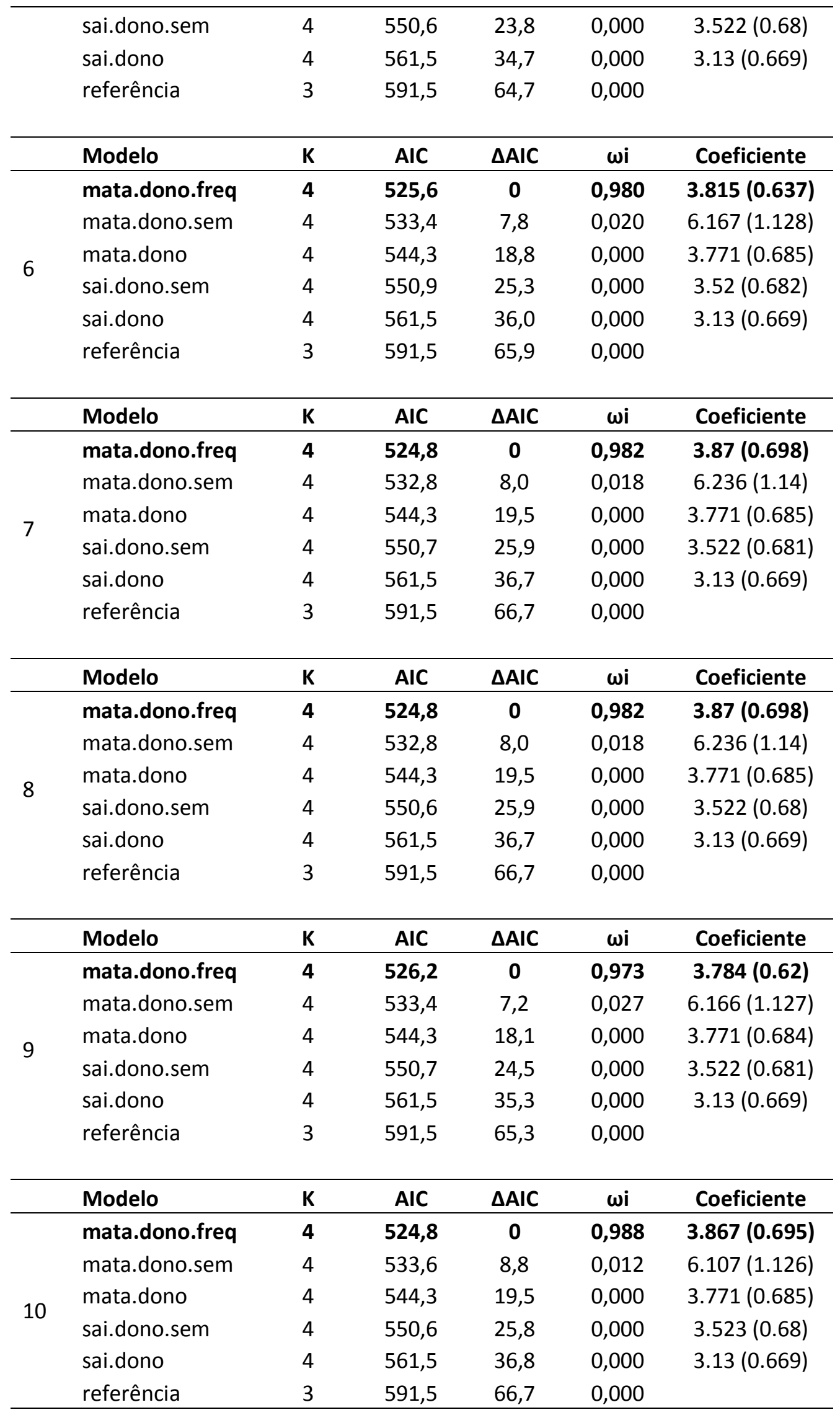


Anexo 4. Multicolineariedade (Variance Inflation Factor - VIF) entre variáveis independentes utilizadas para explicar a chance de cachorros visitarem remanescentes florestais.

Tabela S6. Variance Inflation Factor (VIF) para cada variável independente em relação a todas as outras para cada conjunto de dados imputado. SEX: sexo, IDA: idade, SAU: condição de saúde, EXP: comportamento exploratório, TAM: tamanho, RAC: raça, INC: incentivo à movimentação, MOT: motivo para criação, CON: confinamento, ALI: frequência de alimentação, PRO: proximidade à mata nativa.

\begin{tabular}{llllllllllll}
\hline $\begin{array}{l}\text { Conjunto } \\
\text { de dados }\end{array}$ & SEX & IDA & SAU & EXP & TAM & RAC & INC & MOT & CON & ALI & PRO \\
\hline 1 & 1,01 & 1,02 & 1,02 & 1,07 & 1,10 & 1,09 & 1,03 & 1,04 & 1,13 & 1,02 & 1,03 \\
2 & 1,01 & 1,02 & 1,02 & 1,06 & 1,08 & 1,07 & 1,03 & 1,03 & 1,12 & 1,02 & 1,03 \\
3 & 1,01 & 1,02 & 1,02 & 1,06 & 1,10 & 1,09 & 1,03 & 1,03 & 1,13 & 1,02 & 1,03 \\
4 & 1,02 & 1,04 & 1,02 & 1,06 & 1,12 & 1,11 & 1,03 & 1,03 & 1,13 & 1,02 & 1,03 \\
5 & 1,01 & 1,03 & 1,02 & 1,06 & 1,10 & 1,09 & 1,03 & 1,04 & 1,13 & 1,02 & 1,03 \\
6 & 1,01 & 1,04 & 1,02 & 1,06 & 1,11 & 1,10 & 1,03 & 1,04 & 1,13 & 1,02 & 1,03 \\
7 & 1,01 & 1,04 & 1,02 & 1,07 & 1,11 & 1,09 & 1,03 & 1,04 & 1,13 & 1,03 & 1,03 \\
8 & 1,01 & 1,03 & 1,02 & 1,06 & 1,06 & 1,06 & 1,03 & 1,03 & 1,13 & 1,02 & 1,03 \\
9 & 1,01 & 1,03 & 1,02 & 1,06 & 1,07 & 1,06 & 1,03 & 1,03 & 1,12 & 1,02 & 1,03 \\
10 & 1,01 & 1,03 & 1,02 & 1,06 & 1,08 & 1,08 & 1,03 & 1,03 & 1,13 & 1,02 & 1,03 \\
\hline
\end{tabular}


Anexo 5. Histograma dos atributos individuais, formas de manejo, contexto ambiental, entre outras informações, na população de cachorr os das paisagens de estudo.
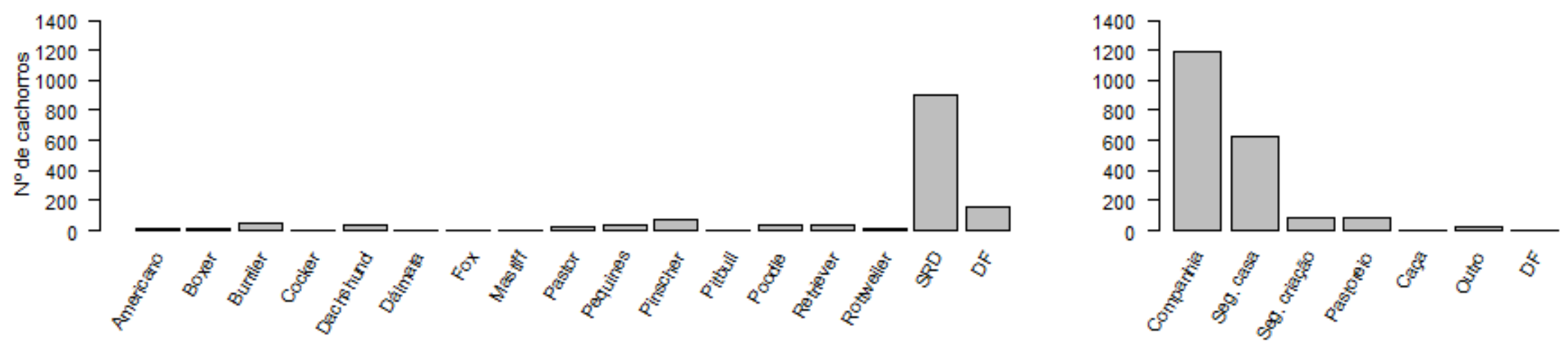

Figura S2. Número de cachorros por raça e motivo para criação.
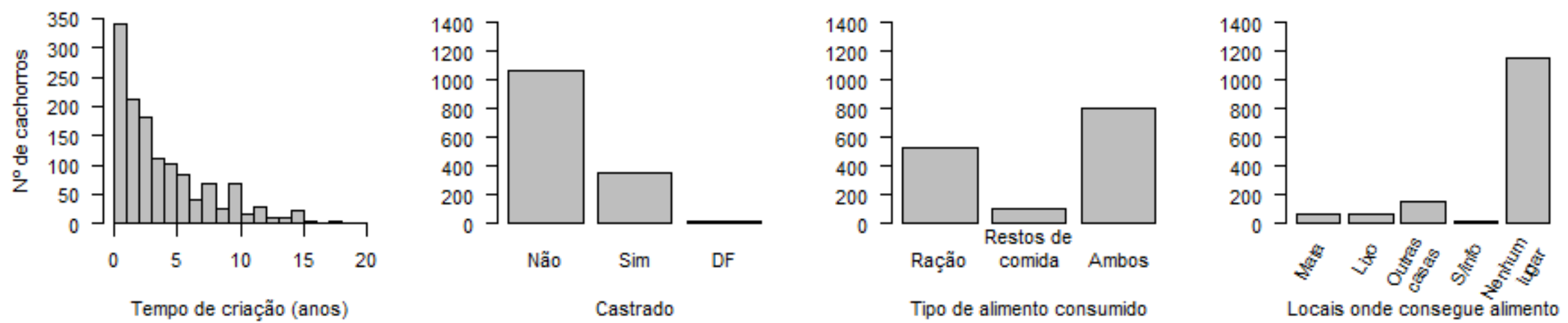

Figura S3. Número de cachorros por tempo criado pelo mesmo dono, castração, tipo de alimento que recebem dos donos e locais em que conseguem alimento fora do domicílio de criação. 

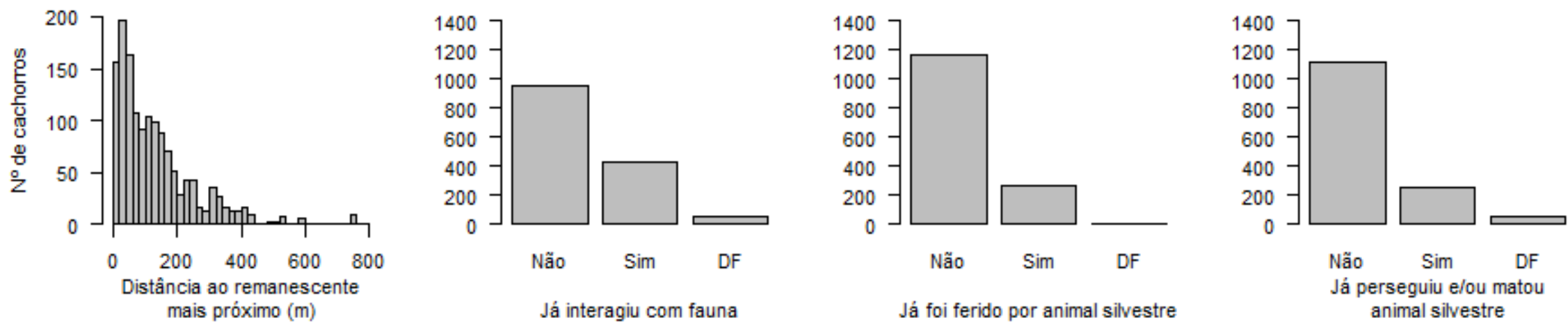

Figura S4. Número de cachorros por classes de distância dos domicílios onde são criados ao remanescente florestal mais próximo, que já interagiram com animais silvestres, que já foram feridos por animais silvestres e que já perseguiram e/ou mataram animais silvestres.

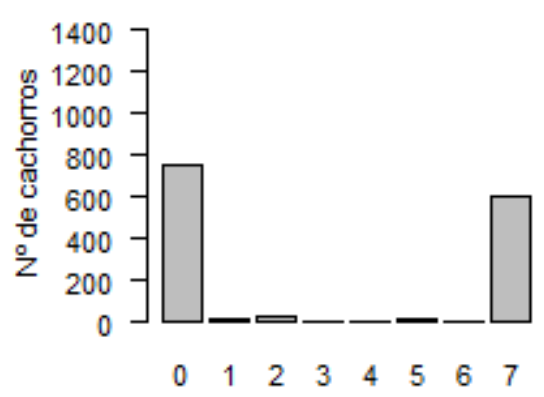

$N^{\circ}$ de dias preso (semana)

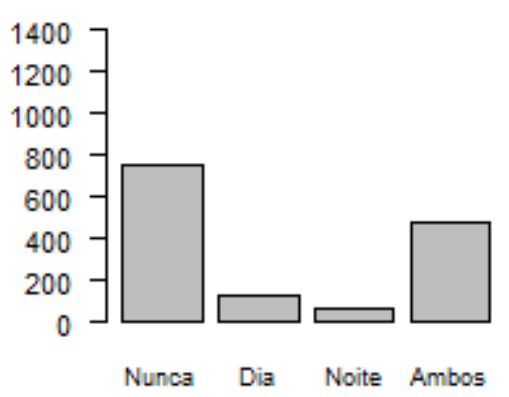

Período do dia preso

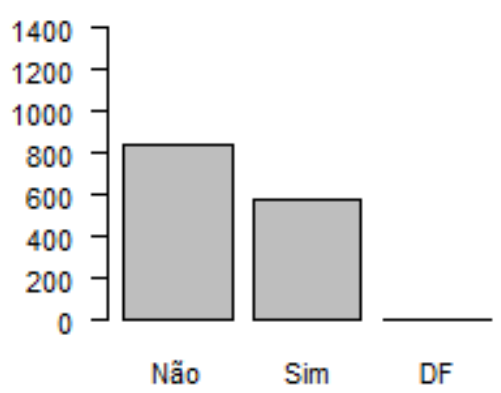

Sai sozinho do domicilio

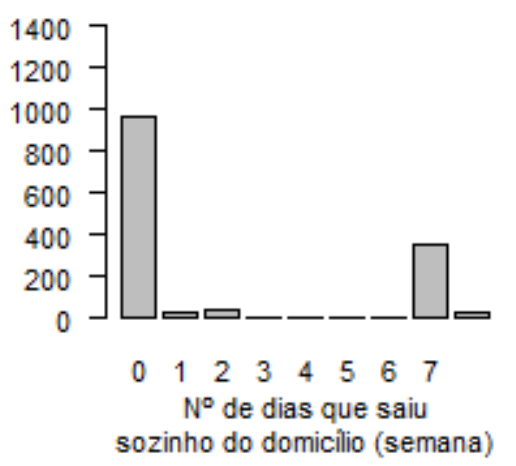

Figura S5. Número de cachorros por número de dias na semana e período do dia em que ficam confinados, que saem sozinhos dos arredores do domicilio de criação e frequência com que saíram na semana anterior à entrevista. 


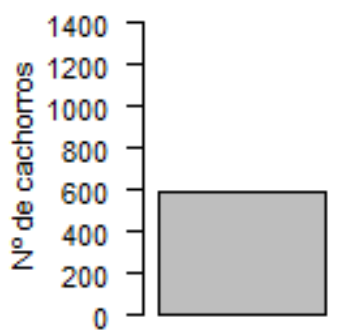

Não

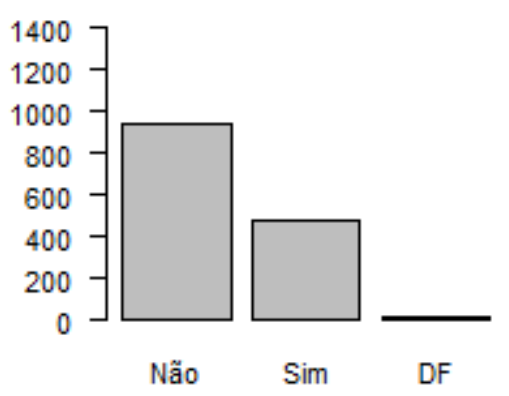

Saiu com o dono (semana)

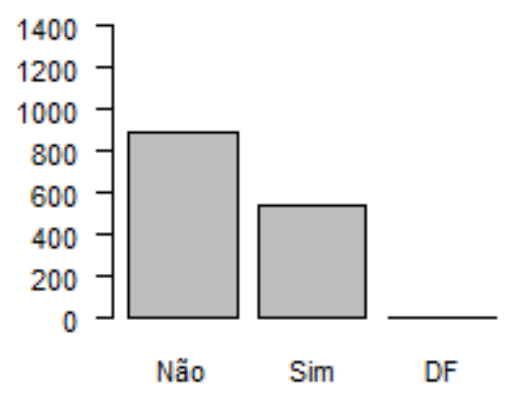

Entra na mata com o dono

Figura S6. Número de cachorros que acompanham os responsáveis quando estes saem dos arredores do domicilio, que fizeram isso na semana anterior à entrevista e que acompanham os responsáveis quando estes visitam remanescentes florestais.

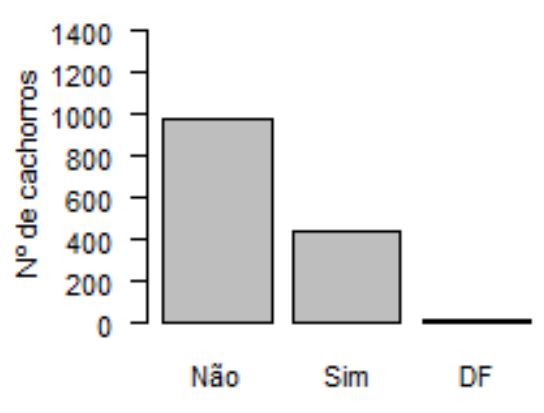

Consultado por veterinário (ano)

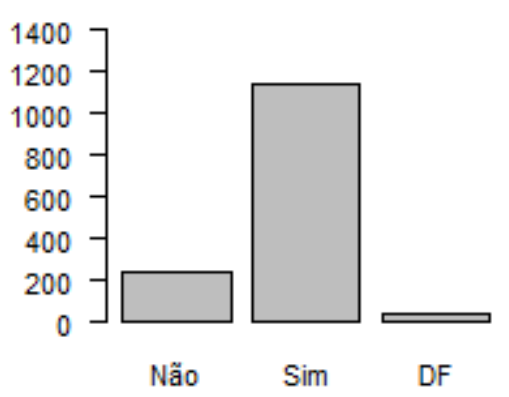

Tomou vacina antirrábica (ano)

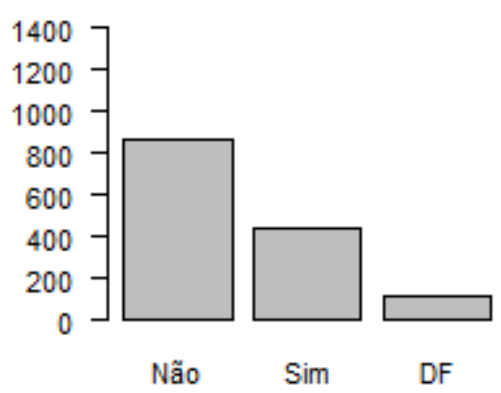

Tomou vacina polivalente (ano)

Figura S7. Número de cachorros que foram ao veterinário, que tomaram vacina antirrábica e que tomaram vacina polivalente no ano anterior à entrevista. 

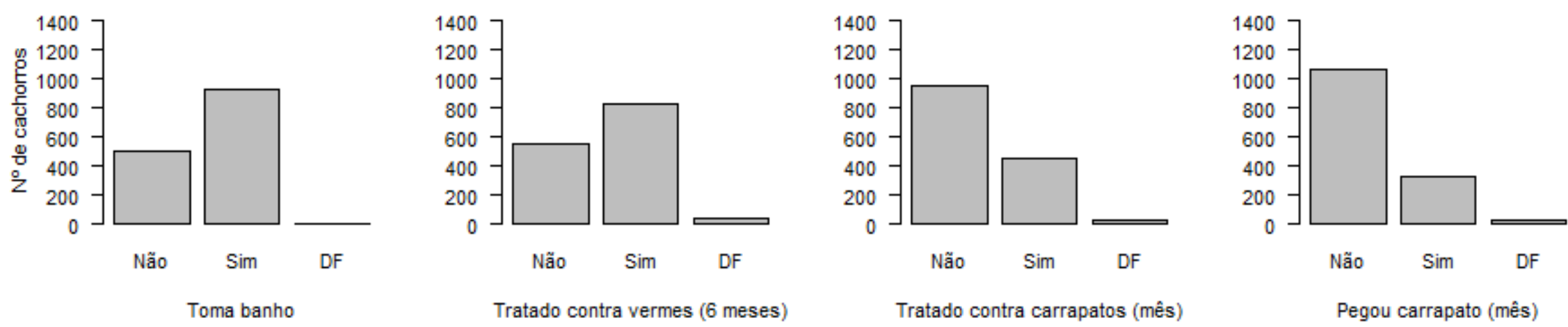

Figura S8. Número de cachorros que tomam banho, que foram tratados contra vermes nos 6 meses anteriores à entrevista, que foram tratados contra carrapatos e que foram observados com carrapatos no mês anterior à entrevista. 
Anexo 6. Resultados da segunda etapa da seleção de modelos para determinar a chance de cachorros visitarem remanescentes florestais, individualizados por conjunto de dados imputado.

Tabela S7. Resultados da seleção de modelos para determinar a chance de cachorros visitarem remanescentes florestais em função das 11 variáveis independentes associadas aos atributos individuais, às formas de manejo e ao contexto ambiental, para cada um dos 10 conjuntos de dados imputados. K: número de parâmetros. AIC: valor do AIC. $\triangle A I C$ : diferença no valor do AIC em relação ao modelo melhor ranqueado. wi: peso de evidência do modelo. SEX: sexo, IDA: idade, SAU: condição de saúde, EXP: comportamento exploratório, TAM: tamanho (2, 3 e 4 são categorias crescentes de tamanho), RAC: raça, INC: incentivo à movimentação, MOT: motivo para criação, CON: confinamento, ALI: frequência de alimentação, PRO: proximidade à mata nativa. São mostrados apenas os modelos selecionados ( $\triangle \mathrm{AIC}<2$ ).

\begin{tabular}{|c|c|c|c|c|c|c|c|c|c|c|c|c|c|c|c|c|c|}
\hline \multirow[b]{2}{*}{ Modelo } & \multirow[b]{2}{*}{ K } & \multirow[b]{2}{*}{ AIC } & \multirow[b]{2}{*}{$\triangle \mathrm{AIC}$} & \multirow[b]{2}{*}{$\omega \mathbf{i}$} & \multicolumn{13}{|c|}{ Coeficientes estimados (erro padrão) } \\
\hline & & & & & SEX & IDA & SAU & EXP & TAM2 & TAM3 & TAM4 & RAC & INC & мот & CON & ALI & PRO \\
\hline \multirow[t]{2}{*}{$I D A+E X P+T A M+I N C+C O N$} & 10 & 498,15 & 0 & 0,13 & & $\begin{array}{c}-0.596 \\
(0.296)\end{array}$ & & $\begin{array}{c}3.526 \\
(0.866)\end{array}$ & $\begin{array}{c}0.862 \\
(0.796)\end{array}$ & $\begin{array}{c}1.853 \\
(0.759)\end{array}$ & $\begin{array}{c}0.943 \\
(0.861)\end{array}$ & & $\begin{array}{c}4.061 \\
(0.712)\end{array}$ & & $\begin{array}{c}-1.091 \\
(0.466)\end{array}$ & & \\
\hline & & & & & & -0.506 & & 3.741 & & & & & 4.024 & & -1.000 & & \\
\hline \multirow[t]{2}{*}{ IDA+EXP+INC+CON } & 7 & 499,61 & 1,47 & 0,06 & & $(0.284)$ & & $(0.883)$ & & & & & (0.729) & & $(0.462)$ & & \\
\hline & & & & & \multicolumn{13}{|c|}{ Coeficientes estimados (erro padrão) } \\
\hline \multirow[t]{2}{*}{ Modelo } & K & AIC & $\triangle \mathrm{AIC}$ & $\omega \mathbf{i}$ & SEX & IDA & SAU & EXP & TAM2 & TAM3 & TAM4 & RAC & INC & Мот & CON & ALI & PRO \\
\hline & & & & & & & & 3.517 & & & & & 3.846 & & -0.96 & & \\
\hline \multirow[t]{2}{*}{$\mathrm{EXP}+\mathrm{INC}+\mathrm{CON}$} & 6 & 504,54 & 0 & 0,06 & & & & $(0.865)$ & & & & & (0.615) & & $(0.452)$ & & \\
\hline & & & & & & & & 3.385 & 1.171 & 1.851 & 1.226 & & 3.839 & & -1.02 & & \\
\hline \multirow[t]{2}{*}{ EXP+TAM+INC+CON } & 9 & 504,75 & 0,21 & 0,06 & & & & $(0.849)$ & $(0.864)$ & $(0.841)$ & $(0.915)$ & & $(0.596)$ & & $(0.458)$ & & \\
\hline & & & & & & & & 3.563 & & & & & 3.781 & & -0.961 & & 0.568 \\
\hline \multirow[t]{2}{*}{$E X P+I N C+C O N+P R O$} & 7 & 505,56 & 1,03 & 0,04 & & & & $(0.859)$ & & & & & (0.649) & & $(0.452)$ & & (0.549) \\
\hline & & & & & -0.503 & & & 3.365 & 1.232 & 1.943 & 1.311 & & 3.851 & & -1.06 & & \\
\hline \multirow[t]{2}{*}{$\mathrm{SEX}+\mathrm{EXP}+\mathrm{TAM}+\mathrm{INC}+\mathrm{CON}$} & 10 & 505,67 & 1,13 & 0,03 & $(0.486)$ & & & $(0.847)$ & $(0.871)$ & $(0.855)$ & $(0.928)$ & & (0.594) & & $(0.468)$ & & \\
\hline & & & & & -0.387 & & & 3.503 & & & & & 3.854 & & -0.982 & & \\
\hline \multirow[t]{2}{*}{$S E X+E X P+I N C+C O N$} & 7 & 505,88 & 1,34 & 0,03 & (0.478) & & & $(0.862)$ & & & & & $(0.613)$ & & $(0.456)$ & & \\
\hline & & & & & & & & 3.412 & 1.17 & 1.832 & 1.185 & & 3.737 & & -1.015 & & 0.54 \\
\hline \multirow[t]{2}{*}{ EXP+TAM+INC+CON+PRO } & 10 & 505,90 & 1,36 & 0,03 & & & & $(0.843)$ & $(0.865)$ & $(0.842)$ & $(0.917)$ & & $(0.632)$ & & $(0.457)$ & & $(0.56)$ \\
\hline & & & & & & & & 3.539 & & & & & 3.908 & & -0.974 & 2.045 & \\
\hline \multirow[t]{2}{*}{$\mathrm{EXP}+\mathrm{INC}+\mathrm{CON}+\mathrm{ALI}$} & 7 & 505,95 & 1,41 & 0,03 & & & & $(0.867)$ & & & & & $(0.656)$ & & $(0.453)$ & (3.211) & \\
\hline & & & & & & & & 3.408 & 1.186 & 1.873 & 1.248 & & 3.889 & & -1.035 & 2.282 & \\
\hline \multirow[t]{2}{*}{$E X P+T A M+I N C+C O N+A L I$} & 10 & 506,05 & 1,51 & 0,03 & & & & $(0.851)$ & $(0.866)$ & $(0.843)$ & $(0.917)$ & & (0.619) & & $(0.458)$ & $(3.216)$ & \\
\hline & & & & & & & -0.795 & 3.492 & & & & & 3.838 & & -0.945 & & \\
\hline$S A U+E X P+I N C+C O N$ & 7 & 506,11 & 1,58 & 0,03 & & & $(1.244)$ & $(0.861)$ & & & & & $(0.616)$ & & $(0.449)$ & & \\
\hline
\end{tabular}




\begin{tabular}{|c|c|c|c|c|c|c|c|c|c|c|c|c|c|c|}
\hline & & & & & -0.074 & & 3.536 & & & & & 3.848 & & -0.967 \\
\hline \multirow[t]{2}{*}{ IDA+EXP+INC+CON } & 7 & 506,44 & 1,90 & 0,02 & $(0.238)$ & & $(0.867)$ & & & & & $(0.616)$ & & $(0.453)$ \\
\hline & & & & & -0.133 & & 3.415 & 1.213 & 1.885 & 1.219 & & 3.857 & & -1.031 \\
\hline \multirow[t]{2}{*}{ IDA+EXP+TAM+INC+CON } & 10 & 506,45 & 1,91 & 0,02 & $(0.244)$ & & $(0.851)$ & $(0.866)$ & (0.841) & (0.914) & & $(0.607)$ & & (0.458) \\
\hline & & & & & & -0.658 & 3.357 & 1.144 & 1.82 & 1.17 & & 3.826 & & -1.003 \\
\hline \multirow[t]{2}{*}{$\mathrm{SAU}+\mathrm{EXP}+\mathrm{TAM}+\mathrm{INC}+\mathrm{CON}$} & 10 & 506,47 & 1,93 & 0,02 & & $(1.264)$ & $(0.845)$ & $(0.862)$ & $(0.84)$ & $(0.92)$ & & $(0.597)$ & & $(0.455)$ \\
\hline & 7 & 506,49 & 1,95 & 0,02 & & & $\begin{array}{c}3.503 \\
(0.865)\end{array}$ & & & & $\begin{array}{c}-0.132 \\
(0.607)\end{array}$ & $\begin{array}{c}3.833 \\
(0.609)\end{array}$ & & $\begin{array}{l}-0.951 \\
(0.455)\end{array}$ \\
\hline$E X P+R A C+I N C+C O N$ & & & & & & & 3.502 & & & & & 3.841 & 0.164 & -0.973 \\
\hline EXP+INC+MOT+CON & 7 & 506,52 & 1,99 & 0,02 & & & $(0.872)$ & & & & & $(0.616)$ & $(1.328)$ & $(0.465)$ \\
\hline
\end{tabular}

Coeficientes estimados (erro padrão)

\begin{tabular}{|c|c|c|c|c|c|c|c|c|c|c|c|c|c|c|c|c|c|}
\hline \multirow[b]{2}{*}{ Modelo } & \multirow[b]{2}{*}{ K } & \multirow[b]{2}{*}{ AIC } & \multirow[b]{2}{*}{$\triangle \mathrm{AIC}$} & \multirow[b]{2}{*}{$\omega \mathbf{i}$} & \\
\hline & & & & & SEX & IDA & SAU & EXP & TAM2 & TAM3 & TAM4 & RAC & INC & мот & CON & ALI & PRO \\
\hline \multirow{3}{*}{$E X P+T A M+I N C+C O N$} & & & & & & & & 3.279 & 0.725 & 2.136 & 1.298 & & 3.973 & & -1.097 & & \\
\hline & 9 & 497,89 & 0 & 0,14 & & & & $(0.827)$ & $(0.826)$ & $(0.796)$ & $(0.88)$ & & $(0.697)$ & & $(0.464)$ & & \\
\hline & & & & & & & & 3.355 & 1.134 & 2.565 & 1.453 & 0.817 & 3.994 & & -1.173 & & \\
\hline \multirow[t]{2}{*}{$E X P+T A M+R A C+I N C+C O N$} & 10 & 498,39 & 0,51 & 0,11 & & & & $(0.833)$ & $(0.907)$ & $(0.89)$ & $(0.897)$ & $(0.672)$ & $(0.717)$ & & $(0.467)$ & & \\
\hline & & & & & & & & 3.314 & 0.737 & 2.156 & 1.32 & & 4.032 & & -1.11 & 2.855 & \\
\hline \multirow[t]{2}{*}{ EXP+TAM+INC+CON+ALI } & 10 & 498,95 & 1,06 & 0,08 & & & & $(0.83)$ & $(0.827)$ & $(0.796)$ & $(0.881)$ & & $(0.733)$ & & $(0.463)$ & $(3.643)$ & \\
\hline & & & & & & & & 3.356 & 0.713 & 2.096 & 1.251 & & 3.884 & & -1.09 & & 0.592 \\
\hline \multirow[t]{2}{*}{ EXP+TAM+INC+CON+PRO } & 10 & 498,99 & 1,10 & 0,08 & & & & $(0.835)$ & $(0.825)$ & $(0.794)$ & (0.879) & & $(0.696)$ & & $(0.461)$ & & $(0.592)$ \\
\hline & & & & & -0.456 & & & 3.251 & 0.759 & 2.184 & 1.41 & & 3.983 & & -1.131 & & \\
\hline \multirow[t]{2}{*}{$\mathrm{SEX}+\mathrm{EXP}+\mathrm{TAM}+\mathrm{INC}+\mathrm{CON}$} & 10 & 499,04 & 1,16 & 0,08 & $(0.5)$ & & & $(0.825)$ & $(0.832)$ & $(0.807)$ & $\begin{array}{c}1.41 \\
(0.897)\end{array}$ & & $(0.694)$ & & $(0.472)$ & & \\
\hline & & & & & & -0.198 & & 3.31 & 0.817 & 2.188 & 1.39 & & 4.024 & & -1.117 & & \\
\hline \multirow[t]{2}{*}{$I D A+E X P+T A M+I N C+C O N$} & 10 & 499,27 & 1,38 & 0,07 & & $(0.253)$ & & $(0.83)$ & $(0.837)$ & $(0.799)$ & $(0.89)$ & & (0.719) & & $(0.465)$ & & \\
\hline & & & & & & & -0.543 & 3.255 & 0.717 & 2.113 & 1.252 & & 3.962 & & -1.08 & & \\
\hline \multirow[t]{2}{*}{$\mathrm{SAU}+\mathrm{EXP}+\mathrm{TAM}+\mathrm{INC}+\mathrm{CON}$} & 10 & 499,69 & 1,81 & 0,06 & & & (1.244) & $(0.825)$ & $(0.825)$ & $(0.796)$ & $(0.885)$ & & (0.698) & & $(0.462)$ & & \\
\hline & & & & & & & & 3.269 & 0.718 & 2.132 & 1.296 & & 3.972 & 0.117 & -1.106 & & \\
\hline $\mathrm{EXP}+\mathrm{TAM}+\mathrm{INC}+\mathrm{MOT}+\mathrm{CON}$ & 10 & 499,88 & 1,99 & 0,05 & & & & $(0.833)$ & $(0.83)$ & $(0.798)$ & $(0.881)$ & & $(0.696)$ & $(1.346)$ & $(0.478)$ & & \\
\hline
\end{tabular}

\begin{tabular}{|c|c|c|c|c|c|c|c|c|c|c|c|c|c|c|c|c|c|}
\hline \multirow[b]{2}{*}{ Modelo } & \multirow[b]{2}{*}{$\mathbf{K}$} & \multirow[b]{2}{*}{ AIC } & \multirow[b]{2}{*}{$\triangle \mathrm{AIC}$} & \multirow[b]{2}{*}{$\omega i$} & \multicolumn{13}{|c|}{ Coeficientes estimados (erro padrão) } \\
\hline & & & & & SEX & IDA & SAU & EXP & TAM2 & TAM3 & TAM4 & RAC & INC & МOT & CON & ALI & PRO \\
\hline & & & & & & & & 3.339 & 0.014 & 1.241 & 0.273 & & 3.664 & & -1.081 & & \\
\hline \multirow[t]{2}{*}{$E X P+T A M+I N C+C O N$} & 9 & 511,28 & 0 & 0,06 & & & & $(0.842)$ & $(0.749)$ & $(0.687)$ & $(0.826)$ & & $(0.55)$ & & $(0.466)$ & & \\
\hline & & & & & & & & 3.394 & & & & & 3.68 & & -0.951 & & \\
\hline \multirow{2}{*}{$E X P+I N C+C O N$} & 6 & 511,42 & 0,14 & 0,06 & & & & $(0.844)$ & & & & & $(0.545)$ & & $(0.45)$ & & \\
\hline & & & & & & -0.241 & & 3.42 & -0.021 & 1.228 & 0.334 & & 3.69 & & -1.121 & & \\
\hline \multirow[t]{2}{*}{ IDA+EXP+TAM+INC+CON } & 10 & 512,36 & 1,08 & 0,04 & & $(0.255)$ & & $(0.851)$ & $(0.748)$ & $(0.685)$ & $(0.831)$ & & $(0.562)$ & & $(0.47)$ & & \\
\hline & & & & & -0.44 & & & 3.322 & 0.049 & 1.292 & 0.352 & & 3.673 & & -1.118 & & \\
\hline$S E X+E X P+T A M+I N C+C O N$ & 10 & 512,45 & 1,18 & 0,03 & $(0.487)$ & & & $(0.839)$ & $(0.751)$ & $(0.694)$ & $(0.832)$ & & $(0.55)$ & & $(0.475)$ & & \\
\hline$E X P+T A M+I N C+C O N+P R O$ & 10 & 512,47 & 1,19 & 0,03 & & & & 3.356 & 0.018 & 1.221 & 0.234 & & 3.558 & & -1.077 & & 0.514 \\
\hline
\end{tabular}




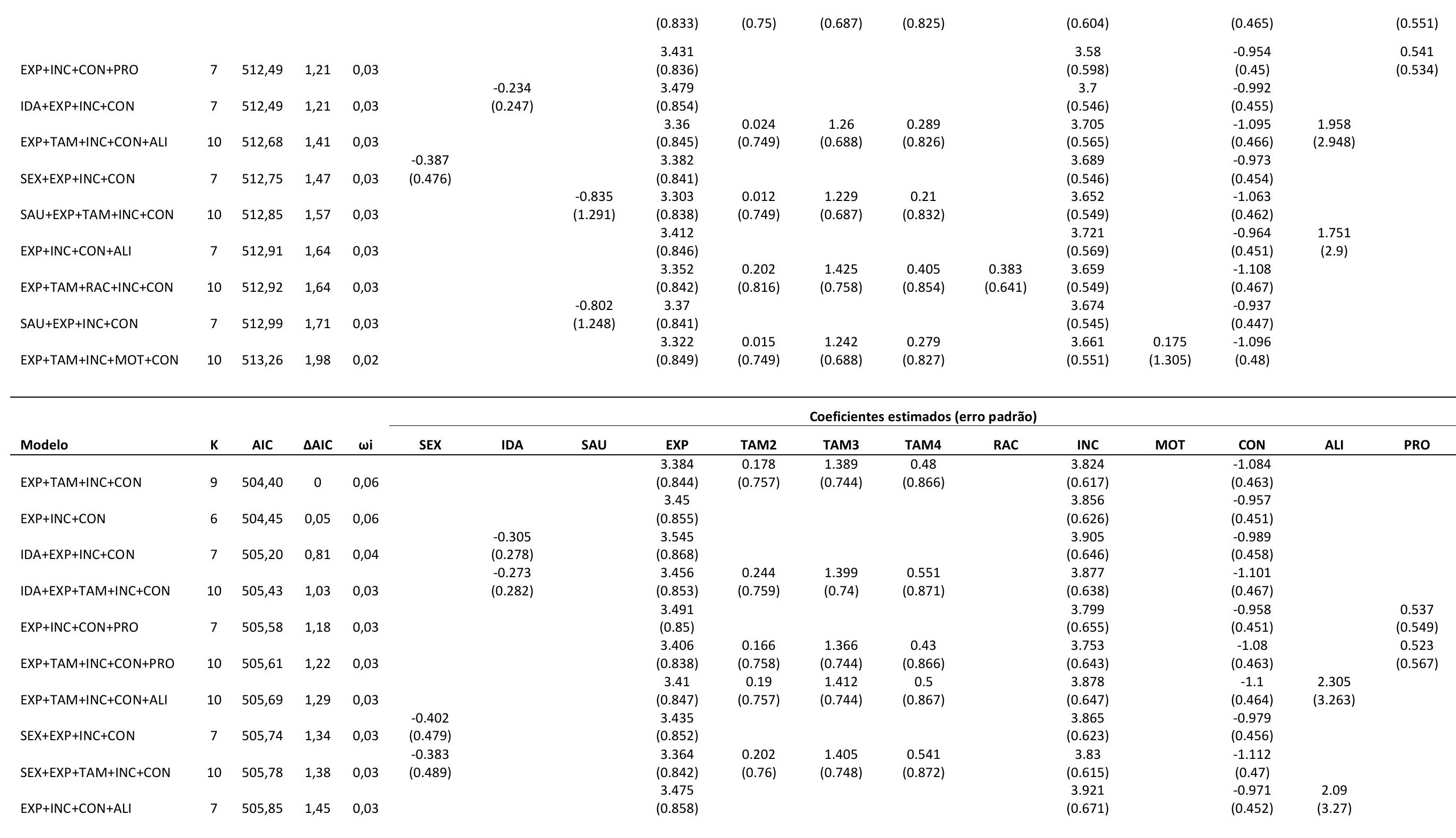




\begin{tabular}{|c|c|c|c|c|c|c|c|c|c|c|c|c|c|c|c|c|c|}
\hline & & & & & & & -0.773 & 3.347 & 0.177 & 1.376 & 0.434 & & 3.813 & & -1.061 & & \\
\hline \multirow[t]{2}{*}{$\mathrm{SAU}+\mathrm{EXP}+\mathrm{TAM}+\mathrm{INC}+\mathrm{CON}$} & 10 & 506,02 & 1,62 & 0,03 & & & $(1.27)$ & $(0.84)$ & $(0.757)$ & $(0.743)$ & $(0.868)$ & & $(0.617)$ & & $(0.46)$ & & \\
\hline & & & & & & & -0.785 & 3.424 & & & & & 3.851 & & -0.941 & & \\
\hline \multirow[t]{2}{*}{$S A U+E X P+I N C+C O N$} & 7 & 506,04 & 1,65 & 0,02 & & & (1.251) & $(0.852)$ & & & & & $(0.628)$ & & $(0.448)$ & & \\
\hline & & & & & & & & 3.389 & 0.311 & 1.531 & 0.586 & 0.294 & 3.827 & & -1.106 & & \\
\hline $\mathrm{EXP}+\mathrm{TAM}+\mathrm{RAC}+\mathrm{INC}+\mathrm{CON}$ & 10 & 506,19 & 1,79 & 0,02 & & & & $(0.844)$ & $(0.814)$ & $(0.81)$ & $(0.896)$ & $(0.646)$ & $(0.622)$ & & $(0.465)$ & & \\
\hline \multirow[t]{2}{*}{$I D A+E X P+I N C+C O N+P R O$} & 8 & 506,23 & 1,83 & 0,02 & & $\begin{array}{l}-0.319 \\
(0.279)\end{array}$ & & $\begin{array}{c}3.588 \\
(0.862)\end{array}$ & & & & & $\begin{array}{c}3.846 \\
(0.666)\end{array}$ & & $\begin{array}{l}-0.993 \\
(0.457)\end{array}$ & & $\begin{array}{c}0.569 \\
(0.548)\end{array}$ \\
\hline & & & & & \multicolumn{13}{|c|}{ Coeficientes estimados (erro padrão) } \\
\hline \multirow[t]{2}{*}{ Modelo } & $\mathbf{K}$ & AIC & $\triangle \mathrm{AIC}$ & $\omega \mathbf{i}$ & SEX & IDA & SAU & EXP & TAM2 & TAM3 & TAM4 & RAC & INC & MOT & CON & ALI & PRO \\
\hline & & & & & & -0.589 & & 3.677 & 0.529 & 1.656 & 0.453 & & 3.898 & & -1.213 & & \\
\hline \multirow[t]{2}{*}{ IDA+EXP+TAM+INC+CON } & 10 & 498,38 & 0 & 0,15 & & $(0.293)$ & & $(0.86)$ & $(0.792)$ & $(0.747)$ & $(0.88)$ & & $(0.639)$ & & $(0.488)$ & & \\
\hline & & & & & & -0.568 & & 3.735 & & & & & 3.908 & & -1.095 & & \\
\hline \multirow[t]{2}{*}{ IDA+EXP+INC+CON } & 7 & 499,73 & 1,35 & 0,08 & & $(0.29)$ & & $(0.861)$ & & & & & $(0.626)$ & & $(0.474)$ & & \\
\hline & & & & & \multicolumn{13}{|c|}{ Coeficientes estimados (erro padrão) } \\
\hline \multirow{4}{*}{ EXP+TAM+INC+CON } & $\mathbf{K}$ & AIC & $\triangle \mathrm{AIC}$ & $\omega \mathbf{i}$ & SEX & IDA & SAU & EXP & TAM2 & TAM3 & TAM4 & RAC & INC & Мот & CON & ALI & PRO \\
\hline & & & & & & & & 2.849 & 0.827 & 1.948 & 0.541 & & 3.78 & & -0.975 & & \\
\hline & 9 & 504,72 & 0 & 0,11 & & & & $(0.829)$ & $(0.82)$ & $(0.79)$ & $(0.928)$ & & $(0.614)$ & & $(0.451)$ & & \\
\hline & & & & & & -0.339 & & 2.975 & 0.865 & 1.958 & 0.635 & & 3.864 & & -1.036 & & \\
\hline \multirow[t]{2}{*}{ IDA+EXP+TAM+INC+CON } & 10 & 504,94 & 0,22 & 0,10 & & $(0.261)$ & & $(0.845)$ & $(0.822)$ & $(0.787)$ & $(0.935)$ & & $(0.654)$ & & $(0.456)$ & & \\
\hline & & & & & & & & 2.893 & 0.825 & 1.937 & 0.503 & & 3.706 & & -0.975 & & 0.5 \\
\hline \multirow[t]{2}{*}{$E X P+T A M+I N C+C O N+P R O$} & 10 & 505,95 & 1,23 & 0,06 & & & & $(0.83)$ & $(0.821)$ & $(0.79)$ & $(0.928)$ & & $(0.63)$ & & $(0.451)$ & & $(0.541)$ \\
\hline & & & & & & & & 2.87 & 0.839 & 1.967 & 0.56 & & 3.823 & & -0.988 & 2.355 & \\
\hline \multirow[t]{2}{*}{ EXP+TAM+INC+CON+ALI } & 10 & 505,99 & 1,27 & 0,06 & & & & $(0.833)$ & $(0.821)$ & $(0.791)$ & $(0.929)$ & & $(0.635)$ & & $(0.451)$ & $(3.346)$ & \\
\hline & & & & & -0.354 & & & 2.82 & 0.869 & 1.979 & 0.623 & & 3.784 & & & & \\
\hline \multirow[t]{2}{*}{ SEX+EXP+TAM+INC+CON } & 10 & 506,19 & 1,47 & 0,05 & $(0.487)$ & & & $(0.826)$ & $(0.827)$ & $(0.798)$ & $(0.939)$ & & $(0.612)$ & & $-1(0.456)$ & & \\
\hline & & & & & & & & 2.874 & 1.056 & 2.156 & 0.664 & 0.409 & 3.785 & & -1.011 & & \\
\hline \multirow[t]{2}{*}{ EXP+TAM+RAC+INC+CON } & 10 & 506,34 & 1,62 & 0,05 & & & & $(0.832)$ & $(0.907)$ & $(0.866)$ & $(0.95)$ & $(0.663)$ & $(0.62)$ & & $(0.454)$ & & \\
\hline & & & & & & & -0.721 & 2.81 & 0.815 & 1.931 & 0.46 & & 3.766 & & -0.96 & & \\
\hline \multirow[t]{2}{*}{ SAU+EXP+TAM+INC+CON } & 10 & 506,37 & 1,65 & 0,05 & & & $(1.243)$ & $(0.83)$ & $(0.818)$ & $(0.788)$ & $(0.937)$ & & $(0.613)$ & & $(0.45)$ & & \\
\hline & & & & & & & & 2.842 & 0.824 & 1.945 & 0.535 & & 3.779 & 0.071 & -0.981 & & \\
\hline EXP+TAM+INC+MOT+CON & 10 & 506,72 & 2,00 & 0,04 & & & & $(0.837)$ & $(0.823)$ & $(0.792)$ & $(0.934)$ & & $(0.614)$ & (1.302) & $(0.463)$ & & \\
\hline
\end{tabular}

\begin{tabular}{|c|c|c|c|c|c|c|c|c|c|c|c|c|c|c|c|c|c|}
\hline \multirow[b]{2}{*}{ Modelo } & \multirow[b]{2}{*}{ K } & \multirow[b]{2}{*}{ AIC } & \multirow[b]{2}{*}{$\triangle \mathrm{AIC}$} & \multirow[b]{2}{*}{$\omega \mathbf{i}$} & \multicolumn{13}{|c|}{ Coeficientes estimados (erro padrão) } \\
\hline & & & & & SEX & IDA & SAU & EXP & TAM2 & TAM3 & TAM4 & RAC & INC & MOT & CON & ALI & PRO \\
\hline EXP+TAM+INC+CON & 9 & 501,84 & 0 & 0,05 & & & & $\begin{array}{c}3.322 \\
(0.835)\end{array}$ & $\begin{array}{c}0.529 \\
(0.795)\end{array}$ & $\begin{array}{c}1.542 \\
(0.745)\end{array}$ & $\begin{array}{c}0.641 \\
(0.849)\end{array}$ & & $\begin{array}{l}3.905 \\
(0.68)\end{array}$ & & $\begin{array}{c}-1.054 \\
(0.463)\end{array}$ & & \\
\hline
\end{tabular}




\begin{tabular}{|c|c|c|c|c|c|c|c|c|c|c|c|c|c|c|c|c|c|}
\hline \multirow[t]{2}{*}{ EXP+INC+CON } & 6 & 501,91 & 0,07 & 0,05 & & & & $\begin{array}{c}3.453 \\
(0.838)\end{array}$ & & & & & $\begin{array}{c}3.931 \\
(0.705)\end{array}$ & & $\begin{array}{c}-0.952 \\
(0.45)\end{array}$ & & \\
\hline & & & & & & -0.334 & & 3.412 & 0.518 & 1.541 & 0.646 & & 3.962 & & -1.108 & & \\
\hline \multirow[t]{2}{*}{ IDA+EXP+TAM+INC+CON } & 10 & 502,56 & 0,72 & 0,04 & & $(0.301)$ & & $(0.847)$ & $(0.796)$ & $(0.746)$ & $(0.854)$ & & $(0.703)$ & & (0.469) & & \\
\hline & & & & & & & & 3.588 & & & & & 3.872 & & -0.956 & & 0.677 \\
\hline \multirow[t]{2}{*}{$E X P+I N C+C O N+P R O$} & 7 & 502,56 & 0,73 & 0,04 & & & & $(0.853)$ & & & & & $(0.7)$ & & $(0.448)$ & & $(0.544)$ \\
\hline & & & & & & -0.318 & & 3.541 & & & & & 3.964 & & -1.01 & & \\
\hline \multirow[t]{2}{*}{ IDA+EXP+INC+CON } & 7 & 502,64 & 0,81 & 0,03 & & $(0.288)$ & & $(0.848)$ & & & & & $(0.727)$ & & $(0.458)$ & & \\
\hline & & & & & & & & 3.43 & 0.521 & 1.513 & 0.599 & & 3.827 & & -1.052 & & 0.662 \\
\hline \multirow[t]{2}{*}{$E X P+T A M+I N C+C O N+P R O$} & 10 & 502,66 & 0,82 & 0,03 & & & & $(0.845)$ & $(0.793)$ & $(0.742)$ & $(0.848)$ & & $(0.682)$ & & $(0.46)$ & & $(0.574)$ \\
\hline & & & & & & & & 3.386 & 0.762 & 1.78 & 0.672 & 0.683 & 3.892 & & -1.102 & & \\
\hline \multirow[t]{2}{*}{$E X P+T A M+R A C+I N C+C O N$} & 10 & 502,73 & 0,89 & 0,03 & & & & $(0.838)$ & $(0.834)$ & $(0.789)$ & $(0.85)$ & $(0.65)$ & $(0.681)$ & & $(0.462)$ & & \\
\hline & & & & & & & & 3.357 & 0.539 & 1.558 & 0.663 & & 3.967 & & -1.068 & 2.631 & \\
\hline \multirow[t]{2}{*}{ EXP+TAM+INC+CON+ALI } & 10 & 502,98 & 1,14 & 0,03 & & & & $(0.838)$ & $(0.795)$ & $(0.745)$ & $(0.85)$ & & $(0.721)$ & & $(0.463)$ & (3.517) & \\
\hline & & & & & & & & 3.491 & & & & & 4.013 & & -0.966 & 2.47 & \\
\hline \multirow[t]{2}{*}{$E X P+I N C+C O N+A L I$} & 7 & 503,12 & 1,28 & 0,03 & & & & $(0.842)$ & & & & & $(0.765)$ & & $(0.452)$ & (3.54) & \\
\hline & & & & & & -0.336 & & 3.69 & & & & & 3.903 & & -1.018 & & 0.711 \\
\hline \multirow[t]{2}{*}{ IDA+EXP+INC+CON+PRO } & 8 & 503,15 & 1,32 & 0,03 & & (0.289) & & $(0.865)$ & & & & & $(0.717)$ & & $(0.455)$ & & $(0.538)$ \\
\hline & & & & & -0.38 & & & 3.439 & & & & & 3.939 & & -0.973 & & \\
\hline \multirow[t]{2}{*}{$S E X+E X P+I N C+C O N$} & 7 & 503,27 & 1,44 & 0,03 & $(0.479)$ & & & $(0.836)$ & & & & & $(0.697)$ & & $(0.454)$ & & \\
\hline & & & & & -0.347 & & & 3.301 & 0.55 & 1.546 & 0.692 & & 3.911 & & -1.074 & & \\
\hline \multirow{2}{*}{$\mathrm{SEX}+\mathrm{EXP}+\mathrm{TAM}+\mathrm{INC}+\mathrm{CON}$} & 10 & 503,34 & 1,50 & 0,02 & $(0.492)$ & & & $(0.832)$ & $(0.797)$ & $(0.748)$ & $(0.856)$ & & $(0.68)$ & & $(0.467)$ & & \\
\hline & & & & & & & -0.844 & 3.293 & 0.52 & 1.524 & 0.565 & & 3.892 & & -1.036 & & \\
\hline \multirow[t]{2}{*}{$S A U+E X P+T A M+I N C+C O N$} & 10 & 503,39 & 1,56 & 0,02 & & & $(1.288)$ & $(0.831)$ & (0.794) & $(0.744)$ & $(0.857)$ & & (0.681) & & (0.459) & & \\
\hline & & & & & & & -0.825 & 3.431 & & & & & 3.924 & & -0.937 & & \\
\hline \multirow[t]{2}{*}{$S A U+E X P+I N C+C O N$} & 7 & 503,45 & 1,61 & 0,02 & & & $(1.241)$ & $(0.835)$ & & & & & $(0.707)$ & & $(0.447)$ & & \\
\hline & & & & & & & & 3.479 & & & & 0.227 & 3.937 & & -0.965 & & \\
\hline \multirow[t]{2}{*}{$E X P+R A C+I N C+C O N$} & 7 & 503,76 & 1,93 & 0,02 & & & & $(0.841)$ & & & & $(0.591)$ & $(0.709)$ & & $(0.45)$ & & \\
\hline & & & & & & & & 3.63 & & & & & 3.934 & & -0.972 & 2.53 & 0.677 \\
\hline \multirow[t]{2}{*}{$E X P+I N C+C O N+A L I+P R O$} & 8 & 503,77 & 1,93 & 0,02 & & & & $(0.86)$ & & & & & $(0.716)$ & & $(0.448)$ & (3.568) & $(0.544)$ \\
\hline & & & & & & & & 3.332 & 0.534 & 1.549 & 0.643 & & 3.908 & -0.133 & -1.043 & & \\
\hline \multirow[t]{2}{*}{ EXP+TAM+INC+MOT+CON } & 10 & 503,83 & 1,99 & 0,02 & & & & $(0.843)$ & $(0.797)$ & $(0.748)$ & $(0.85)$ & & $(0.683)$ & (1.391) & (0.475) & & \\
\hline & & & & & \multicolumn{13}{|c|}{ Coeficientes estimados (erro padrão) } \\
\hline \multirow[t]{2}{*}{ Modelo } & $\mathrm{K}$ & AIC & $\triangle \mathrm{AIC}$ & $\omega i$ & SEX & IDA & SAU & EXP & TAM2 & TAM3 & TAM4 & RAC & INC & Мот & CON & ALI & PRO \\
\hline & & & & & & & & 3.349 & 0.038 & 1.527 & 0.379 & & 3.864 & & -1.116 & & \\
\hline \multirow[t]{2}{*}{ EXP+TAM+INC+CON } & 9 & 501,51 & 0 & 0,11 & & & & $(0.837)$ & $(0.761)$ & $(0.723)$ & $(0.855)$ & & (0.654) & & $(0.472)$ & & \\
\hline & & & & & & & & 3.451 & 0.228 & 1.74 & 0.382 & 0.815 & 3.898 & & -1.175 & & \\
\hline \multirow[t]{2}{*}{$E X P+T A M+R A C+I N C+C O N$} & 10 & 501,67 & 0,16 & 0,10 & & & & $(0.848)$ & $(0.784)$ & (0.751) & $(0.855)$ & (0.604) & $(0.686)$ & & $(0.473)$ & & \\
\hline & & & & & & & & 3.466 & 0.04 & 1.497 & 0.353 & & 3.786 & & -1.113 & & 0.701 \\
\hline EXP+TAM+INC+CON+PRO & 10 & 502,25 & 0,74 & 0,07 & & & & $(0.852)$ & (0.759) & (0.719) & $(0.852)$ & & $(0.67)$ & & (0.469) & & $(0.585)$ \\
\hline & & & & & & & & 3.386 & 0.048 & 1.547 & 0.402 & & 3.921 & & -1.131 & 2.553 & \\
\hline EXP+TAM+INC+CON+ALI & 10 & 502,68 & 1,17 & 0,06 & & & & $(0.84)$ & $(0.762)$ & $(0.723)$ & $(0.855)$ & & $(0.688)$ & & $(0.472)$ & (3.402) & \\
\hline
\end{tabular}




\begin{tabular}{|c|c|c|c|c|c|c|c|c|c|c|c|c|c|c|c|c|c|}
\hline & & & & & -0.33 & & & 3.332 & 0.041 & 1.521 & 0.416 & & 3.869 & & -1.143 & & \\
\hline $\mathrm{SEX}+\mathrm{EXP}+\mathrm{TAM}+\mathrm{INC}+\mathrm{CON}$ & 10 & 503,06 & 1,55 & 0,05 & $(0.495)$ & & & $(0.835)$ & $(0.763)$ & $(0.725)$ & $(0.858)$ & & $(0.654)$ & & $(0.479)$ & & \\
\hline & & & & & & & -0.792 & 3.319 & 0.042 & 1.522 & 0.326 & & 3.854 & & -1.098 & & \\
\hline \multirow[t]{2}{*}{$S A U+E X P+T A M+I N C+C O N$} & 10 & 503,11 & 1,60 & 0,05 & & & $(1.269)$ & $(0.834)$ & $(0.761)$ & $(0.722)$ & $(0.86)$ & & $(0.655)$ & & $(0.469)$ & & \\
\hline & & & & & & -0.038 & & 3.361 & 0.044 & 1.538 & 0.385 & & 3.872 & & -1.126 & & \\
\hline IDA+EXP+TAM+INC+CON & 10 & 503,49 & 1,98 & 0,04 & & $(0.256)$ & & $(0.842)$ & $(0.761)$ & $(0.726)$ & $(0.855)$ & & (0.659) & & $(0.477)$ & & \\
\hline \multirow[t]{2}{*}{ EXP+TAM+INC+MOT+CON } & 10 & 503,50 & 1,99 & 0,04 & & & & $\begin{array}{c}3.338 \\
(0.842)\end{array}$ & $\begin{array}{c}0.029 \\
(0.767)\end{array}$ & $\begin{array}{c}1.522 \\
(0.724)\end{array}$ & $\begin{array}{c}0.376 \\
(0.855)\end{array}$ & & $\begin{array}{c}3.862 \\
(0.653)\end{array}$ & $\begin{array}{c}0.145 \\
(1.383)\end{array}$ & $\begin{array}{c}-1.13 \\
(0.491)\end{array}$ & & \\
\hline & & & & & \multicolumn{13}{|c|}{ Coeficientes estimados (erro padrão) } \\
\hline Modelo & $\mathbf{K}$ & AIC & $\triangle \mathrm{AIC}$ & $\omega \mathbf{i}$ & SEX & IDA & SAU & EXP & TAM2 & TAM3 & TAM4 & RAC & INC & Мот & CON & ALI & PRO \\
\hline \multirow[t]{2}{*}{$E X P+T A M+I N C+C O N$} & 9 & 501,36 & 0 & 0,08 & & & & $\begin{array}{l}3.357 \\
(0.84)\end{array}$ & $\begin{array}{l}0.133 \\
(0.81)\end{array}$ & $\begin{array}{c}1.461 \\
(0.741)\end{array}$ & $\begin{array}{c}0.599 \\
(0.867)\end{array}$ & & $\begin{array}{c}3.902 \\
(0.676)\end{array}$ & & $\begin{array}{c}-1.091 \\
(0.466)\end{array}$ & & \\
\hline & & & & & & -0.313 & & 3.401 & 0.183 & 1.565 & 0.699 & & 3.979 & & -1.132 & & \\
\hline \multirow[t]{2}{*}{ IDA+EXP+TAM+INC+CON } & 10 & 501,99 & 0,63 & 0,06 & & $(0.274)$ & & $(0.846)$ & $(0.814)$ & $(0.749)$ & $(0.88)$ & & $(0.718)$ & & $(0.472)$ & & \\
\hline & & & & & & & & 3.417 & & & & & 3.95 & & -0.964 & & \\
\hline \multirow[t]{2}{*}{$E X P+I N C+C O N$} & 6 & 502,42 & 1,06 & 0,04 & & & & $(0.84)$ & & & & & $(0.714)$ & & $(0.451)$ & & \\
\hline & & & & & & & & 3.389 & 0.146 & 1.48 & 0.618 & & 3.965 & & -1.106 & 2.611 & \\
\hline \multirow[t]{2}{*}{$E X P+T A M+I N C+C O N+A L I$} & 10 & 502,52 & 1,16 & 0,04 & & & & $(0.842)$ & $(0.811)$ & $(0.741)$ & $(0.868)$ & & $(0.718)$ & & $(0.466)$ & (3.511) & \\
\hline & & & & & & & & 3.42 & 0.126 & 1.434 & 0.555 & & 3.828 & & -1.094 & & 0.554 \\
\hline \multirow[t]{2}{*}{ EXP+TAM+INC+CON+PRO } & 10 & 502,54 & 1,18 & 0,04 & & & & $(0.844)$ & $(0.81)$ & $(0.74)$ & $(0.868)$ & & $(0.681)$ & & $(0.466)$ & & $(0.587)$ \\
\hline & & & & & -0.352 & & & 3.335 & 0.13 & 1.453 & 0.618 & & 3.907 & & -1.115 & & \\
\hline \multirow[t]{2}{*}{$S E X+E X P+T A M+I N C+C O N$} & 10 & 502,84 & 1,48 & 0,04 & $(0.489)$ & & & $(0.838)$ & $(0.811)$ & $(0.744)$ & $(0.871)$ & & $(0.676)$ & & $(0.472)$ & & \\
\hline & & & & & & & -0.775 & 3.334 & 0.122 & 1.44 & 0.534 & & 3.891 & & -1.075 & & \\
\hline \multirow[t]{2}{*}{$S A U+E X P+T A M+I N C+C O N$} & 10 & 502,98 & 1,63 & 0,03 & & & $(1.287)$ & $(0.836)$ & $(0.808)$ & (0.739) & $(0.873)$ & & $(0.678)$ & & $(0.463)$ & & \\
\hline & & & & & & & & 3.331 & 0.024 & 1.373 & 0.556 & -0.314 & 3.898 & & -1.073 & & \\
\hline \multirow[t]{2}{*}{ EXP+TAM+RAC+INC+CON } & 10 & 503,14 & 1,78 & 0,03 & & & & $(0.839)$ & $(0.843)$ & $(0.762)$ & $(0.873)$ & $(0.672)$ & $(0.664)$ & & $(0.47)$ & & \\
\hline & 10 & 503,34 & 1,99 & 0,03 & & & & $\begin{array}{c}3.344 \\
(0.845)\end{array}$ & $\begin{array}{c}0.127 \\
(0.812)\end{array}$ & $\begin{array}{c}1.456 \\
(0.743)\end{array}$ & $\begin{array}{c}0.59 \\
(0.872)\end{array}$ & & $\begin{array}{c}3.898 \\
(0.675)\end{array}$ & $\begin{array}{c}0.154 \\
(1.354)\end{array}$ & $\begin{array}{c}-1.104 \\
(0.481)\end{array}$ & & \\
\hline
\end{tabular}

